IGNAZIO GIUNTOLI

\title{
Sistema Web-GIS participativo associado a indicadores de gestão descentralizada de risco de inundações
}

Dissertação apresentada à Escola de Engenharia de São Carlos da Universidade de São Paulo como parte dos requisitos para obtenção do título de Mestre em Engenharia (Hidráulica e Saneamento).

Orientador: Prof. Dr. Eduardo Mario Mendiondo 
AUTORIZO A REPRODUÇÃO E DIVULGAÇÃO TOTAL OU PARCIAL DESTE TRABALHO, POR QUALQUER MEIO CONVENCIONAL OU ELETRÔNICO, PARA FINS DE ESTUDO E PESQUISA, DESDE QUE CITADA A FONTE.

Ficha catalográfica preparada pela Seção de Tratamento da Informação do Serviço de Biblioteca - EESC/USP

\begin{tabular}{|c|c|}
\hline \multirow[t]{3}{*}{ G537s } & $\begin{array}{l}\text { Giuntoli, Ignazio } \\
\text { Sistema Web-GIS participativo associado a indicadores } \\
\text { de gestão descentralizada de risco de inundaçoses / } \\
\text { Ignazio Giuntoli ; orientador Eduardo Mario Mendiondo. } \\
\text {-- São Carlos, } 2008 \text {. }\end{array}$ \\
\hline & $\begin{array}{l}\text { Dissertação (Mestrado-Programa de Pós-Graduação e Área } \\
\text { de Concentração em Hidráulica e Saneamento) -- Escola de } \\
\text { Engenharia de São Carlos da Universidade de São Paulo, } \\
2008 \text {. }\end{array}$ \\
\hline & $\begin{array}{l}\text { 1. Enchentes urbanas. 2. Web-GIS. 3. Gestão de risco } \\
\text { de inundação. 4. Percepção de risco. 5. Indicadores de } \\
\text { risco de inundação. 6. WPPGIS (Web-based Public } \\
\text { Participation GIS). I. Título. }\end{array}$ \\
\hline
\end{tabular}




\section{Candidato: Engenheiro IGNAZIO GIUNTOLI}

Dissertação defendida e julgada em 12/08/2008 perante a Comissão Julgadora:
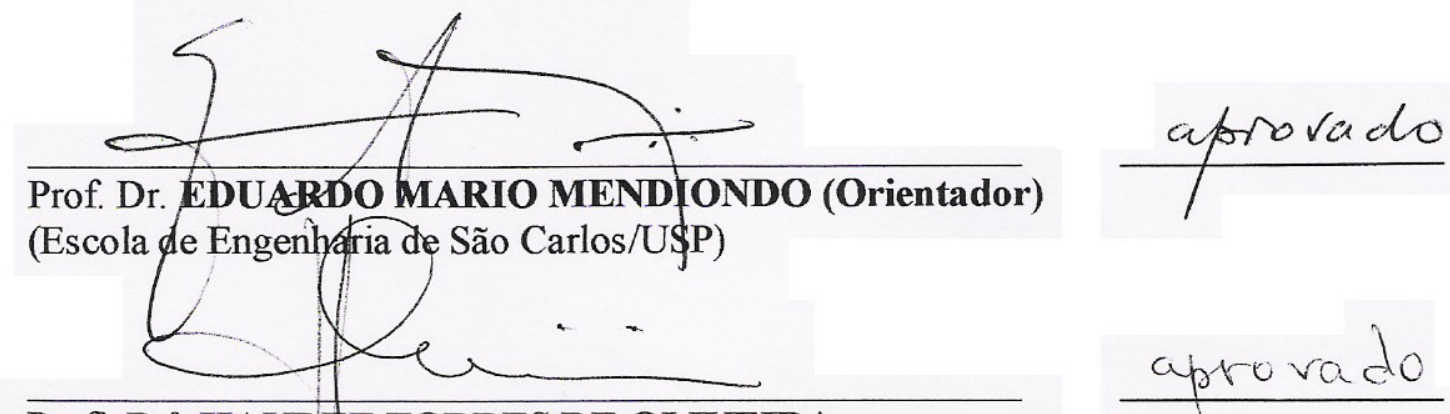

Prof ${ }^{a}$. Dr ${ }^{\text {a }}$. HAYDAE TORRES DE OLIVEIRA

(Universidade Federal de São Carlos/UFSCar)

$$
\text { Onuado T. Onh wo }
$$

Prof. Dr. OSVALDO TADATOMO OSHIIRO

(Empresa Brasileira de Pesquisa Agropecuária/EMBRAPA)
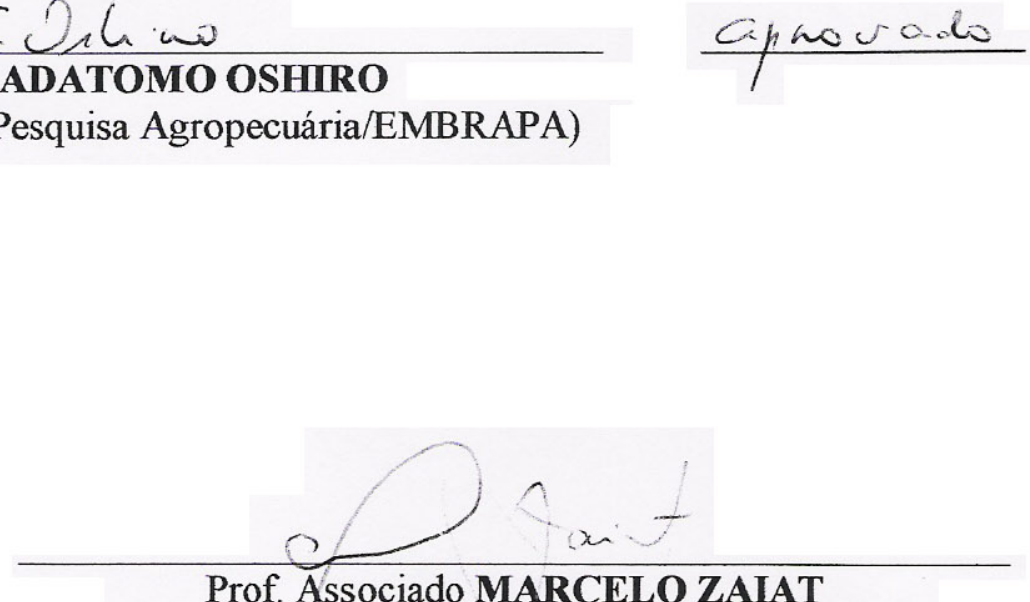

Prof. Associado MARCELO ZAIAT

Coordenador do Programa de Pós-Graduação em

Engenharia (Hidráulica e Saneamento)

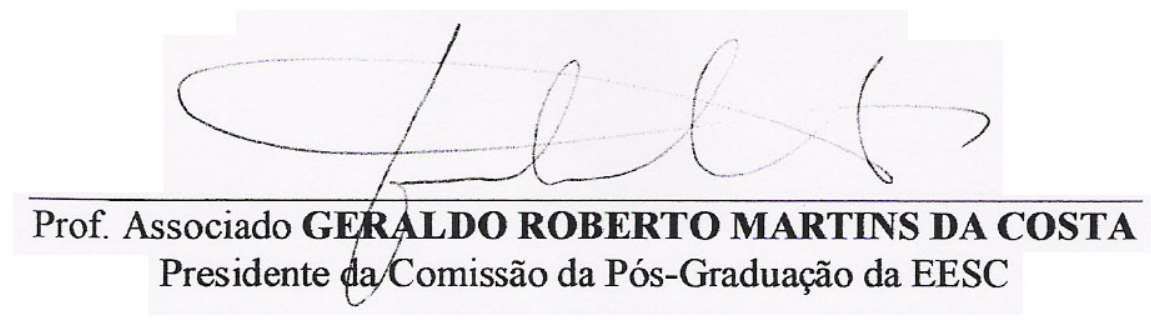


"Ubiquitous computer communications networks are bringing about a dramatic change in the scope, scale, and efficacy of peer production throughout the information and cultural production system. As computers become cheaper and as network connections become faster, cheaper, and ubiquitous, we are seeing the phenomenon of peer production of information scale to much larger sizes, performing more complex tasks than were possible in the past for nonprofessional production"

Yochai Benkler 


\section{AGRADECIMENTOS}

Agradeço ao CNPq pela concessão da bolsa de mestrado. Agradeço ao professor Mario pela orientação e por ter me apoiado nas relevantes experiências vividas no exterior durante o mestrado. Agradeço à minha família que sempre me apoiou e encorajou nas minhas escolhas. Agradeço à Camila sem a qual não teria vivenciado esta experiência tão enriquecedora. Agradeço também toda sua família pelo contínuo incentivo e apoio. Agradeço a todos os amigos do NIBH, em particular a Flávia, Tatiane, Juliana, Valter, Micheli, Diogo e Pedro. Agradeço também ao André pela fundamental contribuição para realização e aprimoramento do portal web-GIS. Finalmente agradeço à professora Haydée Torres de Oliveira e ao doutor Osvaldo Oshiro pelas valiosas contribuições na bancas de qualificação e de defesa. 


\section{RESUMO}

GIUNTOLI, I. (2008). Sistema web-GIS participativo associado a indicadores de gestão descentralizada de risco de inundações. Dissertação de Mestrado - Escola de Engenharia de São Carlos, Universidade de São Paulo, São Carlos, 2008.

A presente pesquisa propôs o desenvolvimento e a aplicação de um web-GIS interativo alimentado por usuários visando ao mapeamento do risco de inundações por meio da coleta de dados de ameaça, exposição e vulnerabilidade percebidos pela população. Foi também estimado o risco de inundação a partir de uma expressão de indicadores propostos por Mendiondo (2008). As duas metodologias foram aplicadas em sub-bacias urbanas da cidade de São Carlos. Foram realizadas entrevistas com a população da cidade para coletar dados de percepção de risco, enquanto se desenvolvia o web-GIS, para o qual, uma vez terminado, foram transferidos os referidos dados online. O portal se mostrou uma ferramenta de uso simples e confiável. As estimativas de risco calculadas por meio da expressão citada levaram a concluir que as sub-bacias com maior risco de inundação são as dos córregos Tijuco Preto e Medeiros. Entretanto, o risco estimado a partir da análise de percepção evidenciou as subbacias Gregório e Santa Maria Madalena como as de maior risco de inundação. As duas ferramentas apresentaram-se valiosas e econômicas para estimativa de risco de inundação em ambiente urbano, podendo constituir ótimos sistemas de apoio à decisão. O web-GIS, em particular, é potencialmente útil para informar aos moradores sobre quais são as áreas de risco de inundação na cidade.

Palavras Chave: Risco de Inundação, Gestão descentralizada de risco, Web-GIS, WPPGIS (web-based Public Participation GIS). 


\begin{abstract}
GIUNTOLI, I. (2008). A Participatory web-GIS system associated to decentralized flood risk management indicators. MEng Master's Thesis - Escola de Engenharia de São Carlos, Universidade de São Paulo, São Carlos, 2008 (in Portuguese).
\end{abstract}

This dissertation presents the development and application of an interactive web-GIS in which internet users map flood risk collaboratively by filling up a geotagged form with questions on flood hazard, exposure and vulnerability. Flood risk was also assessed through the use of a set of environmental risk indicators proposed by Mendiondo (2008). The two methodologies were applied to six urban watersheds of the city of São Carlos (State of São Paulo, Brazil). Interviews including questions asked on the web-GIS were carried out in city streets while the portal was being developed. Thus perceived risk data gathered from the interviews was later transferred online onto the web-GIS. The web-GIS proved to be an easy to use and intuitive tool. According to the results of Risk calculation obtained with the indicators expression the watersheds with higher flood risk were the Tijuco Preto and Medeiros, which were also the ones with smallest area and higher population density. The results of perceived risk, which was assessed through the analysis of the interviews data, gave evidence that Gregorio and Santa Maria Madalena where the watersheds at higher risk. These watersheds are the two which experience a higher rate of occurrence on a year basis. The two approaches for assessing risk proved to be consistent and relatively inexpensive for the estimate of flood risk in urban areas, with the potential of representing valid decision support systems. The web-GIS is a particularly interesting solution as a medium of information to inhabitants on the level of risk to which they are exposed.

Key words: Flood risk, Risk management, Web Mapping, Risk Perception, Risk Indicators, WPPGIS (web-based Public Participation GIS). 


\section{SUMÁRIO}

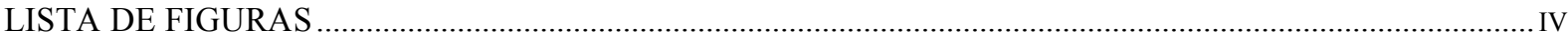

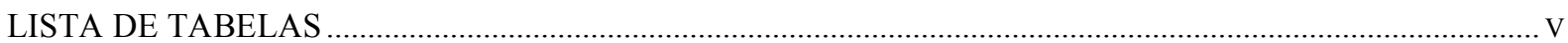

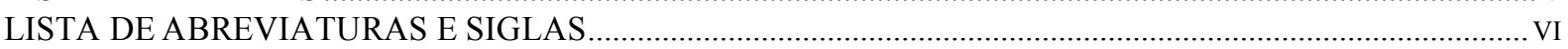

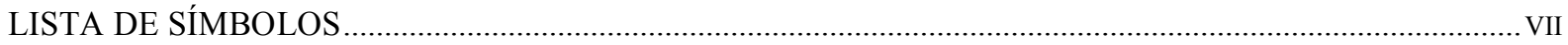

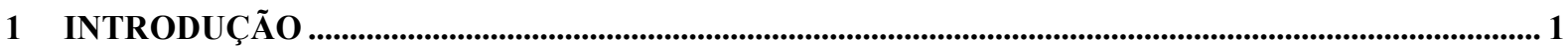

2 OBJETIVOS

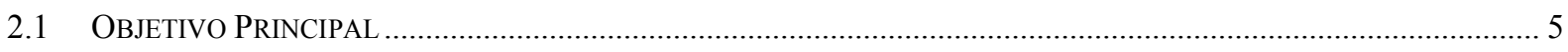

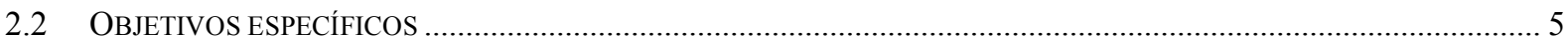

3 REVISÃO BIBLIOGRÁFICA

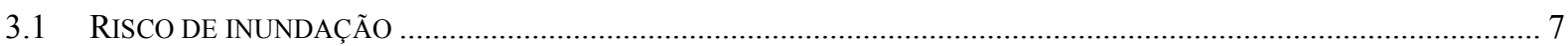

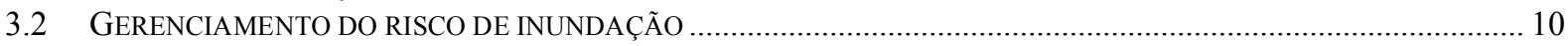

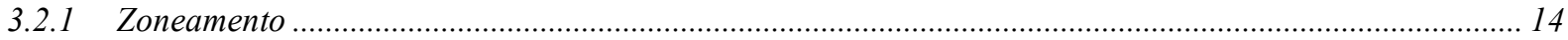

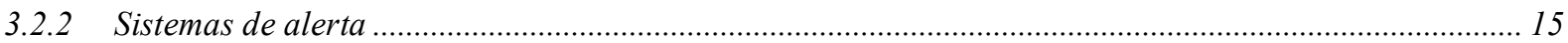

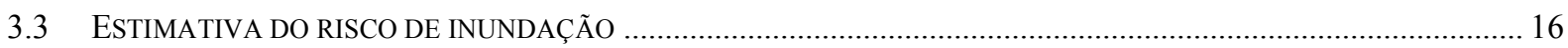

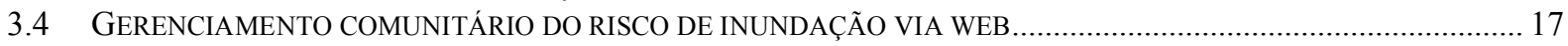

3.4.1 Plataformas Web 2.0 e co-criação de conteúdos ............................................................................... 18

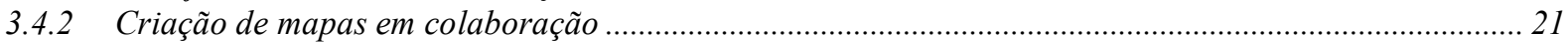

3.4.3 SIG de Participação Pública (Public Participation GIS - PPGIS) ......................................................... 23

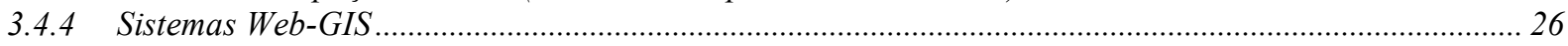

3.4.5 Elementos para a criação de web-sites com base na experiência do usuário ......................................... 37

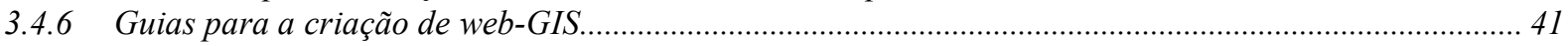

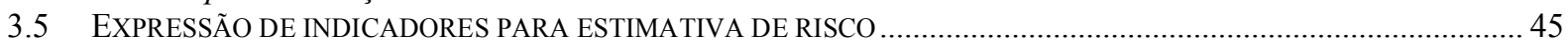

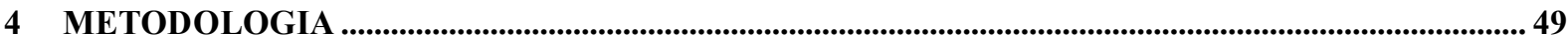

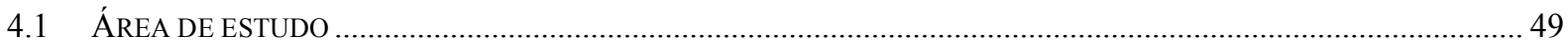

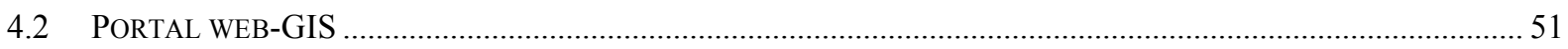

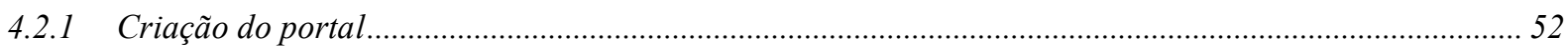

4.2.2 Entrevista sobre risco de inundação aos habitantes ......................................................................... 53

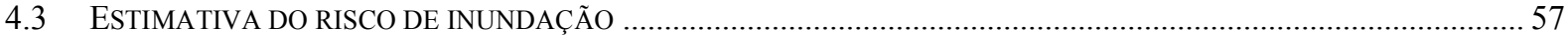

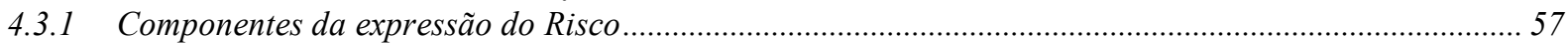

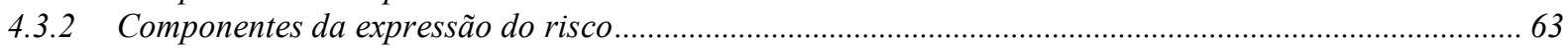

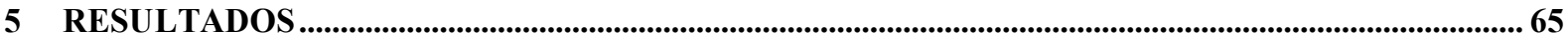

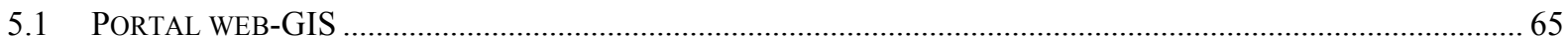

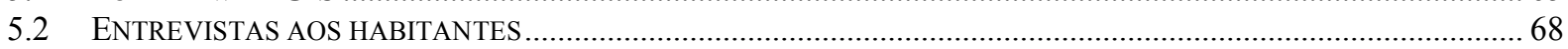

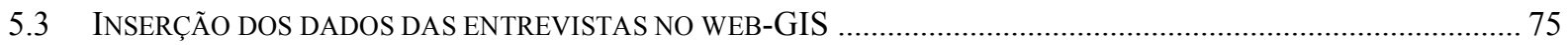

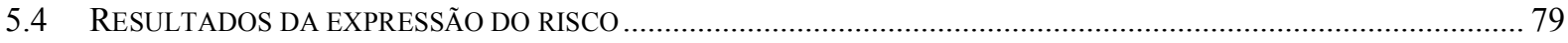

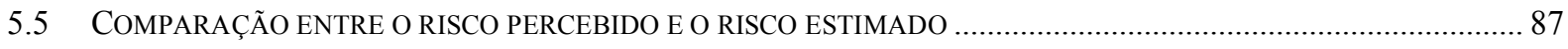

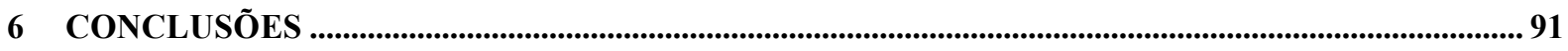

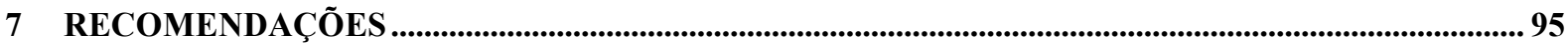

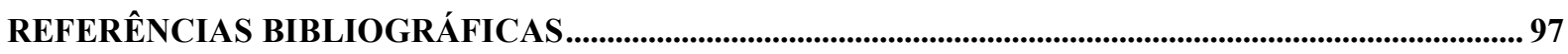

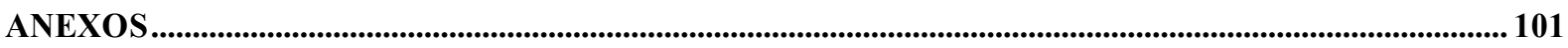

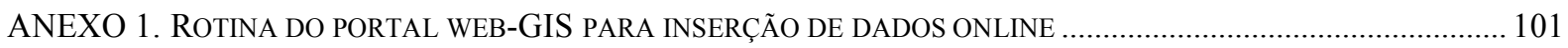

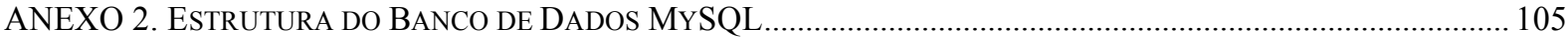

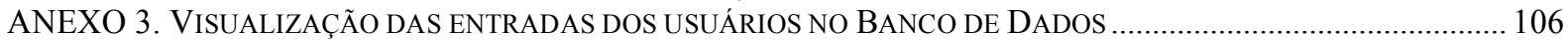

ANEXO 4. ENTREVISTAS PARA COLETA DE DADOS DE RISCO PERCEBIDO ........................................................ 107

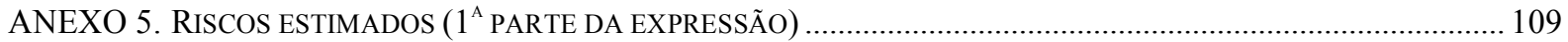

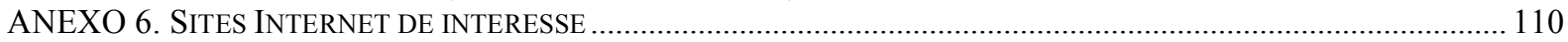




\section{LISTA DE FIGURAS}

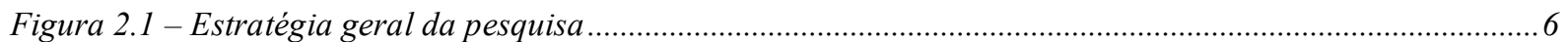

Figura 3.1 - Triângulo do risco (Fonte: Andrade, 2006; adaptado de Crichton, 1999). .....................................8

Figura 3.2 - Conceitos e princípios em gerenciamento de riscos de inundações. Fonte: Mendiondo, 2005.......11

Figura 3.3 - Fases de um desastre. Fonte: Marcelino, 2005, adaptado de Tobin e Montz (1997)......................12

Figura 3.4 - O ciclo de gerenciamento de risco. Fonte: WWAP, 2006; adaptado de Swiss Civil Protection;

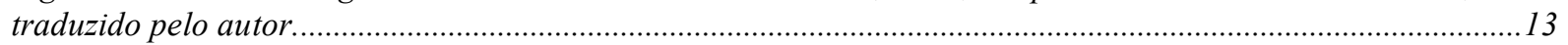

Figura 3.5 - SIG, participação publica, Internet e suas integrações. Adaptado de Tang e Waters (2005)..........24

Figura 3.6 - Comparação entre os procedimentos dos modelos Web clássico e Ajax. Fonte: Garrett (2005).....27

Figura 3.7 - Comparação operativa entre o modelo Web clássico e o modelo AJAX. Fonte: Garrett (2005). ....29

Figura 3.8 - Esquema de funcionamento de um portal web-GIS. Adaptado de Negretti (2007)............................30

Figura 3.9 - Arquitetura das soluções para sistemas integrados webGIS baseadas em software livre. Fonte:

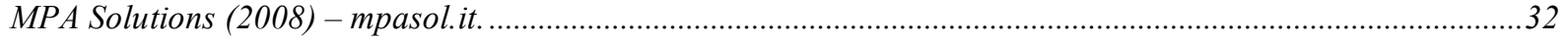

Figura 3.10 - Os elementos da experiência do usuário. Adaptado de Garrett (2000)........................................39

Figura 3.11 - Os elementos da experiência do usuário. Ao lado esquerdo a web é considerada como uma

interface software, orientada à tarefa (task-oriented); Ao lado direito a web é considerada como um sistema de

hipertextos, orientada à informação (information-oriented). Adaptado de Garrett (2000)...............................40

Figura 4.1 - Imagem das sub-bacias hidrográficas selecionadas na área urbana de São Carlos: 1) Santa Maria

Madalena; 2) Mineirinho; 3) Tijuco Preto; 4) Gregório; 5) Medeiros; 6) Água Quente. .....................................50

Figura 4.2 - Seqüência de passos seguidos para armazenar os dados obtidos das entrevistas para

sucessivamente disponibiliza-los online ......................................................................................................5

Figura 4.3 - Roteiro de questões fechadas sobre risco de inundações em São Carlos proposto aos habitantes..55

Figura 5.1 - Tela de apresentação da homepage do portal web-GIS..................................................................65

Figura 5.2 - Visualização das sub-bacias carregadas pelo mapa dinâmico em formato “.kml”. ........................66

Figura 5.3 - Janela que aparece clicando em um ponto do mapa para avaliar o risco. ....................................67

Figura 5.4 - Distribuição de freqüências de valores obtidos dos produtos $R_{P, 1}$ e $R_{P, 2}$ segundo a divisão em

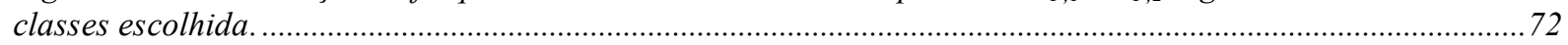

Figura 5.5 - Intervalos de Risco percebido $\left(R_{P, 1}-R_{P, 2}\right)$ por sub-bacia e respectivos valores médios. ....................74

Figura 5.6 - Tela do portal web-GIS após a inserção dos dados dos entrevistados. Os níveis de cores se referem

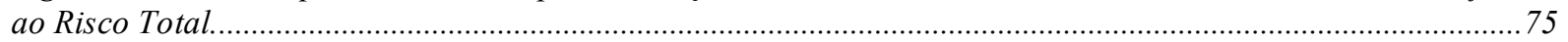

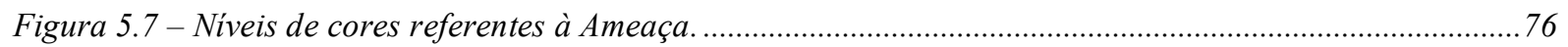

Figura 5.8 - Niveis de cores referentes à Exposição .................................................................................. 76

Figura 5.9 - Niveis de cores referentes à Vulnerabilidade. ..............................................................................7

Figura 5.10 - Distribuição da freqüência dos resultados de Risco Total $\left(R_{P, 1}\right)$ em classes: muito baixo (0-9),

baixo (9-25), médio (25-40), alto (40-60), muito alto (60-225).........................................................................78

Figura 5.11 - Relação entre tempo de resgate $t_{\text {resg }}$ e tempo de concentração $t_{c}$ nos dois cenários........................79

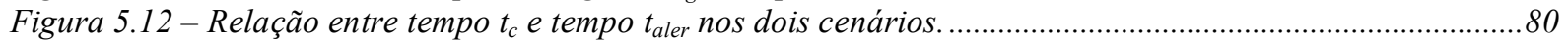

Figura 5.13 - Relação entre tempo $t_{\text {resg }}$ e tempo $t_{c}$ nos dois cenários....................................................................8 81

Figura 5.14 - Andamento das componentes da expressão do risco segundo o cenário Reativo. Bacia do

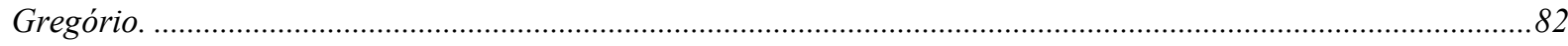

Figura 5.15 - Andamento das componentes da expressão do risco segundo o cenário Pro-ativo. Bacia do Gregório.

Figura 5.16 - Curvas de tendência referentes ao risco estimado no cenário Reativo e no cenário Pro-ativo.

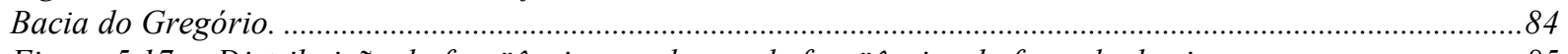

Figura 5.17 - Distribuição da freqüencia em classes de freqüências da formula do risco. ................................85

Figura 5.18 - Risco acumulado em 50 anos segundo os cenários $\left(R_{E, \text { Rea }(\text { Acum }, 50)}\right.$ e $\left.R_{E, \text { Pro(Acum }, 50)}\right)$..........................86

Figura 5.19 - Comparação entre intervalos de risco médio $\left(R_{E, 1, R e a}-R_{E, 1, P r o}\right)$ e intervalos de risco percebido

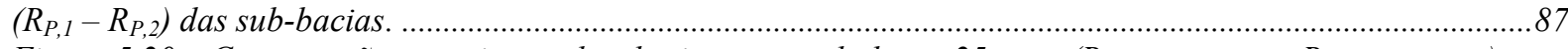

Figura 5.20 - Comparação entre intervalos de risco acumulado em 25 anos $\left(R_{E, 1, \operatorname{Rea}(\operatorname{Acum}, 25)}-R_{E, 1, \operatorname{Pro}(\operatorname{Acum}, 25)}\right) e$

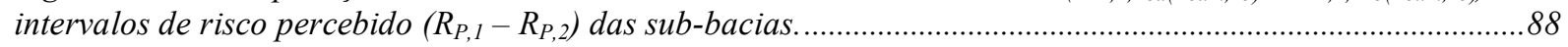

Figura 5.21 - Comparação entre intervalos de risco acumulado em 50 anos $\left(R_{E, 1, \operatorname{Rea}(A \operatorname{Acum}, 50)}-R_{E, 1, \operatorname{Pro}(\operatorname{Acum}, 50)}\right) e$

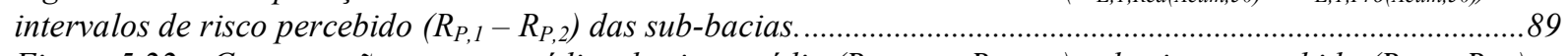

Figura 5.22 - Comparação entre as médias do risco médio $\left(R_{E, 1, R e a}-R_{E, 1, P r o}\right)$ e do risco percebido $\left(R_{P, 1}-R_{P, 2}\right)$,

associadas à porcentagem de área impermeável (\%) e à densidade habitacional (hab/ha) das sub-bacias.........90 


\section{LISTA DE TABELAS}

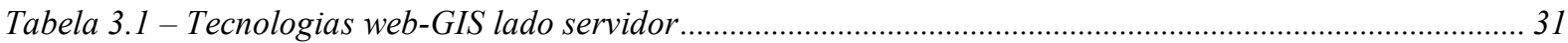

Tabela 3.2 - Tecnologias web-GIS lado client ............................................................................................... 31

Tabela 4.1 - Características de 6 sub-bacias urbanas do município de São Carlos objeto de estudo. *Fonte:

Esteves 2003

Tabela 4.2 - Tendências de cada componente da fórmula do risco ao longo do prazo considerado de 50 anos para os cenários reativo e pró-ativo.

Tabela 5.1 - Número de entrevistas efetuadas por data e respectivos locais................................................ 68

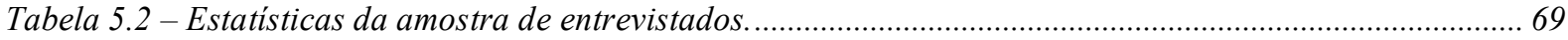

Tabela 5.3 - Estatísticas das respostas às perguntas do questionário por sub-bacia....................................... 71

Tabela 5.4 - Legenda da escala de risco percebido subdividida em cinco níveis................................................ 73

Tabela 5.5 - Riscos percebidos resultantes do produto das componentes Ameaça, Exposição e Vulnerabilidade

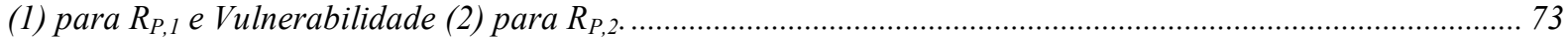

Tabela 5.6 - Legenda da escala de risco médio subdividida em cinco níveis. ................................................... 84

Tabela 5.7 - Resultados da estimativa do risco para cada sub-bacia. .............................................................. 86 


\section{LISTA DE ABREVIATURAS E SIGLAS}

AAS

AJAX

API

CSS

DBMS

DOM

GIS

GNU

GPL

HTML

KML

IBGE

MNT

NIBH

OGC

PHP

PPGIS

SIG

XML

Web-GIS
Amostra Aleatória Simples

Asynchronous JavaScript and XML

Application Programming Interface

Cascading Style Sheets

Database management system

Document Object Model

Geographic Information System

GNU's Not Unix

General Public License

HyperText Markup Language

Keyhole Markup Language

Instituto Brasileiro de Geografia e Estatística

Modelo Numérico de Terreno

Núcleo Integrado de Bacias Hidrográficas

Open Geospatial Consortium

Hypertext Preprocessor

Public Participation Geographic Information System

Sistema de Informações Geográficas

Extensible Markup Language

Web-based Geographic Information System 


\section{LISTA DE SÍMBOLOS}

$T_{r}$

$T^{*}$

$A_{f, T r}$

$A_{b}$

$n_{f, T r}$

$n_{b}$

$\mathrm{CN}$

$S_{\text {atual }}$

$S_{\text {inicial }}$

$\Delta S$

$t_{v}$

$t_{f}$

$t_{\text {conc }}$

$t_{\text {aler }}$

$t_{\text {resg }}$

$N$

$R_{P, 1}$

$R_{P, 2}$

$R_{E, 1}$

$R_{E, 2}$

$R_{E}$

$R_{E, R e a}$

$R_{E, P r o}$

$R_{E,(\text { Acum,\#) }}$

$R_{E, R e a / P r o a(A c u m, \#)}$

$R_{E, 1, \text { Rea/Pro(Acum,H) }}$ tempo de retorno de inundação [anos]

tempo de retorno de projeto referente à altura de extravasamento [anos] área inundável segundo o tempo de retorno $T_{r}\left[\mathrm{~km}^{2}\right]$

área total da bacia hidrográfica $\left[\mathrm{km}^{2}\right]$

população que vive na área inundável $A_{f, T r}$ [hab]

população total da bacia [hab]

Curve Number - parâmetro adimensional

armazenamento atual de água no solo [mm]

armazenamento de água no solo em ausência de urbanização [mm]

diferença de armazenamento potencial de água no solo $S_{\text {now }}-S_{\text {past }}[\mathrm{mm}]$

tempo de vulnerabilidade de um individuo vulnerável [min]

tempo de vulnerabilidade de um individuo não vulnerável [min]

tempo de concentração da bacia [min]

tempo de alerta da bacia [min]

tempo de concentração da bacia [min]

tempo de vida útil das obras [anos]

risco percebido resultante da pergunta de vulnerabilidade (1)

risco percebido resultante da pergunta de vulnerabilidade (2)

risco estimado resultante da $1^{\mathrm{a}}$ parte da expressão do risco (estimativa)

risco estimado resultante da $2^{\mathrm{a}}$ parte da expressão do risco (gestão)

risco estimado pela expressão do risco $\left(R_{E}=R_{E, I} \times R_{E, 2}\right)$

risco estimado pela expressão do risco segundo o cenário reativo

risco estimado pela expressão do risco segundo o cenário pró-ativo

risco estimado acumulado em \# anos

risco acumulado em \# anos estimado pela expressão do risco (cenário reativo ou proativo)

risco acumulado em \# anos estimado pela $1^{\text {a }}$ parte da expressão do risco (cenário reativo ou pró-ativo) 



\section{INTRODUÇÃO}

O estado de São Paulo, bem como muitos outros no Brasil, apresenta numerosos fatores de exasperação do risco hidrológico ligados, não só às fortes chuvas que ocorrem nos meses de verão, como também à alta concentração da população em determinadas áreas.

Outros fatores que têm influído sobre a fragilidade hidrológica são as obras do homem como os desvios dos cursos fluviais, as canalizações, as barragens, a impermeabilização das margens dos rios e o desflorestamento. Estas intervenções, adicionadas à escassez de manutenção que na moderna economia resultam pouco convenientes, tendem a intensificar os desequilíbrios e a produzir uma verdadeira fragilidade ambiental.

Segundo Becchi (2001), o que faz aumentar a periculosidade dos fenômenos naturais é na realidade um outro fator, ou seja a crescente falta de preparo da população frente aos fenômenos de inundação. Para ele, a educação sobre os riscos naturais representa a melhor arma contra as enchentes. Quando se verifica um evento com risco de enchente, é importante primeiramente, informar-se antes sobre o histórico do território em que reside, intervenções humanas impactantes e eventos catastróficos que já se verificaram; planejar uma estratégia de evacuação durante o fenômeno enchente; conhecer quais são os agentes locais responsáveis pela coordenação da proteção civil, para servir possivelmente de ajuda (Becchi, 2001).

Segundo o mesmo autor, a defesa contra as enchentes pode-se realizar seguindo três diferentes estratégias:

1. a preparação da população; 2. a construção de obras de defesa; e 3. o aprimoramento das infra-estruturas de previsão. A adoção racional dos três sistemas juntos pode produzir uma forte redução de risco para população, porém a adoção de uma única estratégia não consegue garantir a segurança.

Analogamente Ahmad et al. (2001) consideram que as estratégias para lidar com a ameaça dos desastres naturais podem se dividir em três categorias: 1 . O controle do evento em 
si; 2. O controle dos padrões de ocupação; 3. O desenvolvimento, por parte dos que estão em risco, de técnicas de previsão e sistemas de alerta que geram uma resposta para proteção.

O presente trabalho propôs, no âmbito da preparação da população, o estudo e a criação de um web-GIS interativo alimentado pelos moradores da bacia hidrográfica em estudo. Já no que diz respeito à estimativa do risco, demonstra-se a aplicação de uma expressão de indicadores que avalia os riscos de inundação para bacias urbanas escolhidas na cidade de São Carlos. Em um terceiro momento, confrontam-se os dados obtidos pelas percepções da população com os resultados obtidos pela expressão do risco.

Os Sistemas de Informação Geográfica (em inglês GIS - Geographic Information Stystem) estão evoluindo (Hansen e Prosperi 2005) de sistemas tradicionais constituídos por softwares desktop GIS (Arcview, Spring, Grass) que rodam num único micro e são operados por um grupo elitista de técnicos e cientistas para os sistemas baseados na web (web-GIS), caracterizados por visualização e interoperabilidade acessíveis aos usuários que têm acesso à rede. O desenvolvimento dos sistemas SIG para web é particularmente interessante, pois permite, sem a necessidade de ter instalado no próprio computador um software SIG complexo e/ou de preço elevado, a consulta de dados mapeados por meio de um navegador comum de internet.

O SIG tradicional é amplamente utilizado para monitoramento e estudos de intervenções na gestão de recursos hídricos (Al-Sabham et al., 2003). Almeida (2006), por exemplo, realizou um trabalho para a implantação de um sistema de suporte a decisão, denominado ARENA (Análise de Recursos Naturais), que utiliza um SIG como ferramenta para simular o fluxo de água subterrânea e superficial. A integração destes sistemas com a web (web-GIS), apesar de não constituir uma tecnologia consolidada por ter sido desenvolvido recentemente, representa uma ferramenta eficaz para que usuários da internet tenham acesso às informações e possam inserir dados considerados úteis para a coletividade e 
para os órgãos tomadores de decisões. A queda dos preços dos produtos de informática e o aumento da demanda de acesso à internet permite inferir que num futuro próximo um número crescente da população mundial terá acesso à web, que cada vez mais se tornará veículo de comunicação, transmissão, e troca de informações. Nesta perspectiva, o objetivo deste estudo é fomentar o conhecimento do território e a gestão participativa dos recursos hídricos. 


\section{OBJETIVOS}

\subsection{Objetivo Principal}

Criar um sistema SIG integrado à internet que permita a participação de usuários via web, visando a gestão descentralizada de risco de cheias e inundações.

\subsection{Objetivos específicos}

a) Estudar os aplicativos que compõem um sistema de informações geográficas baseado na internet (web-GIS);

b) Mapear elementos de risco de inundações e alagamentos percebidos por usuários residentes em sub-bacias da cidade de São Carlos no portal web-GIS de maneira amigável;

c) Estimar indicadores quantitativos de risco de inundação para cenários de longo prazo;

d) Relacionar o risco percebido por usuários (objetivo b) com o obtido por meio da expressão quantitativa (objetivo c).

A estratégia da pesquisa é resumida na Figura 2.1 


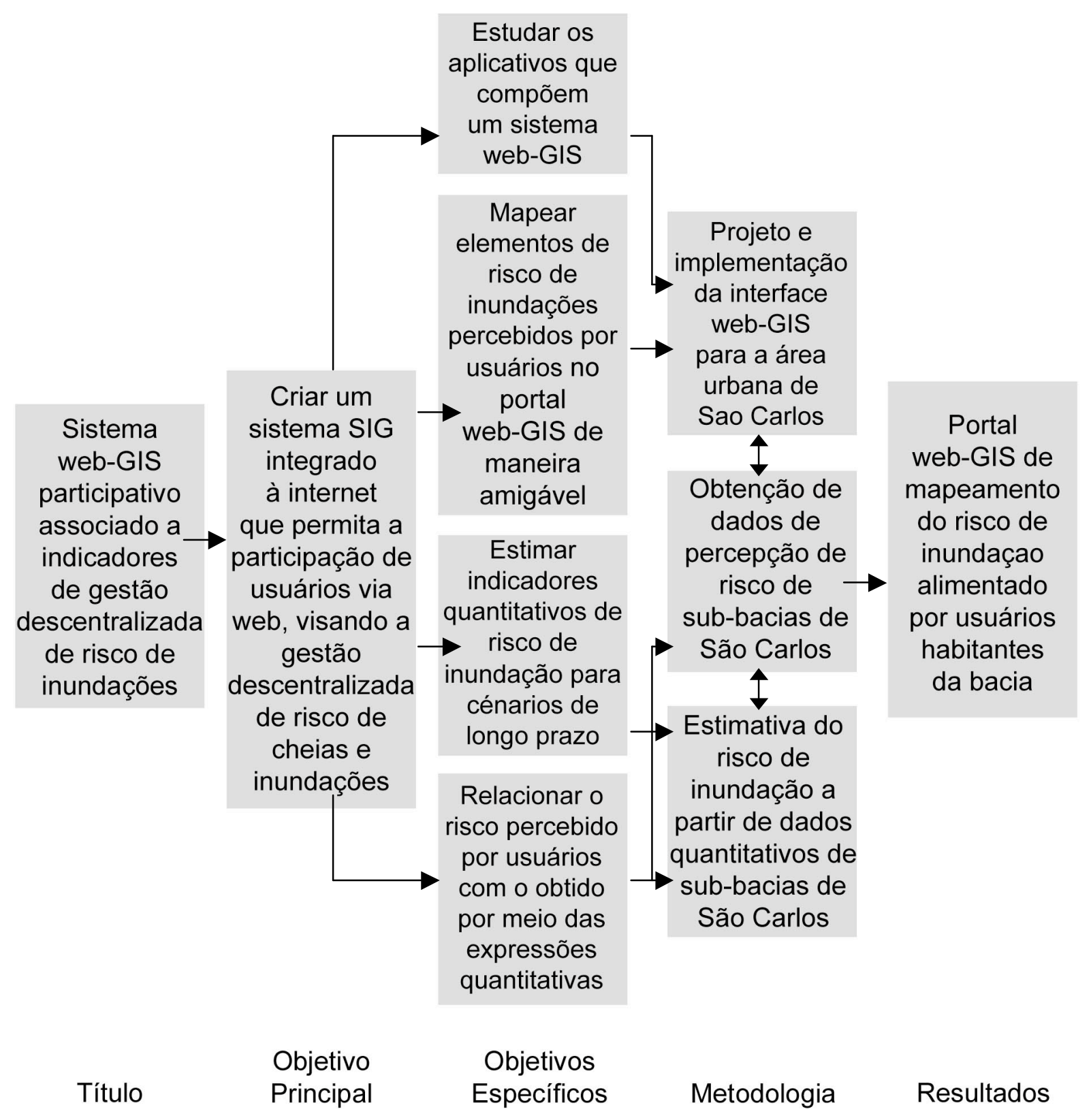

Figura 2.1 - Estratégia geral da pesquisa 


\section{REVISÃO BIBLIOGRÁFICA}

\subsection{Risco de inundação}

A urbanização das cidades e conseqüentemente a redução de superfícies permeáveis, a ocupação de planícies de inundação dos cursos de águas e em alguns casos, a limitação destes em canais, que não respeitam morfologia e ciclos naturais, tem acentuado fenômenos de inundação, em alguns casos repentinos e inesperados.

Segundo Treby et al. (2006) o risco de inundação pode ser estimado em termos quantitativos como também por meio de investigações qualitativas. Desta maneira o risco é associado não somente à natureza física do perigo, como freqüência, magnitude e proximidade; mas se relaciona à habilidade de gerenciar e se adaptar ao evento em si.

O risco de inundação pode-se considerar como o conjunto de ameaça natural física e a vulnerabilidade sócio-econômica da população afetada (Priest, 2003).

Um dos exemplos adotados em literatura (Gwilliam et al., 2006; Treby et al., 2006) para explicar a relação entre ameaça, vulnerabilidade e exposição e o risco resultante destas é o triângulo do risco, proposto por Crichton et al. (1997). Como afirmam Treby et al. (2006) este modelo é útil pela sua simplicidade e pelo fato de descrever como o risco é constituído por uma combinação de ameaça, exposição e vulnerabilidade. Deste modo o risco é representado pela área do triângulo (Figura 3.1), cujos lados representam as componentes citadas. Isto indica que ao aumentar ou diminuir um elemento, também aumentará ou diminuirá o lado a ele referido, e conseqüentemente a área do triângulo. 


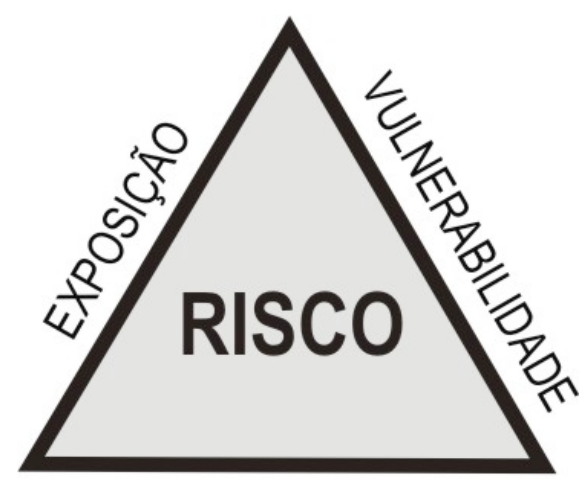

AMEAÇA

Figura 3.1 - Triângulo do risco (Fonte: Andrade, 2006; adaptado de Crichton, 1999).

A relação matemática do risco pode-se exprimir pela relação descrita em:

$$
\text { Risco }=\text { Ameaça } * \text { Vulnerabilidade } * \text { Exposição }
$$

A ameaça é o fenômeno natural que atinge uma região e o seu grau de risco é geralmente avaliado pelo tempo de retorno $\left(T_{r}\right)^{1}$. Acredita-se que a mesma tem tendência a aumentar devido às mudanças climáticas (Environment Agency, 2001 apud Treby et al., 2007).

A exposição representa a quantidade de pessoas e bens econômicos situados na área atingida pelo desastre.

A vulnerabilidade indica quão bem preparada está a área para receber a ameaça (Andrade, 2006), ou a propensão de uma área em sofrer dano causado por uma ameaça (Douglas, 2007). Este termo apresenta o maior desafio para ser definido e avaliado pois consta de uma componente física e uma social. Turner et al. (2003) definem a vulnerabilidade como o grau ao qual o sistema esta propenso a ter dano causado pela exposição à ameaça, mas salientam como a vulnerabilidade depende também da resiliência do sistema ameaçado, ou seja da capacidade do sistema em absorver distúrbios e em se reorganizar durante a mudança para manter as mesmas funções, estrutura e identidade.

\footnotetext{
${ }^{1}$ Segundo Baptista et al. (2005) o tempo de retorno $\left(T_{r}\right)$ é o intervalo médio decorrido entre duas ocorrências sucessivas de um dado evento ou sua superação. 
$\mathrm{Na}$ estimativa do risco de inundação Penning-Rowsell et al. (2005) consideram a vulnerabilidade como composta por "vulnerabilidade da área" e "vulnerabilidade da população". Segundo os autores a primeira depende de vários fatores quais a velocidade de chegada da inundação, a disponibilidade de alerta antecipados, tempo de alerta, consciência sobre inundações, a existência de planos de emergência, as características da área (tipo de propriedades, tamanho das planícies de inundação). No segundo caso, uma vez levantada a população em risco, a medição da "vulnerabilidade das pessoas" requer informações sobre idade e saúde desta, inclusive o número de pessoas doentes ou com dificuldades motoras.

A redução do triângulo do risco pode ser atingida pelo uso de medidas estruturais e não estruturais. Medidas estruturais como construções "à prova" de inundação, atenuam a magnitude da ocorrência, diminuindo tanto a parcela de ameaça como a de vulnerabilidade na estimativa do risco. Já medidas não estruturais, como sistemas de alerta ou zoneamentos econômico-ambientais, podem ser considerados meios de reduzir ao mesmo tempo vulnerabilidade e exposição da área.

Mays (2000), indica outras medidas não-estruturais que podem ser utilizadas para diminuir os danos potenciais às estruturas, com o objetivo de reduzir o triângulo do risco. Estas medidas são:

- Medidas de prevenção (Flood Proofing) - como a elevação das estruturas, a impermeabilização dos muros externos, a realocação dos lugares de trabalho. Essas medidas são tomadas preferencialmente na implantação de novas estruturas.

- Planos de preparação pré-inundação (Flood Warning Preparedness Plans - FWP) oferecem ao público a oportunidade de agir antes que a inundação aumente seus efeitos destrutivos. Este tipo de medida comunica aos habitantes o perigo iminente com antecedência para que eles possam reduzir o dano do evento. O FWP necessita ser integrado com estruturas de previsão de inundações em tempo real e de comunicação para alertar os habitantes. 
- Controles do uso do solo (Land use controls) - referem-se às ações administrativas tomadas para modificar o tipo de uso das várzeas para que estas sejam compatíveis com o risco de inundação. Fazem parte destes controles os zoneamentos e as leis para construção, seguros para inundação e programas de informação promovidos por agências públicas.

\subsection{Gerenciamento do risco de inundação}

O que se chama de gerenciamento de desastres naturais é um conjunto de ações, que têm como objetivo mitigar os efeitos negativos dos eventos extremos (Andrade, 2006). Segundo Treby et al. (2006), as questões técnicas e sociais são consideradas, por alguns países, de grande importância para uma eficaz compreensão e gerenciamento das inundações. Ainda segundo os mesmos autores, é hoje bem reconhecida a importância de acomodar o entendimento das ameaças públicas e a percepção do risco em modelos de gerenciamento das inundações.

Segundo Mendiondo (2005), as propostas modernas de gestão de riscos de inundação contêm três etapas principais: “Antes” (estágio de preparo, sistemas de alerta e prevenção), "Durante" (ações de controle de manejo, medidas de proteção) e "Após" o evento (reconstrução/reabilitação das áreas atingidas). O modelo referencial Técnico - Prático ilustrado no esquema abaixo (Mendiondo, 2005) mostra as etapas e suas integrações (Figura $3.2)$. 




Figura 3.2 - Conceitos e princípios em gerenciamento de riscos de inundações. Fonte: Mendiondo, 2005.

Da mesma maneira, Marcelino (2007) aborda a questão da gestão de risco de inundação, ressaltando que o ciclo de gerenciamento de desastres também envolve as fases Antes, Durante e Depois, como apresentado no esquema proposto por Tobin e Montz (1997). Tal esquema (Figura 3.3) é representado por um gráfico que relaciona as fases de risco ao longo do tempo (eixo das abscissas) com três indicadores ambientais: qualidade de vida, atividade econômica, estabilidade social (eixo das ordenadas). Como se observa no gráfico, a partir do momento em que ocorre o desastre, todos os indicadores considerados decrescem, uma vez atingido um ponto mínimo os indicadores tendem a melhorar de maneira gradual. 


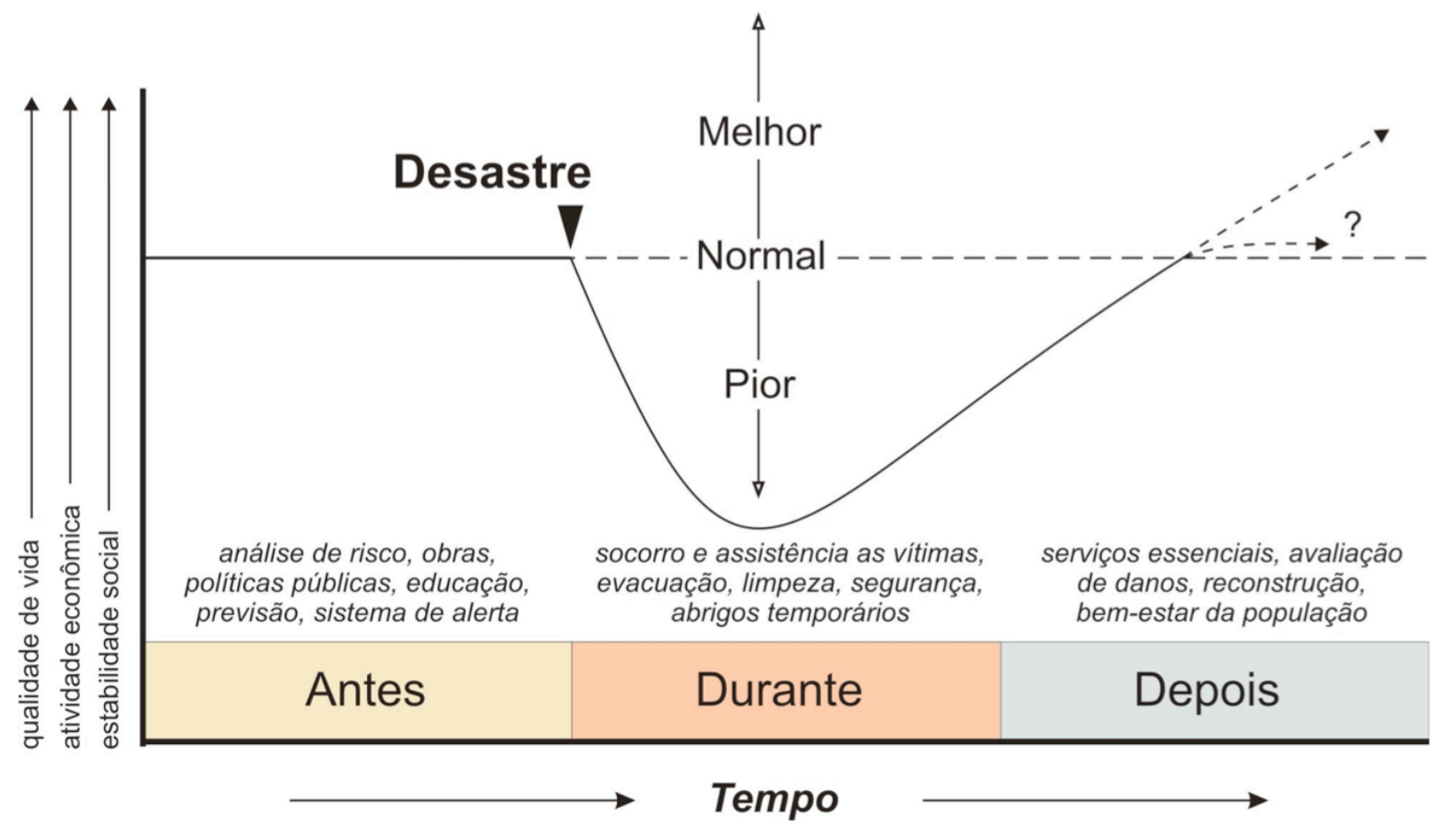

Figura 3.3 - Fases de um desastre. Fonte: Marcelino, 2005, adaptado de Tobin e Montz (1997).

Para citar um outro exemplo de ciclo de gerenciamento de risco, pode-se observar o esquema proposto pelo "Programa de Avaliação da Água mundial das Nações Unidas" (United Nations World Water Assessment Programme - WWAP, 2006), que adaptou o ciclo de mitigação-crise-reabilitação da Defesa Civil Suíça (Figura 3.4).

O relatório da WWAP salienta como os desastres relacionados à água perturbam o desenvolvimento econômico e também o tecido das sociedades vulneráveis comprometendo os ganhos acumulados em desenvolvimento social e econômico e os investimentos em melhorias nas condições e na qualidade de vida. As políticas e as medidas de redução dos riscos de desastre devem portanto ser projetadas de maneira a ser consistentes com objetivos integrados de desenvolvimento de longo prazo e planos de implementação. Esta abordagem demonstra como o gerenciamento de riscos relacionados à água é uma questão de governança (governance). Em particular, as atividades de assistência e reconstrução após desastre precisam ser melhoradas com o objetivo de "reconstruir melhor" ("building back better") a 
longo prazo. Isso significa que é preciso analisar as causas dos desastres para guiar os investimentos em reconstrução, em particular para infra-estruturas e uso do solo. Como mostrado no esquema, limitar a grandeza dos danos e reduzir a vulnerabilidade são dois objetivos principais interligados do ciclo de gerenciamento de risco.

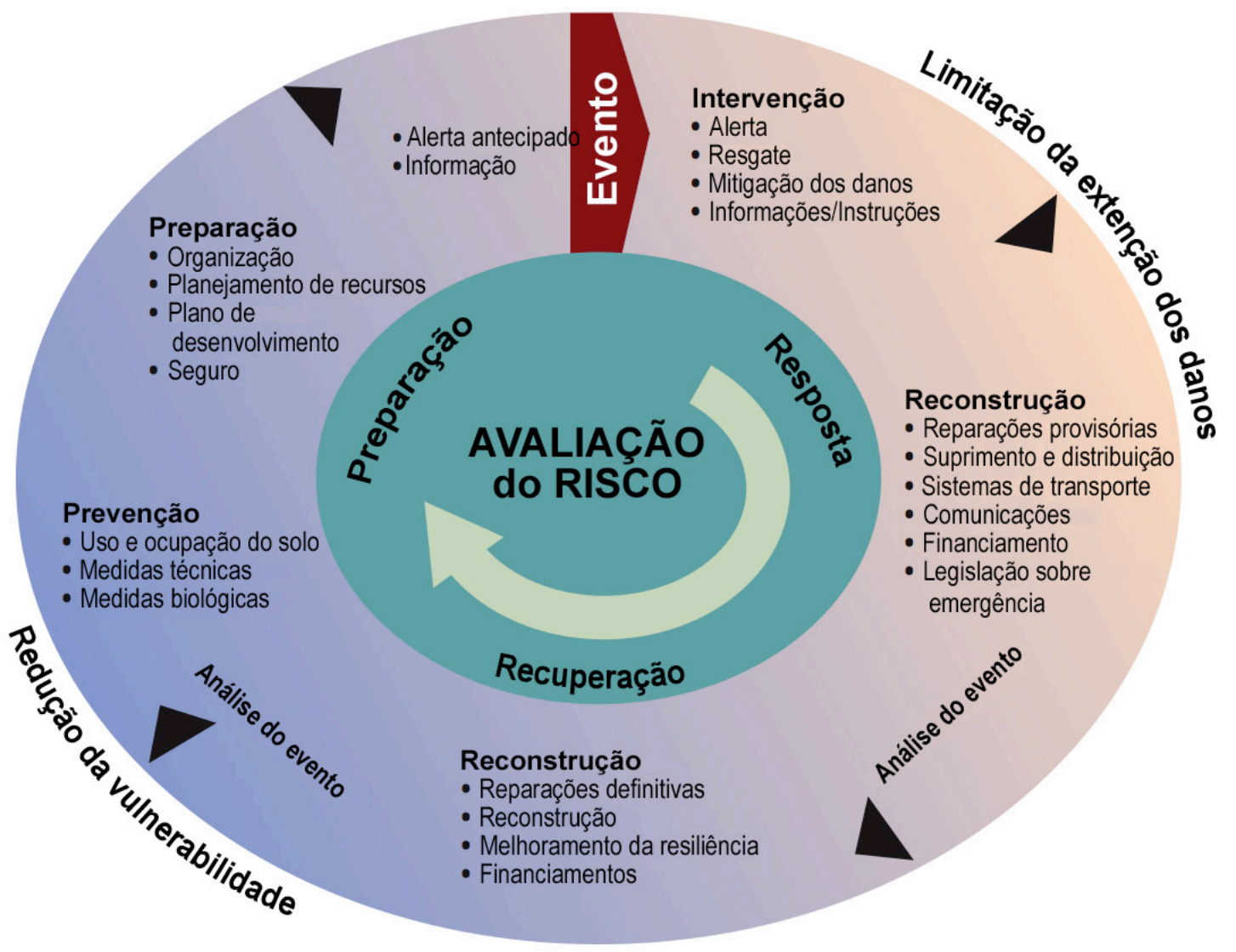

Figura 3.4 - O ciclo de gerenciamento de risco. Fonte: WWAP, 2006; adaptado de Swiss Civil Protection; traduzido pelo autor.

Seguindo a divisão proposta pelos três exemplos de gestão de risco, o sistema webGIS e a estimativa de risco por indicadores - enfoque deste trabalho - estão situados no momento prévio à ocorrência de alagamentos e inundações. Portanto relatam-se nos tópicos a seguir algumas medidas que podem ser tomadas durante essa etapa: o zoneamento e a implantação de sistemas de alerta. 


\subsubsection{Zoneamento}

O zoneamento é uma divisão territorial, de acordo com as diversas vocações e finalidades de uma determinada área, com o objetivo de potencializar o seu uso sem comprometer o meio ambiente, promovendo a qualidade de vida e o desenvolvimento sustentável (Kobiyama et al, 2006).

Para a classificação e definição de setores ou zonas e seus respectivos usos, a organização das informações espaciais deve considerar fatores de ordem física, territorial e cultural. É importante considerar tanto os fatores de ordem cultural e territorial quanto os físicos, pois os interesses comerciais e políticos influenciam fortemente no processo de ocupação. Em muitos casos estes fatores fazem com que a população com menor poder aquisitivo ocupe áreas com maior suscetibilidade a risco, como encostas íngremes e planícies de inundação.

Para realização desta medida não estrutural, é necessário enfatizar que a delimitação e classificação das áreas de perigo antecedem a criação das áreas de risco. No caso do mapeamento de perigo, podem ser utilizadas três metodologias distintas (Kobyiama et al, 2006):

- Empírica: Após a ocorrência do fenômeno, a área atingida é verificada em trabalho de campo e considerada como área de perigo;

- Semi-empírica: Além de caracterizar a área atingida como área de perigo, os fatores ambientais (topografia e solo entre outros) também são analisados, sendo que os valores críticos de fatores que podem causar o mesmo fenômeno são determinados numericamente (peso). Com base nesses valores, as áreas que possuem características semelhantes, também serão consideradas como áreas de perigo; 
- Física: Com base nas leis da física são analisados os mecanismos de ocorrência de determinado fenômeno. Depois da realização de simulações numérica ou física, procura-se onde, teoricamente, o fenômeno poderá ocorrer.

Após a elaboração do mapa de perigo, as áreas de risco poderão ser mapeadas. Neste caso, todas as variáveis (população, vegetação, animais, propriedades, residências, infraestrutura, entre outros) devem ser consideradas e seus valores computados.

\subsubsection{Sistemas de alerta}

O sistema de alerta é um instrumento que permite que a comunidade seja informada da ocorrência de eventos extremos e minimize os danos materiais e humanos. Kobiyama et al. (2006) apresentam um esquema de implantação de sistema de alerta em bacia hidrográfica, com seus principais componentes: (1) monitoramento; (2) transmissão dos dados; (3) modelagem e simulação; (4) orientação para as instituições responsáveis e alerta para a população localizada nas áreas de risco.

Segundo os autores, o sistema de monitoramento e de alerta para os fenômenos súbitos, deve ser realizado na escala local, ou seja, em nível municipal. A municipalização do sistema diminui a logística envolvida e, conseqüentemente, diminui os custos e agiliza seu funcionamento. A aquisição dos dados em tempo real é cada vez mais importante para o sistema de alerta. No artigo "A real-time hydrological model for flood prediction using GIS and the www" Al-Sabhan et al. (2003) discutiram o uso de SIG e Internet para a previsão de inundação e para o sistema de alerta. Os autores afirmam que para obtenção de um sistema de alerta e previsão eficiente é preciso considerar as questões ligadas à acessibilidade dos dados e à participação publica no planejamento do gerenciamento das inundações. Portanto, fornecer ao publico o acesso e analise de vários bancos de dados ambientais pode contribuir para que 
comunidades locais e pesquisadores participem ativamente nas decisões ambientais com impacto direto na vida das pessoas.

\subsection{Estimativa do risco de inundação}

O risco de inundação pode se exprimir pela intensidade - altura da água e velocidade de um evento de inundação e pela probabilidade com que este ocorre (Basler et al., 2003, apud Siegrist et al., 2006). E é geralmente representado em mapas muito detalhados onde se distingüem estágios de ameaça, do risco mais alto ao risco nulo (Siegrist et al., 2006).

Não obstante o progresso das tecnologias e as crescentes conveniências nas compras de equipamentos, o custo para a elaboração de mapas de inundação - geralmente feito por agências governamentais - permanece elevado. É requerido know-how no âmbito da utilização de um SIG - sistema software de elevado valor - para a análise espacial e a aplicação de modelos hidrológicos a fim de definir as áreas de inundação. Além disso, é necessária a obtenção de dados de vazão dos cursos de água da região analisada com os quais se constrói um banco de dados geográficos e um Modelo Numérico de Terreno (MNT). Portanto os custos, não somente de hardware e software, mas também de treinamento dos funcionários e de coleta de dados são importantes, e poucos órgãos municipais, tanto no Brasil como no mundo, conseguem atingir um equilíbrio satisfatório destes componentes para implementar e manter estes sistemas.

Há igualmente o problema da diferenciação e falta de continuidade dos mapas fornecidos por região. Siegrist et al. (2006) relatam o exemplo da Suíça, onde nem todas as regiões possuem mapas de inundação e, como o sistema político do país não é centralizado, os alertas de inundação e a divulgação de mapas variam muito para cada região.

Segundo a Comissão Européia (2006), o custo médio para produção de mapas de risco de inundação para regiões das nações européias, pode ser estimado entre 100 e 350 Euros (250 e 1000 Reais) por $\mathrm{km}^{2}$ de bacia hidrográfica. Esta estimativa, se aplicada à hidrografia 16 
da área urbana de São Carlos ${ }^{2}$, igual a $92 \mathrm{~km}^{2}$, levaria a um custo total variável de 50 a 70 mil Reais.

Para mapear o risco de inundação podem-se seguir outros caminhos menos sofisticados e acurados, e no entanto com custos menores e com maior rapidez na obtenção de resultados.

\subsection{Gerenciamento comunitário do risco de inundação via web}

As ferramentas de suporte ao conhecimento e ao gerenciamento do risco de inundação podem ser implementadas numa plataforma web que respeite alguns requisitos fundamentais para ser acessível a todo usuário. A filosofia é a de um portal web participativo, como as experiências desenvolvidas na web nos últimos anos: blogs, wikis, RSS feeds, o compartilhamento de vídeos amadores $\left(\right.$ Youtube $\left.^{\circledR}\right)$ e fotos $\left(\right.$ Flickr $\left.^{\circledR}\right)$. Estes exemplos refletem o papel de local de encontro midiático que a Internet tem assumido, onde todo usuário tem potencialidade de se exprimir, participar de projetos comuns, consultar, adicionar e alterar dados ou notícias, compartilhar conteúdos e sobretudo comunicar-se com os outros usuários, sejam eles próximos geograficamente ou distribuídos pelo mundo inteiro.

No artigo What is Web 2.0 de 2005, o autor Tim O'Reilly descreve como a web foi marcada por um momento decisivo após a crise das companhias de Internet em 2001. Notouse que a Internet em vez de sofrer uma queda, apresentou um crescimento de sua importância devido a novas aplicações e sites que surgiam regularmente e que as companhias que sobreviveram ao colapso apresentavam características comuns.

O colapso das companhias Internet marcou uma reviravolta para a web que originou a Web 2.0. O termo Web 2.0 tem uma ampla abrangência e é muito recorrente na internet, refere-se a um conjunto de princípios e práticas que são características comuns das

\footnotetext{
${ }^{2}$ Por hidrografia da área urbana de São Carlos entende-se a superfície equivalente à somatória das seguintes subbacias: Alto Monjolinho, Médio Monjolinho, Tijuco Preto, Gregório, Água Quente, Medeiros, Mineirinho e Santa Maria Madalena. Algumas destas sub-bacias incluem regiões não ocupadas pela mancha urbana da cidade.
} 
companhias Internet Web 2.0, entre outros: a web como plataforma; possibilitar a inteligência coletiva; o papel determinante do gerenciamento de dados; o fim do ciclo de lançamento de software; os modelos de programação leves; o software acima do nível de um único instrumento; a atenção à experiência do usuário na web.

Google Maps é um excelente exemplo de aplicação web 2.0: a interface Ajax (Javascript and XML) foi rapidamente decodificada pelos programadores que reaplicaram os dados a novos serviços. Serviços web relacionados a mapas já haviam sido disponibilizados por companhias especializadas em SIG (como a ESRI, MapQuest e Microsoft MapPoint), mas Google Maps teve um enorme sucesso graças à sua simplicidade de constituição e de uso. Enquanto as aplicações para mapping fornecidas pelas companhias SIG requeriam um contrato entre as partes (companhia e usuário), a maneira que Google Maps foi implementado, deixou os dados livres para serem utilizados, o que facilitou aos programadores a reutilização criativa de tais dados.

\subsubsection{Plataformas Web 2.0 e co-criação de conteúdos}

O caso NASA Clickworkers (Benkler, 2005) descreve as potencialidades dos usuários da rede quanto ao chamado User Generated Content (UGC) ou conteúdo gerado pelo usuário. O NASA Clickworkers foi um experimento realizado para verificar se voluntários públicos, cada um trabalhando por alguns minutos de tempo em tempo, pudessem fazer uma análise científica de rotina que teria sido feita por um pesquisador ou aluno de graduação trabalhando durante meses. O trabalho dos usuários consistia em marcar crateras em mapas de Marte, classificar crateras que já tivessem sido marcadas, ou buscar estruturas sextavadas (honeycomb) presentes na superfície de Marte.

O projeto foi um estudo piloto com fundos limitados, supervisionado durante meioperíodo por um engenheiro da computação, com inferências ocasionais de dois pesquisadores. 
Nos primeiros seis meses de funcionamento, mais de 85000 usuários visitaram o site somando quase dois milhões de entradas (incluindo entradas múltiplas na mesma cratera, usadas para minimizar os erros). Uma análise da qualidade das marcas tem mostrado que as entradas de um grande número de usuários ocasionais (clickworkers) é praticamente indistinguível das de um geólogo com anos de experiência na identificação de crateras em Marte $\left({ }^{3}\right.$ Clickworkers Results: Crater Marking Activity, July3, 2001). As tarefas operadas pelos clickworkers foram discretizadas, cada uma operada em poucos minutos. Os usuários podiam portanto optar por trabalhar poucos minutos fazendo uma única ação ou por horas, fazendo várias.

O projeto Clickworkers é um claro exemplo de como uma tarefa profissional complexa, que requer indivíduos especializados com dedicação exclusiva, pode ser reorganizada para ser desempenhada por milhares de voluntários não especializados, com um orçamento e um tempo muito menor. O que os pesquisadores da NASA encontraram foi uma vasta operação de 5 minutos de incrementos de julgamento humano, aplicado com motivação em participar de uma tarefa não relacionada a uma remuneração. O Clickworkers foi um experimento distinto, mas que sugere características da produção distribuída que são amplamente observáveis na rede (Benkler 2005). A enciclopédia on-line Wikipedia, fundada em 2001, representa outro exemplo de co-criação de conteúdos na rede com três características Web 2.0:

1 - o uso de uma ferramenta de escrita colaborativa (Wiki), que permite a qualquer um, incluindo usuários anônimos, a edição de qualquer página do projeto completo. Nela todas as versões e as alterações feitas são facilmente visíveis, permitindo aos usuários mudança do documento para uma versão anterior, além de permitir que façam quaisquer alterações. Toda contribuição e alteração são exibidas por meio de software e banco de dados;

${ }^{3}$ http://clickworkers.arc.nasa.gov/documents/crater-marking.pdf 
2 - é um esforço na criação de uma enciclopédia em representar todos os pontos de vista sobre um sujeito, mais do que atingir objetividade;

3 - todo conteúdo gerado desta colaboração é lançado com licença GNU Free Documentation License, uma adaptação do GNU GPL aos textos.

A adoção de um modelo aberto e colaborativo (peer produced) resultou em um grande sucesso. O site teve um grande crescimento no número de colaboradores, incluindo os ativos e os muito ativos e no número de artigos incluídos na enciclopédia.

Surgiram outras iniciativas na Internet parecidas com a Wikipedia. Por exemplo Rossignol (2008) relata sobre o site alemão "Eisteges ${ }^{4}$ ". Este site foi lançado pelo semanal Der Spiegel em outubro de 2007, com a idéia de recolher na Internet depoimentos sobre a história contemporânea, a fim de constituir uma memória nacional coletiva acessível a todos. Após acessar o site, os alemães podem contar suas experiências e interesses pessoais quanto à cultura popular, seja isto um programa de televisão, ou a chegada do rap alemão, ou temáticas mais graves como a Segunda Guerra Mundial. Até a data de publicação do artigo contavam-se 8000 membros e 20 milhões de visitas por mês. A autenticidade dos fatos evocados é verificada pelo grupo de redação do site antes de colocar o conteúdo online. Cerca de 600 temas foram propostos aos usuários que são convidados a contribuir com envio de fotos ou vídeos, contando a história também por meio de imagens. Segundo afirmado pelo mesmo autor, o site funciona em parceria com instituições de prestigio como o Arquivo nacional ou a Fototeca alemã. O material recolhido pelo site constitui um banco de dados historiográfico de grande valor para pesquisa e para memória.

Uma outra iniciativa de produção participativa é descrita no artigo "Personal Weather Stations Helping with Weather Forecasting" (Estações meteorológicas pessoais ajudam na

\footnotetext{
${ }^{4} \mathrm{http}: / / w w w . e i n e s t a g e s . s p i e g e l . d e$
} 20 
previsão do tempo) apresentado pelo portal Slashdot em janeiro $2008^{5}$. Trata-se do Citizen Weather Observer Program ${ }^{6}$ (CWOP) programa pelo qual algumas agências privadas e públicas, como a National Oceanic and Atmospheric Administration (NOAA) e o Department of Homeland Security (US-DHS), utilizam informações de estações meteorológicas pessoais para fazer previsão do tempo. $\mathrm{O} \mathrm{CWOP}$ foi criado por alguns rádio-amadores que experimentavam a transmissão de dados meteorológicos por meio de sinais rádio (packet radios), e com o advento da Internet o programa se expandiu para incluir dados transmitidos pela internet por donos de estações meteorológicas. Shaw et al. (2006) descrevem que, no âmbito do programa citado, por meio de uma instalação apropriada dos sistemas de medição meteorológica e um adequado sistema de controle, os usuários podem providenciar dados suplementares valiosos que aumentam a densidade das medições de uma dada região. $\mathrm{O}$ programa CWOP fornece conselhos para instalação e retorno aos donos das estações através um controle básico sobre a qualidade dos dados enviados. Ainda os mesmos autores afirmam que nos Estados Unidos há cerca de 6000 estações CWOP ativas. No caso do NOAA, os dados das estações CWOP são enviados a cada 15 minutos ao "Meterological Assimilation Data Ingest System" (MADIS), controlados para consistência temporal e espacial, e em seguida utilizados em computadores com modelos de previsão e programas de verificação de previsão. Analogamente no restante do mundo existiam em 2007 cerca de 5000 estações que forneciam regularmente dados meteorológicos para o banco de dados FindU do CWOP.

\subsubsection{Criação de mapas em colaboração}

Indivíduos conectados na web têm a capacidade (Bleecker, 2005) de fazer o chamado mapeamento colaborativo (colaborative mapping). Interfaces web do tipo Location User Interface (LUI) guiam os usuários no referenciamento geográfico de dados, sejam eles

\footnotetext{
${ }^{5} \mathrm{http}: / /$ science.slashdot.org/article.pl? sid= $=08 / 01 / 19 / 1835237$

${ }^{6} \mathrm{http}: / /$ www.wxqa.com/index.html
} 
anotações ou imagens, na criação de mapas produzidos pela colaboração de autores que, juntos, produzem mais do que um poderia criar sozinho. A criação de conteúdos relacionados a uma posição no mundo real gera o chamado Geospatial Web que requer um Location Based Service (LBS) o mais aberto e acessível possível. Etiquetar conteúdo e dados com metadados geográficos, dando assim ao conteúdo um lugar (location) no mundo real, o que representa uma nova fronteira desafiadora. A abordagem dos projetos baseados na posição (location based) inclui três aspectos: Location Awareness, Location User Interfaces, Collaborative Mapping. Há exemplos na internet: wikimapia.org, craigslist.com, placeopedia.com, openstreetmap.org, EEmap.org, communitywalk.com.

Talvez o exemplo que mais comprove a eficácia do mapeamento colaborativo via web seja o scipionus.com. Criado em ocasião do furacão Katrina, o site consiste numa página HTML que contém uma janela Google Maps posicionada na região atingida. Nesse mapa encontram-se centenas de marcadores de cor vermelho, verde e violeta com breves anotações associadas. Os usuários, pessoas de New Orleans e região, adicionaram os marcadores no mapa dinâmico logo após o desastre, fornecendo indicações valiosas para as equipes de resgate, pois as anotações referenciadas continham informações sobre danos estruturais, pessoas não encontradas ou animais domésticos presos em casas. Miller (2006) descreve que tais marcadores são de tipo comum, com simbologia (verde para as 50 entradas mais recentes, violeta para os marcadores em que foram adicionadas novas informações), coordenadas de latitude e longitude, e meta-atributos sobre a criação e a modificação. Os dados são fornecidos por uma fonte não usual: a comunidade que vem sendo mapeada. $\mathrm{O}$ mesmo autor afirma que o Scipionus é um fórum em que as entradas não são organizadas de maneira hierárquica, por argumento ou por cronologia, mas sim por geografia. Trata-se de um mapa do desastre criado imediatamente, com informações imediatas e por cidadãos que estavam no lugar ou estavam em contato com alguém que estava no lugar, ou tinham informações a fornecer que 
organizações locais e federais não tinham. A participação foi tão alta que em poucos dias registraram-se milhares de entradas que facilitaram a visualização das áreas atingidas.

\subsubsection{SIG de Participação Pública (Public Participation GIS - PPGIS)}

No artigo "The internet, GIS and public participation planning", os autores Tang e Waters (2005) afirmam que os sistemas de informação geográfica (SIG) estão se tornando ferramentas reconhecidas para o planejamento nos sistemas de transporte. Os planejadores de tais sistemas foram desafiados para envolver o público mais plenamente no processo de planejamento. Em razão do uso comum de SIG como ferramenta fundamental de planejamento, pode-se considerar o uso do SIG de Participação Pública, chamado em inglês Public Participation GIS (PPGIS) como um instrumento eficaz e à disposição. Mesmo que o tema de atuação seja a capacitação pública sobre os riscos naturais, o sistema SIG participativo para planejamento de transporte apresenta os mesmos objetivos e diretrizes. Os autores do artigo descrevem como o PPGIS tornou-se conhecido em virtude da publicação de Craig et al. (2002) e do aumento de conferências anuais sobre PPGIS que começaram em 2002. Também Hansen e Prosperi (2005) citam Craig et al. (2002) definindo o termo PPGIS:

"O PPGIS é, como o próprio nome indica, o uso da Internet e de sistemas SIG com base na web no processo de participação de cidadãos" ("Pubic Participation GIS is, as the name implies, the use of Internet and web-based GIS systems in citizen participation processes”) acrescentando que o termo foi aparentemente usado pela primeira vez em 1996 numa conferência em Maine, USA.

Tang e Waters (2005), contudo, definem o PPGIS baseado na web como Web-based PPGIS (WPPGIS) e o consideram como uma das mais avançadas ferramentas de planejamento participativo, especialmente em países industrializados, em que a tecnologia Internet se encontra comumente nas casas da classe média. Citando Sadagopan (2000), os 
mesmos autores destacam como as aplicações web-GIS podem tornar informações complexas mais facilmente compreensíveis às pessoas menos acostumada ao uso de tecnologia.

Por exemplo, incorporando fotos, texto, mapas interativos e outras formas de dados relacionados com uma interface gráfica amigável (user friendly) e instrumentos analíticos na internet ajudariam o acesso público e entendimento de informação.

O esquema da Figura 3.5, proposto por Tang e Waters (2005), mostra onde se colocam os tipos de SIG em relação a participação pública e à Internet.

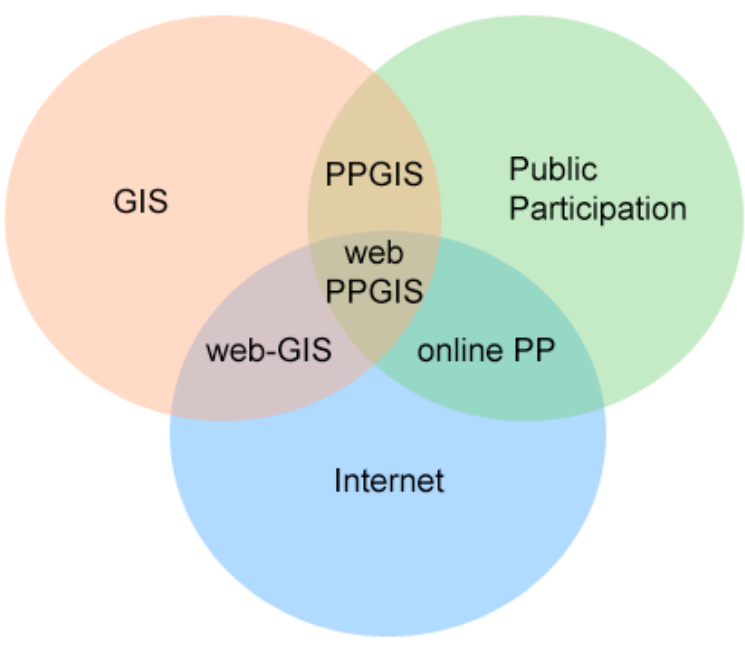

Figura 3.5 - SIG, participação publica, Internet e suas integrações. Adaptado de Tang e Waters (2005).

O web-GIS é uma combinação de Internet e SIG, ou seja um SIG convencional que utiliza Internet como infra-estrutura base de informação para inclusão espacial de dados e análise simples. Pela natureza de Internet, o web-GIS é considerado como um sistema interativo, distribuído, dinâmico, multi-plataforma e cliente/servidor. Web-based PPGIS inclui um componente participativo público, que permite a acessibilidade à informações de qualquer lugar com acesso à web. Tais informações estão também disponíveis 24 horas por dia, o que elimina obstáculos organizacionais de lugar e horário para reuniões para divulgação e discussão, favorecendo a participação de um público potencialmente maior. 
No artigo "Promoting the use of environmental data collected by concerned citizens through information and communication technologies", Gouveia et al. (2004) descrevem o planejamento de sistemas colaborativos para o monitoramento ambiental (ECMS Environmental Collaborative Monitoring System), listando casos encontrados mundialmente e propondo protocolos operacionais a serem utilizados na metodologia de pesquisa.

No âmbito das inundações urbanas, Barroca et al. (2006) apresentam uma metodologia que objetiva organizar, por meio de uma ferramenta software, a escolha de indicadores de vulnerabilidade. Os autores evidenciam a importância de incentivar a adoção da participação pública com os sistemas de informação geográficas (SIG) como mostrado nos PPGIS, salientando como esta ferramenta pode se tornar uma solução moderna e popular.

Menegon et al. (2004) participaram da implantação de protótipos e sistemas web-GIS - implementados com ferramentas livres (open source) - desenvolvidos para a prefeitura de Trento na Itália. Esquematizam características, funcionalidades e vantagens da tecnologia web-GIS:

1. Racionalização dos dados geográficos; 2. integração com dados geográficos provenientes de outras fontes e em sistemas de referência diferentes; 3. simplificação e automatização dos procedimentos de aquisição e de inserção de dados; 4. simplificação do acesso aos dados e da distribuição das informações com níveis de acesso diferenciados; 5. automatização dos procedimentos de produção de relatórios, estatísticas, tabelas e gráficos; 6. melhoria do controle contínuo do fluxo de informações graças à possibilidade de integrar o sistema com procedimentos de análise espacial quando solicitado e com instrumentos para medição automática das situações de interesse (por exemplo o risco emergente); 7. interfaces personalizadas e acesso por meio de dispositivos móveis PDA/sem fio. 


\subsubsection{Sistemas Web-GIS}

Segundo Milan (2006), os primeiros sistemas Web-GIS foram desenvolvidos no fim dos anos 90. Até então o usuário Internet só tinha acesso a imagens estáticas. A primeira geração de Web-GIS, constituída por aplicativos como o ArcIMS (Arc Internet Managing System) da ESRI, forneceu mais opções de visualização pela internet tais como zoom e a seleção de camadas (informação verbal) ${ }^{7}$. Estes produtos permitem ao usuário utilizar o browser para navegar mapas e fazer análises espaciais básicas (Tang et al., 2005). As operações efetuadas, sejam elas zooming, panning, querying, são enviadas aos clients em forma de HTTP (Hipertext Transfer Protocol), passadas ao servidor Web, onde um gateway passa de novo a um servidor SIG, que providencia uma página HTML (Hipertext Markup Language) a ser reenviada ao browser. Os produtos da primeira geração eram desenvolvidos em Java, uma linguagem não muito conveniente para visualizar imagens e dados dinamicamente. As limitações destes sistemas desenvolvidos em Java foram ultrapassadas com o advento de AJAX (Asyncronous Javascript and XML) em 2003, que constitui segundo Milan (2006) a segunda geração Web-GIS.

AJAX (Garett, 2005) não é uma tecnologia única, na realidade, é um conjunto de tecnologias uma independente da outra, que juntas tornam-se uma ferramenta inovadora e eficaz. Google Maps é um ótimo exemplo desta nova abordagem de programação de aplicações web; ações como panning ou zooming acontecem quase instantaneamente, sem espera para carregamento de páginas. AJAX oferece:

- Apresentações baseadas nos padrões XHTML e CSS;

- Visualizações dinâmicas e interações baseadas no Document Object Model (DOM);

\footnotetext{
${ }^{7}$ Informação fornecida pelo professor Milan no curso de Web mapping for public engagement da York University, Toronto, em 2006. 
- Intercâmbio e manipulação de dados utilizando XMLHttpRequest;

- JavaScript como plataforma para união e gestão das referidas tecnologias.

A diferença do modelo clássico de primeira geração para uma aplicação AJAX, é que esta elimina a natureza intermitente da interação usuário-servidor inserindo uma ferramenta intermediária: um motor AJAX. Em vez de carregar a página web em começo de sessão, o navegador carrega o motor AJAX escrito em linguagem JavaScript e geralmente invisível (Figura 3.6).

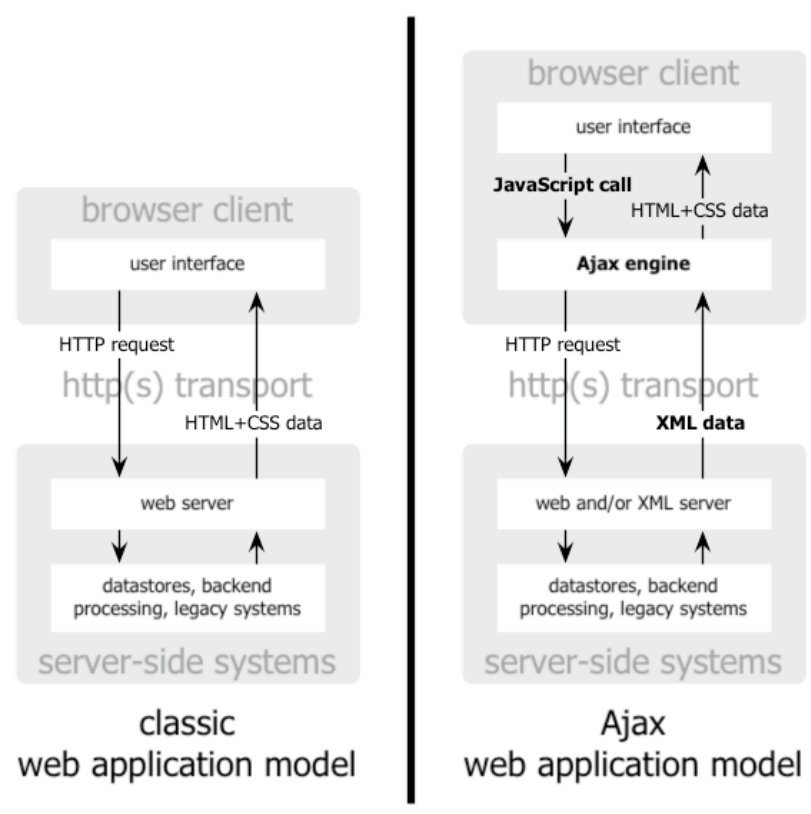

Figura 3.6 - Comparação entre os procedimentos dos modelos Web clássico e Ajax. Fonte: Garrett (2005).

Este motor é responsável pela criação da interface que aparece ao usuário e, ao mesmo tempo, pela comunicação com o servidor com base nas ações do usuário. A interface AJAX permite que a interação do usuário com a aplicação ocorra assincronicamente. Deste modo, o usuário não encontrará páginas vazias na espera da resposta do servidor.

Cada ação do usuário que geraria no modelo de primeira geração uma demanda HTTP, toma a forma de uma chamada JavaScript ao motor AJAX. Cada resposta às ações do usuário 
que não precisem de conexão ao servidor (como validação de dados e a variação de dados em memória) é gerenciada diretamente pelo AJAX. Caso seja preciso recorrer ao servidor (como o envio de dados, o carregamento de novos elementos da interface e a demanda de novos dados), as conexões com este último ocorrem de maneira assincrônica, utilizando geralmente XML (Extensible Markup Language), sem interromper a interação entre usuário e a aplicação (Figura 3.7).

Os Web-GIS de segunda geração, como Google Maps e Ka-Map, utilizam o sistema de caching (Becchi, 2007). Os dados recolhidos por estas aplicações web do MapServer são transformados em imagens no formato de peças (tiles), que no caso do Ka-Map tem lados de 200 pixels. Cada vez que uma mapa é visualizado, a aplicação cria os tiles para a área pedida. Se os tiles já existem, eles não são recriados e o servidor web devolve diretamente as imagens sem consultar o Mapserver, o que permite poupar grandes recursos de cálculo e obter um menor tempo de resposta. 

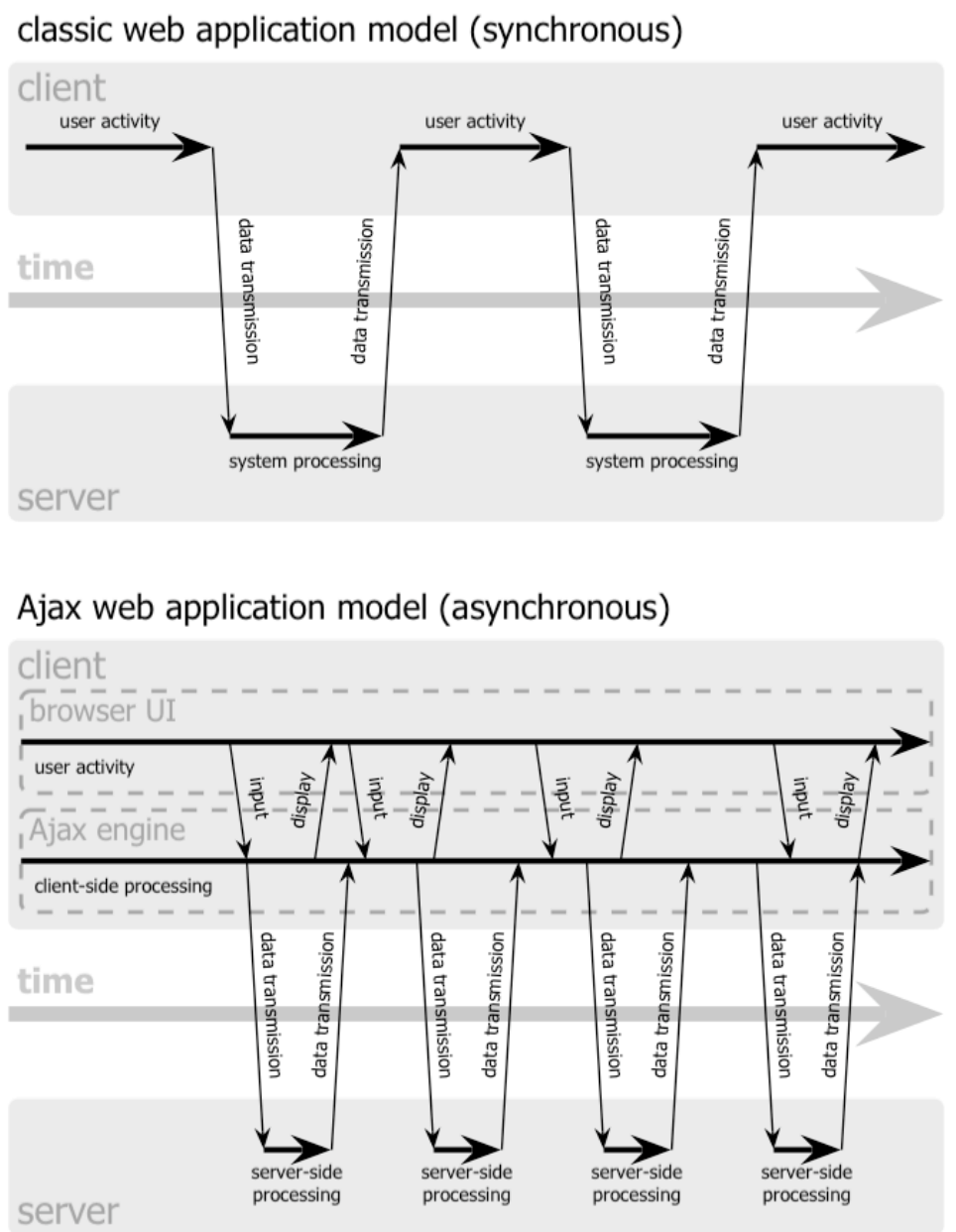

Figura 3.7 - Comparação operativa entre o modelo Web clássico e o modelo AJAX. Fonte: Garrett (2005).

As aplicações Web GIS utilizam também outra ferramenta para tornar a navegação mais fluida possível: o Tile system. Este sistema segundo Becchi (2007), faz com que o Web GIS peça ao MapServer a geração de uma imagem com extensão maior que a área de interesse. Essa única grande imagem, chamada metatile, é constituída por um número de tiles configurável (geralmente 8) e sucessivamente é subdividida em 64 tiles ( 8 x 8) pelas bibliotecas gráficas GD (Graphics Draw). Esta técnica melhora a renderização e permite a geração de tiles com um reduzido número de chamadas ao MapServer, contribuindo mais uma vez para a minimização dos tempos de resposta. 
O advento do AJAX fez com que a interação com mapas fosse intuitivo e fácil, e portanto, observa Miller (2006), tornou o web-GIS rápido, popular e, provavelmente em um futuro iminente, ubiqüitário: ou seja, será utilizável em qualquer lugar por aparelhos portáteis como Palmtop (ou PDA - Personal Digital Assistant) e celulares.

A Figura 3.8 mostra o esquema de funcionamento de um web-GIS com seus elementos constitutivos principais.

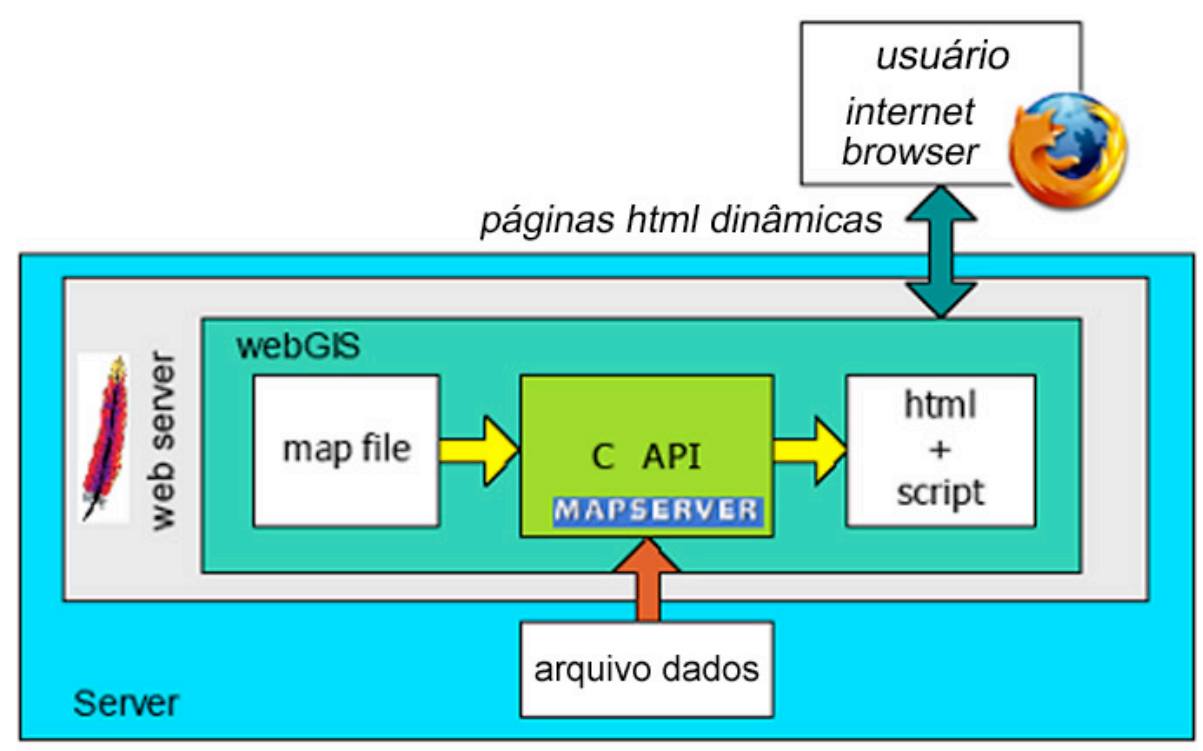

Figura 3.8 - Esquema de funcionamento de um portal web-GIS. Adaptado de Negretti (2007).

O número de tecnologias para implementação dos sistemas web-GIS é elevado e em contínua evolução. Qualquer ambiente de programação, linguagem de programação e plataforma de servidor pode ser utilizada para implementação de projetos web-GIS. As principais tecnologias que constituem os web-GIS pelo lado Servidor e pelo lado Client são resumidas nas tabelas Tabela 3.1 e Tabela 3.2. A lista foi adaptada do artigo "web mapping" que se encontra na enciclopédia on-line Wikipedia. 
Tabela 3.1 - Tecnologias web-GIS lado servidor

\begin{tabular}{ll}
\hline & \multicolumn{1}{c}{ Tecnologias lado servidor } \\
\hline Web server & Apache, Microsoft Internet Information Server \\
\hline CGI & common gateway interface - executables running on the webserver \\
\hline Scripting languages & Embutidas no webserver como modulo - PHP, Perl, Ruby, ASP \\
\hline Web application servers & Comunicacao GIS API - Webserver. Written in Java, C, C++, etc. \\
\hline Spatial databases & Object relational databases - PostGIS, MySQL, Oracle Spatial \\
\hline WMS server & Web mapping servers - UMN Mapserver, ESRI ArcIMS \\
\hline
\end{tabular}

Tabela 3.2 - Tecnologias web-GIS lado client

\begin{tabular}{ll}
\hline \multicolumn{1}{c}{ Tecnologias lado client (usuário) } \\
\hline Web browser & All browser supporting HTML and raster images (jpeg, png and gif format) \\
\hline ECMAScript support & $\begin{array}{l}\text { Standard version of JavaScript. (Standardized by the European Computer } \\
\text { Manufacturers Association - ECMA) }\end{array}$ \\
\hline Events support & Mouse, Keyboard, State, Mutation, SMIL animation, UI, and SVG events \\
\hline Network requests & Ajax - choose between XMLHttpRequests or getURL() and get the best one \\
\hline DOM support & Document Object Model - DHTML (Dynamic HTML) \\
\hline SVG support & Scalable Vector Graphics - Integrates vector graphics, raster graphics and text. \\
\hline Java support & Java virtual machine / Java applets \\
\hline Web browser plugins & $\begin{array}{l}\text { Adobe Acrobat, Adobe Flash, Apple Quicktime, Adobe SVG viewer, Sun Java } \\
\text { plugin }\end{array}$ \\
\hline
\end{tabular}

Menegon et al. (2004) relatam sobre alguns exemplos de soluções Web-GIS desenvolvidas para órgãos públicos com a finalidade de tornar prática, eficaz e rápida a coleta, a organização e o compartilhamento de dados georreferenciados. Segundo os mesmos autores a infra-estrutura informática desenvolvida para um web-GIS é uma integração de diferentes instrumentos open source (Figura 3.9):

- o Sistema Informativo Territorial GRASS ${ }^{8}$;

\footnotetext{
${ }^{8}$ Acronimo de Geographic Resources Analysis Support System. Trata-se de um software SIG livre lançado sob licença GNU GPL do qual existem versões para diferentes plataformas (Linux, Windows, MacOSX).
} 
- PostgreSQL, um Sistema de Gerenciamento de Dados (DBMS) com a extensão para a gestão de dados espaciais e geográficos PostGIS;

- Mapserver para a distribuição dos mapas on-line;

- R-language, software livre para a análise estatística de dados com possibilidade de interface automático de dados espaciais, temporais e banco de dados relacionais.

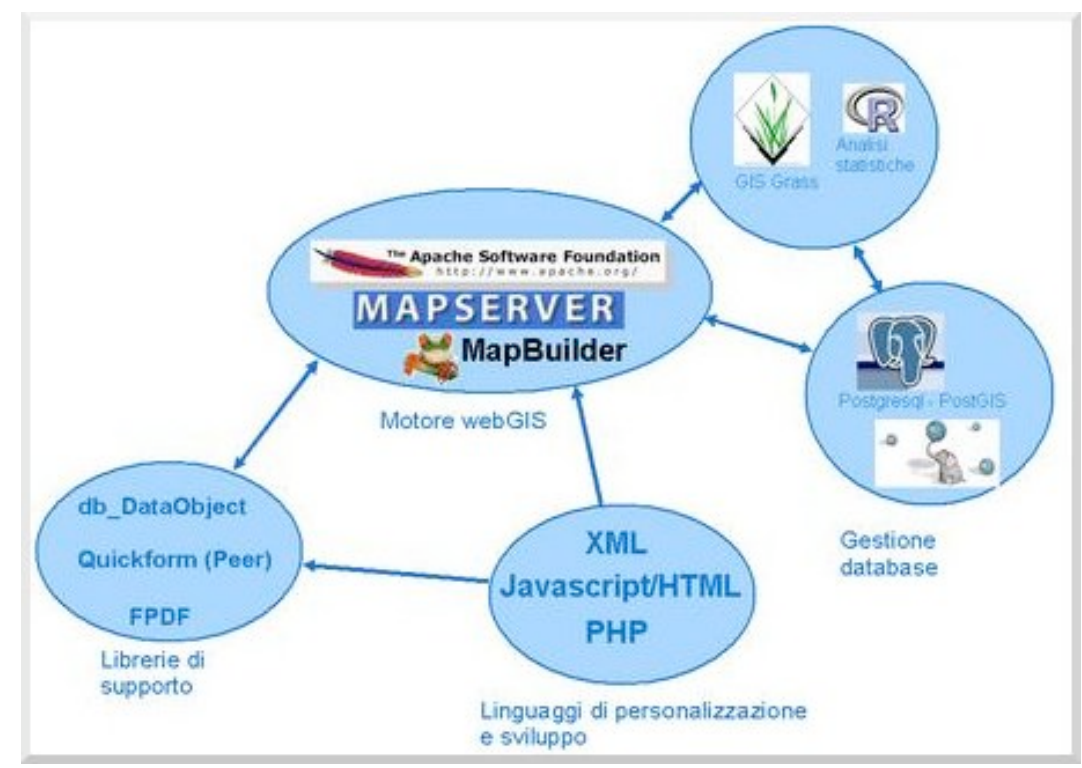

Figura 3.9 - Arquitetura das soluções para sistemas integrados webGIS baseadas em software livre. Fonte: MPA Solutions (2008) - mpasol.it.

As interfaces e os numerosos serviços adicionais realizam-se pela utilização de linguagens comuns de scripting para a web dentre as quais Perl, Javascript, Python, PHP e Java.

\subsubsection{A abordagem "Map 2.0” ao web-GIS}

Hockenberry et al (2005) definem a abordagem Map 2.0 como nome dado à possibilidade recente de construir mapas próprios por meio de aplicações de mapeamento baseadas na web, que oferecem Interfaces de Programação de Aplicativos API (Application 
Programming Interface) cada vez mais poderosas. Os autores trazem como exemplos de API a ferramenta Google Maps e Virtual Earth, considerando a primeira delas como pioneira nesta abordagem.

A Google criou um globo virtual que incorpora dados de elevação que descrevem montanhas e vales. Outros dados são depois superpostos, em particular um mosaico de imagens de satélite e fotografias aéreas licenciadas por alguns provedores públicos e privados. O planeta todo é coberto, com cerca de um terço de todo o terreno mostrado em um detalhe tal que, árvores ou carros podem ser distingüidos. Este sistema tornou-se possível apenas recentemente, graças às imagens comerciais de satélite de alta resolução, conexões à internet de alta velocidade e computadores potentes e baratos.

A empresa americana Keyhole lançou o primeiro "geobrowser" em 2001. A Google comprou depois a Keyhole em 2004 e lançou Google Earth $^{\circledR}$ em 2005. Em julho de 2006 (Purvis et al., 2006), a Google anunciou que o site Google Maps suportaria os arquivos $\mathrm{KML}^{9}$.

Em 2004 a agência espacial americana, NASA, lançou um outro geobrowser, chamado World Wind (disponível somente em ambiente Windows), mas o geobrowser rival da Google é o da Microsoft.

“Encarta", a enciclopédia da Microsoft $^{\circledR}$, e TerraServer $^{\circledR}$, um projeto de banco de dados demonstrativo tinham ambos funcionalidades tipo geobrowser já nos anos 90 . No final de 2005 a Microsoft ${ }^{\circledR}$ comprou GeoTango ${ }^{\circledR}$, que contribuiu ao desenvolvimento do "Live Search Maps", um geobrowser baseado na web que utiliza dados oriundos do "Visual Earth", o modelo digital do planeta da Microsoft ${ }^{\circledR}$ equivalente ao Google Maps.

\footnotetext{
${ }^{9}$ KML - Deriva do inglês Keyhole Markup Language - refere-se ao nome do arquivo de mapas utilizado pelo Keyhole antes e pelo Google Earth depois - uma vez que Google comprou Keyhole - e por outros navegadores que implementam a codificação KML. O arquivo, baseado na linguagem XML, contem o esquema para expressar anotações e visualizações geográficas(por exemplo: Latitude, Longitude, coordenadas de um polígono, cor do objeto a ser representado) para mapas on-line baseadas na web.
} 
A Google conta com a "co-criação" de conteúdos (crowdsourcing) - envolvendo seus usuários na construção e contribuição de imagens, modelos 3D de edifícios, e outros dados para enriquecer o seu planeta digital. A Wikipedia, que utiliza um sistema similar, está também disponível através do Google Earth $^{\circledR}$. Usuários podem ler artigos Wikipedia posicionados no globo por meio de etiquetas geográficas (geotags), que possuem coordenadas espaciais embutidas.

Os globos virtuais estão sendo utilizados para variados fins. Atualmente há muito interesse em torno da combinação de mapas virtuais com outras fontes de dados nos chamados "mash-ups", uma arquitetura emergente da web geográfica (ou geoweb): dados, como informações sobre congestionamentos de tráfego ou tremores sísmicos, são alocados separadamente das imagens e modelos do geobrowser, o qual monta, combina e mostra a informação. GeoCommons.com, por exemplo, hospeda dados como número de crimes ou estatísticas de melanoma, que podem ser combinados para criação de mapas coloridos do tipo "heat maps".

Hoje em dia programadores web e amadores estão adquirindo chaves API do Google Maps e, por meio de implementação JavaScript e código XML, estão criando recursos para informação geoespacial para responder às necessidades específicas de determinadas comunidades, indústrias, eventos ou interesses (Miller, 2006).

Os entusiastas dos mash-ups têm se aproximado da área do SIG, que é utilizado por governos e empresas na análise de dados espaciais. Em comparação com o SIG os navegadores geográficos são ainda bastante primitivos, mas são muito mais simples de se usar. Por outro lado o SIG possui geralmente dados de qualidade impecável.

As imagens aéreas e de satélite dos navegadores geográficos têm tipicamente de seis meses a 3 anos e estão mais disponíveis hoje em dia do que antigamente. Os navegadores 
geográficos fizeram com que o acesso a estas imagens se tornasse muito mais econômico e fácil do que antes.

Com o intuito de facilitar a troca de informações entre este tipo de aplicações criaramse novos padrões de interoperabilidade. A Google por exemplo, submeteu recentemente o KML ao corpo padronizador Open Geospatial Consortium (OGC), o que permitirá a outras empresas suportar este protocolo. O GML, protocolo desenvolvido pelo OGC para codificar modelos de informação espacial, foi adotado formalmente como padrão internacional em 2007. Em breve devem ser lançados padrões para dados geográficos dinâmicos (dynamic geodata), o compartilhamento de modelos 3D de prédios e dados geográficos (geodata) por redes de sensores (sensor networks). A padronização destes protocolos ou dados geográficos segundo Carl Reed - chefe do departamento de tecnologia da OGC (apud The Economist, 2007) - assegurará a interoperabilidade e fará para os dados geográficos o que a web fez para outras formas de dados.

Ao mesmo tempo, a incorporação de tecnologia de posicionamento de satélite em telefones celulares e automóveis representa um campo em desenvolvimento. Como demonstrado pela empresa "Socialight", o simples fato de se deslocar em um bairro representa virtualmente a mesma coisa que navegar e gerar conteúdos. Um serviço como este permite aos usuários anexar notas em qualquer lugar, para serem lidas posteriormente por outros usuários. No futuro o resultado poderá levar os indivíduos a terem consciência da existência de uma informação extra-sensorial, capacidade de anotação e de análise no mundo real. Quando isso acontecer, afirma Jones (apud The Economist 2007) “o mapa será na verdade um pequeno portal sobre nossa própria vida". E ainda segundo ele "a única coisa que pode frear isso é a taxa de adaptação da sociedade". 


\subsubsection{Sistemas web-GIS não proprietários}

No caso do Google Maps, uma vez obtida a chave para um domínio web, o funcionamento da base de mapas dinâmicos nesta é imediata, e consiste no simples ato de inserir na página web o endereço da chave mencionada acima. A mesma coisa acontece com outros provedores de serviços de mapas dinâmicos, como Yahoo Maps, o qual oferece também o serviço de forma gratuita. O grande limite na escolha desses serviços “emprestados” como base para a criação de um web-GIS, é que quem os usa está sujeito à licença de utilização que impõe algumas restrições. Dentre elas a eventualidade pela qual, atingido um alto tráfego de usuários no site com o serviço de mapas embutido, a companhia que o fornece tem direito a fazer aparecer propagandas no mesmo, o que torna inviável a utilização em alguns sites institucionais que como regra não podem expor propaganda.

Um exemplo de interface para o web mapping livre de limitações e desenvolvido com licença open-source, é representado por Ka-Map (Becchi et al, 2007). Trata-se de uma aplicação AJAX criada para navegar em mapas dinâmicos na internet, relacionando-se ao servidor de mapas Mapserver desenvolvido pela University of Minnesota ${ }^{10}$, que já possui componentes desenvolvidos para ele (Miller, 2006).

Ka-Map foi originalmente desenvolvido pela canadense DM Solutions como projeto open source em seguida aprimorado por outros programadores. Os produtos criados com esta ferramenta apresentam uma interface eficaz, uma navegação rápida, e uma ampla possibilidade de customização podendo adicionar-se funcionalidades SIG. Podem-se citar os exemplos: http://zadeh.ugent.be/rwanda/ e http://geoingegneria.dits.uniroma1.it/dighe/kamap/ realizados respectivamente por uma universidade belga e por um órgão regional italiano.

\footnotetext{
${ }^{10}$ Informação obtida em: http://www.ominiverdi.org acessado 29/05/2008 


\subsubsection{Elementos para a criação de web-sites com base na experiência do usuário}

O processo de desenvolvimento de um web-site, seja ou não web-GIS, deve passar por fases de estudo e planejamento. Garrett (2000) descreve os elementos que constituem a experiência do usuário em um site, e salienta que se deve ter muita atenção às etapas de criação do mesmo. É desejável criar o site assegurando que nenhum aspecto da interação do usuário com este ocorra sem a intenção de quem o desenvolveu.

O autor sugere subdividir a produção da experiência do usuário segundo os elementos que a constituem. Tais elementos podem ser considerados como camadas sobrepostas que conjuntamente formam a experiência de navegação do site (Figura 3.8), propõe-se deste modo uma organização conceitual composta por cinco camadas ou planos: Surface Plane, Skeleton Plane, Structure Plane, Scope Plane e Strategy Plane. A primeira camada é o plano de superfície, onde se observa uma série de páginas web formadas por imagens e texto, alguns dos quais acionam, através de toque de mouse, rotinas ou tarefas como por exemplo fazer zoom. Abaixo da superfície há o esqueleto do site: o posicionamento de botões, abas, fotos e blocos de texto. O esqueleto é projetado para otimizar a disposição destes elementos para obtenção do máximo efeito e eficiência do site. O plano sucessivo é representado pela estrutura que define as categorias presentes e os percursos dos usuários dentro do site. A quarta camada, denominada plano de escopo, é onde se realiza a escolha dos atributos e das funções a serem incluídas no site. $\mathrm{Na}$ base das camadas há a estratégia que determina o escopo do site. A estratégia incorpora os objetivos de quem propõe o site, e também, os dos usuários.

Ao passar para camadas superiores (Figura 3.8) as decisões tornam-se mais especificas e envolvem um maior nível de detalhe. Cada plano depende dos planos antepostos e quando as escolhas feitas pelos criadores do site não se alinham, os projetos muitas vezes fracassam pela falta de coerência na composição dos componentes, resultando em sites desapreciados e 
evitados pelos usuários. Essa dependência significa que as decisões no plano estratégico têm efeitos diretos nos níveis sobrepostos. As escolhas disponíveis nos planos estão fortemente ligadas às decisões tomadas nos planos inferiores. Contudo, não necessariamente toda decisão tomada em planos inferiores deve ser tomada antes daquelas dos planos superiores. As dependências são bilaterais, portanto as decisões tomadas nos níveis superiores as vezes provocam uma nova avaliação das decisões tomadas em planos inferiores. Por este motivo o autor sugere um planejamento de maneira que o trabalho em cada plano não termine antes que o trabalho nos planos inferiores seja finalizado.

Inicialmente a web só previa o hipertexto e era considerada como um novo meio de publicação, mas com o avanço da tecnologia e o adição de novas funcionalidades à navegadores e servidores web, esta começou a atrair uma comunidade mais ampla. O desenvolvimento de funcionalidades mais complexas e robustas permitiram aos sites não somente distribuir informação, mas também coletá-las e manipulá-las. A web se tornou, portanto, mais interativa respondendo aos inputs dos usuários de maneira similar às aplicações desktop, a medida que os sites faziam a transição de coleções estáticas de informação para sites dinâmicos baseados em bancos de dados. Quando a comunidade de experiência do usuário na web se formou, os membros estavam divididos em dois grupos: um que considerava cada problema de experiência web como ligado ao projeto de uma aplicação, e outro que considerava a web como fornecimento e busca de informação. Cada um dos grupos propunha sua abordagem para a solução de problemas, apesar da maioria dos sites serem um híbrido entre os dois grupos, incorporando qualidades de cada um.

Para tratar este dualismo na natureza da web, Garrett (2000) divide os cinco planos ao meio (Figura 3.10) destinando à direita os elementos pertencentes aos espaços de informação sob forma de hipertexto, à esquerda, o lado software, as tarefas ou os passos envolvidos no processo de como os usuários pretendem completá-los. No lado esquerdo considera-se o site 
como um conjunto de instrumentos que o usuário utiliza para cumprir tarefas, ao passo que no lado direito o enfoque é a informação e o que ela significa para os usuários que a encontram.

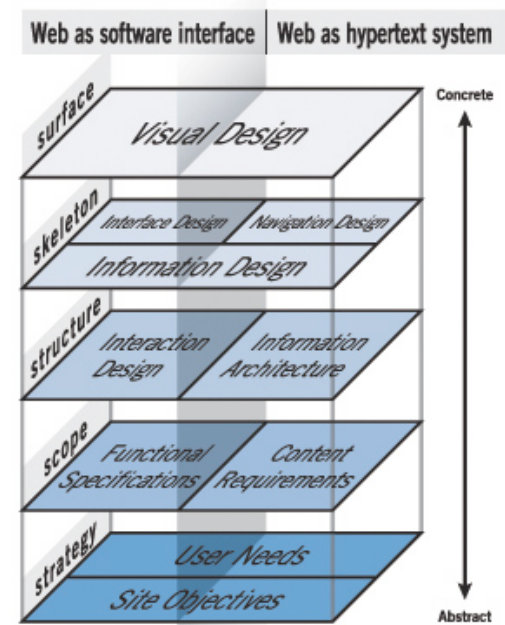

Figura 3.10 - Os elementos da experiência do usuário. Adaptado de Garrett (2000).

O mesmo autor descreve cada plano seguindo a subdivisão software / hipertexto:

A Estratégia: As necessidades do usuário são as metas do site. Nesta fase tem que se entender o que o público alvo quer e como se relaciona com os outros objetivos do site. Os objetivos do site sempre têm que se equilibrar com as necessidades do usuário.

O Escopo: No lado software, a estratégia é traduzida em escopo por meio da criação de especificações funcionais, isto é, uma descrição detalhada do conjunto de características (feature set) do produto. No lado do espaço de informação, o escopo torna-se uma descrição dos requisitos de conteúdo (content requirements).

A Estrutura: Neste plano o escopo é estruturado quanto ao software por meio do projeto de interação (interaction design), no qual se define como o sistema se comporta em resposta ao usuário. Em relação ao lado dos espaços de informação a estrutura é a arquitetura 
da informação (information architecture): a organização dos elementos do conteúdo de informação.

O Esqueleto: Este plano pode-se subdividir em três componentes principais. Em ambos os lados há necessidade de se tratar o projeto da informação (information design), ou apresentação da informação de maneira a facilitar a compreensão. Para os produtos software inclui-se o projeto da interface (interface design). A interface para o espaço de informação é constituída pelo projeto de navegação (navigation design), ou conjunto de elementos de tela que permitem ao usuário se deslocar pela arquitetura de informação (information architecture).

A Superfície: O plano no qual, não importa se o produto final é software ou informação, o interesse é no projeto visual (visual design), ou a aparência do produto final.

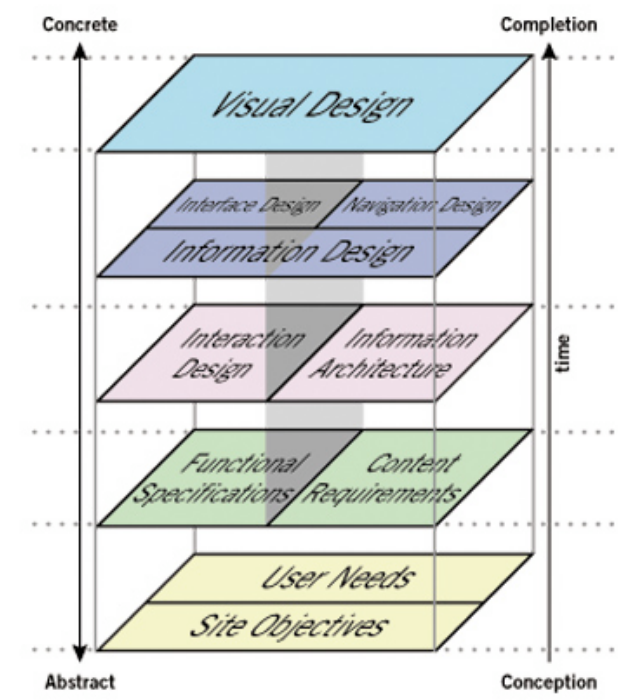

Figura 3.11 - Os elementos da experiência do usuário. Ao lado esquerdo a web é considerada como uma interface software, orientada à tarefa (task-oriented); Ao lado direito a web é considerada como um sistema de hipertextos, orientada à informação (information-oriented). Adaptado de Garrett (2000). 
Esse modelo dividido em planos (Figura 3.11) é muito eficaz para tratar a experiência do usuário, mesmo que muitas vezes seja necessário ter atenção ao se trabalhar em várias camadas ao mesmo tempo, saindo um pouco das margens do modelo proposto.

Os outros fatores que afetam a experiência do usuário, mas não tratados pelo autor anteriormente citado, são o conteúdo e a tecnologia. O primeiro representa o que tem de mais valioso para os usuários, pois estes não visitam um site simplesmente pelo prazer de navegar. O conteúdo disponível (ou que se tem recursos para obter e gerenciar) terá grande importância em dar forma ao site. É essencial que todo conteúdo proposto seja cuidadosamente mantido disponível e em dia para assegurar a melhor experiência do site. O segundo fator, a tecnologia, é tão importante quanto o conteúdo, determinando a natureza da experiência, por exemplo, com o uso de sistemas de navegação dinâmica que mudam em resposta às ações do usuário no site. Com o avanço contínuo da tecnologia o campo da experiência do usuário deve conseqüentemente se adaptar.

\subsubsection{Guias para a criação de web-GIS}

$\mathrm{Na}$ fase de projeto e desenvolvimento os portais web-GIS podem seguir as mesmas linhas gerais utilizadas para criar qualquer site. Existem porém alguns cuidados a serem tomados pelo fato dos web-GIS oferecerem tecnologias e funcionalidades variadas.

Vlugt e Stanley (2005) propõem guias para o projeto do mapeamento via web (web mapping design), que se aplicam aos web-GIS. O enfoque proposto é a facilidade de uso (usability) de um produto ou serviço pelo público alvo, no caso o produto é um portal webGIS e o público alvo são os usuários que o acessam.

Os autores salientam que a abordagem tradicional à publicação de mapas na Internet “criadas por especialistas de SIG para especialistas de SIG” (by GIS experts, for GIS experts) é obsoleta, ineficaz e inutilizável a medida que o web mapping se torna continuamente mais 
comum. As aplicações precisam ser projetadas para facilidade de uso e para satisfazer usuários com conhecimentos limitados sobre mapas, fazendo com que o público aumente e se diversifique, não sendo somente formado por especialistas de SIG.

Como descrito no item 3.4.4, a tecnologia que permite o mapeamento via web é disponível desde os anos 90. Contudo as aplicações de sucesso têm surgido somente nos últimos anos. Vlugt e Stanley (2005) afirmam que excetuando-se alguns casos, como MapQuest e WhereIs, a maioria das aplicações de web mapping foram desenvolvidas por especialistas de SIG. O resultado foi, na maioria das vezes, uma tentativa de esgotar a aplicação de funcionalidades e flexibilidade SIG. Isto é adequado se o público alvo é um grupo de especialistas, mas raramente este é o caso, motivo pelo qual muitos web-GIS são deixados de lado. Ultimamente tal tendência está mudando, o web mapping está se tornando mais integrado com as aplicações Internet mais populares, com o amadurecimento de expectativas entorno da qualidade e da facilidade de uso. Os projetos de web mapping incluem com freqüência a coleta e análise do perfil do usuário, a análise dos requisitos, o teste do projeto gráfico e da facilidade de uso.

A facilidade de uso (usability) descrita acima é estreitamente ligada à utilidade (que por sua vez é ligada à funcionalidade). Segundo os mesmos autores tratar estes atributos é de grande importância para a aceitação de um produto e, citando Jakob Nieslen ${ }^{11}$, apresentam-se os componentes qualitativos da facilidade de uso: Learnability - facilidade para os usuários de cumprir tarefas básicas durante a primeira vez que encontram o design da interface; Efficiency - rapidez na execução de tarefas uma vez que o usuário aprendeu o design da interface; Memorability - nível de facilidade para restabelecer a proficiência após os usuários retornarem ao design depois de um tempo sem usar; Errors - Quantos erros os usuários

\footnotetext{
${ }^{11}$ Nielsen, J. (2003) Usability 101: Introduction to Usability. Jakob Nielsen's Altertbox, Aug 25, 2003. Disponível em http://www.useit.com/alertbox/20030825.html acessado 29/05/2008. 42
} 
cometem, nível de gravidade dos erros e facilidade em recuperar-se destes; Satisfaction Nível de satisfação em utilizar o design.

Para tratar os componentes da facilidade de uso juntamente aos aspectos da utilidade, Vlugt e Stanley (2005) apresentam passos chave de uma metodologia baseada nas necessidades, tarefas e objetivos dos usuários. O primeiro passo é a identificação do público alvo, identificando quais são os usuários e qual experiência têm na utilização de ferramentas de web mapping, de mapas convencionais e de Internet. Sucessivamente identificam-se os requisitos dos usuários, como o que se quer cumprir no site, quais são suas prioridades, onde vai ser usada a ferramenta. Isto pode ser feito por exemplo, observando os usuários em atividade no próprio ambiente habitual, ou por meio de entrevistas, questionários ou em grupo.

Em seguida faz-se um resumo dos requisitos, das oportunidades e das restrições, determinando qual tipo de mapa e quais funcionalidades os satisfazem. Nesta fase se decide sobre qual mapa utilizar, se estático ou dinâmico, qual informação vai ser mostrada no mapa, quais funcionalidades inserir (zoom, arrastar, impressão, salvar e/ou analisar dados). Este sumário atuará como referência para o projeto do portal e pode ser modificado durante o processo de refinamento. Entre os últimos passos desenvolve-se um protótipo sob forma de desenhos em papel das diferentes telas ou de uma versão básica on-line do produto. Não é preciso uma versão completamente funcional, pois nesta fase o objetivo é mostrar uma versão preliminar antes de se investir tempo e recursos no portal. Finalmente testa-se o protótipo com alguns usuários representativos. Indicam-se algumas tarefas a cumprir e observa-se o comportamento do usuários em realizá-las utilizando o protótipo. Anotam-se questões encontradas e sugestões. Após a fase de teste analisam-se os resultados e desenvolvem-se as mudanças necessárias refinando assim o protótipo e testando-o novamente até atingir um nível apropriado de utilidade e facilidade de uso. Neste ponto pode-se construir o produto. 
Envolver usuários no processo de desenvolvimento é um aspecto importante, pois oferece indicações valiosas para um projeto baseado nas necessidades do usuário.

Apresentam-se as diretrizes para o projeto de aplicações de web mapping, assim como propostas por Vlught e Stanley (2005):

- Utilizar um terminologia clara e sem ambigüidade. Os projetistas devem evitar jargões;

- O projeto gráfico do site deve ser cuidado por profissionais de design, realçando e complementando o texto e os mapas, focando na atenção do usuário no conteúdo;

- Apresentar uma legenda na visualização padrão do mapa, de maneira que esta seja auto-explicativa;

- Providenciar um localizador (locator), ou mapa contextual, mostrando onde se encontra o mapa visualizado em relação à área geográfica maior;

- Colocar botões com texto ou ícones com "texto ALT" com seu nome, descrevendo o propósito ou a ação. Os botões devem ser suficientemente grandes para que os usuários identifiquem facilmente o texto ou a imagem e cliquem corretamente com o mouse;

- Providenciar uma Ajuda (Help) e uma gama de mensagens de erros, inclusive a ação requerida para permitir se recuperar de um erro.

Além disso, as funcionalidades avançadas, tais como adicionar camadas ou solicitação de dados (data query), que podem ser disponíveis para usuários especialistas, não devem representar um bloqueio para usuários principiantes.

Como os autores anteriormente citados afirmam, muitos destes pontos são válidos para qualquer aplicação (software) não somente para representações geográficas na web. 


\subsection{Expressão de indicadores para estimativa de risco}

A estimativa do risco e o seu gerenciamento podem ser expressos através de equações operacionais aplicadas a casos reais em áreas urbanas. Mendiondo (2008) propõe uma expressão (equação 3.1) composta pelas fases que constituem o risco: estimativa e gerenciamento. Cada fase é expressa como combinação de componentes. O resultado permite, em âmbito urbano, apresentar e comparar riscos em diferentes sub-bacias.

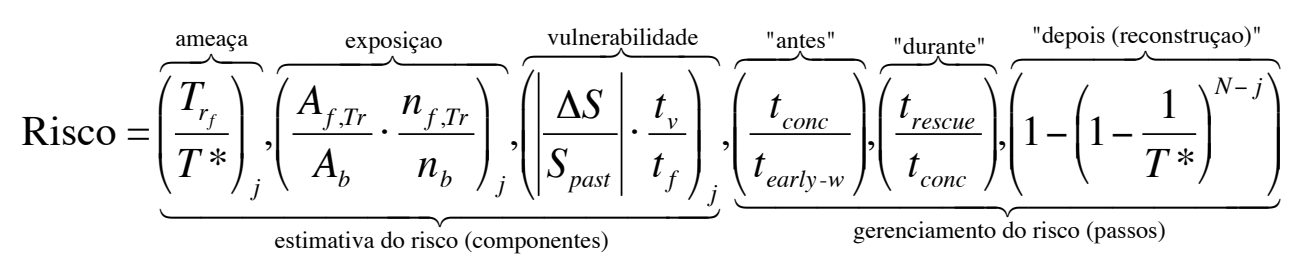

em que:

$T r_{f}$ é o tempo de retorno de inundação; $T^{*}$ é o tempo de retorno de projeto do canal referente à altura de extravasamento (bank-full); $A_{f, T r}$ é a área inundável segundo o tempo de retorno $\operatorname{Tr}_{f} ; A_{b}$ é a área total da bacia hidrográfica; $n_{f, T r}$ é a população que vive na área inundável $A_{f, T r}$; $n_{b}$ é a população total da bacia; $\Delta S$ é igual à diferença $S_{\text {now }}-S_{\text {past }}$ (sendo, $S_{\text {now }}$ o armazenamento atual de água no solo e $S_{\text {past }} \mathrm{o}$ armazenamento de água no solo no passado em ausência de urbanização); $t_{v}$ é a duração média que um indivíduo vulnerável (portador de deficiência ou idoso) leva para atravessar o fundo de vale inundável em condições adversas; $t_{f}$ é a duração média que um individuo não vulnerável leva para atravessar o fundo de vale inundável nas mesmas condições; $t_{c o n c}$ é o tempo de concentração da bacia; $t_{e a r l y-w}$ é o tempo de previsão de alerta; $t_{\text {rescue }}$ é o tempo de resgate necessário para atender a emergência em caso de inundação; $N$ é o tempo de vida útil das obras; $j$ é o tempo de adequação relativo. 
Tal expressão foi proposta com o intuito de aplicá-la ao planejamento ambiental e urbano, e pode ser utilizada para descrever o andamento do risco ao longo de um determinado intervalo de tempo de acordo com diferentes cenários futuros. Mendiondo (2008) traz um exemplo de aplicação da expressão para uma bacia urbana subtropical com área de $13 \mathrm{~km}^{2}$, para o período 2000-2050 com dois cenários distintos - reativo e pró-ativo - como alternativas para auxílio aos tomadores de decisão.

Segundo o autor, as políticas pró-ativas para o gerenciamento de risco de inundação têm por base o zoneamento ambiental, os sistemas de alerta antecipado e mecanismos de seguro para transferência de risco. Os resultados mostram a evolução dos custos do risco de inundação ao longo dos 50 anos considerados para cada cenário, evidenciando custos superiores para o cenário reativo.

Os cenários considerados, geralmente denominados como reativo e pró-ativo referemse à abordagem na exploração de futuros plausíveis.

O Millennium Ecosystem Assessment (2005) desenvolveu quatro cenários para explorar futuros plausíveis para ecossistemas e bem estar humano baseados em hipóteses sobre forças motrizes (driving forces) de mudança e suas possíveis interações. Os quatro cenários - Global Orchestration (GO), Order from Strength (OS), Adapting Mosaic (AM), TechnoGarden (TG) - foram desenvolvidos utilizando modelos e análises quantitativas. Não se trata de predições, mas de averiguações para explorar as características imprevisíveis da mudança nas forças motrizes (drivers) e nos serviços do ecossistema.

Os cenários exploraram duas linhas gerais de desenvolvimento, uma em que se considera que o mundo está em contínuo processo de globalização e outro no qual há um aumento contínuo da regionalização. Além disso, há duas diferentes abordagens relativas ao gerenciamento dos ecossistemas, uma na qual as ações são reativas e os demais problemas são enfrentados após se tornarem evidentes e outra em que o gerenciamento dos ecossistemas 
é pró-ativo com políticas que buscam deliberadamente manter os serviços dos ecossistemas a longo prazo. Os dois primeiros, GO e OS, são cenários reativos, já os demais, AM e TG, são pró-ativos, pois consideram mudanças significativas nas políticas que tratam os desafios do desenvolvimento sustentável. 


\section{METODOLOGIA}

A metodologia utilizada seguiu as seguintes etapas:

1. Estruturação de um portal web-GIS para mapeamento do risco, definindo como parâmetros de avaliação do risco de inundação os três componentes do triângulo do risco, adaptados para exprimir a percepção do público. Elaboração de um roteiro de entrevistas com questões fechadas de percepção do risco da população.

2. Aplicação da expressão do risco (3.1) para uma avaliação do mesmo no presente e suas projeções futuras, segundo cenários reativo e pró-ativo.

\section{1 Área de estudo}

O presente trabalho insere-se nos esforços de informação e formação dos moradores das sub-bacias hidrográficas pertencentes à cidade de São Carlos (SP), onde o Departamento de Hidráulica e Saneamento da EESC/USP realiza estudos hidrológicos para a criação de um sistema de alerta contra enchentes.

As 6 sub-bacias urbanas de estudo, se localizam na parte a montante da bacia do Rio Monjolinho, afluente do rio Jacaré-Guaçú (Figura 4.1):

1. Santa Maria Madalena

2. Mineirinho

3. Tijuco Preto

4. Gregório

5. Medeiros

6. Água Quente

As sub-bacias foram escolhidas por estarem localizadas na área urbana e em função da disponibilidade de dados hidrológicos. A Tabela 4.1 a seguir resume as características das sub-bacias. 


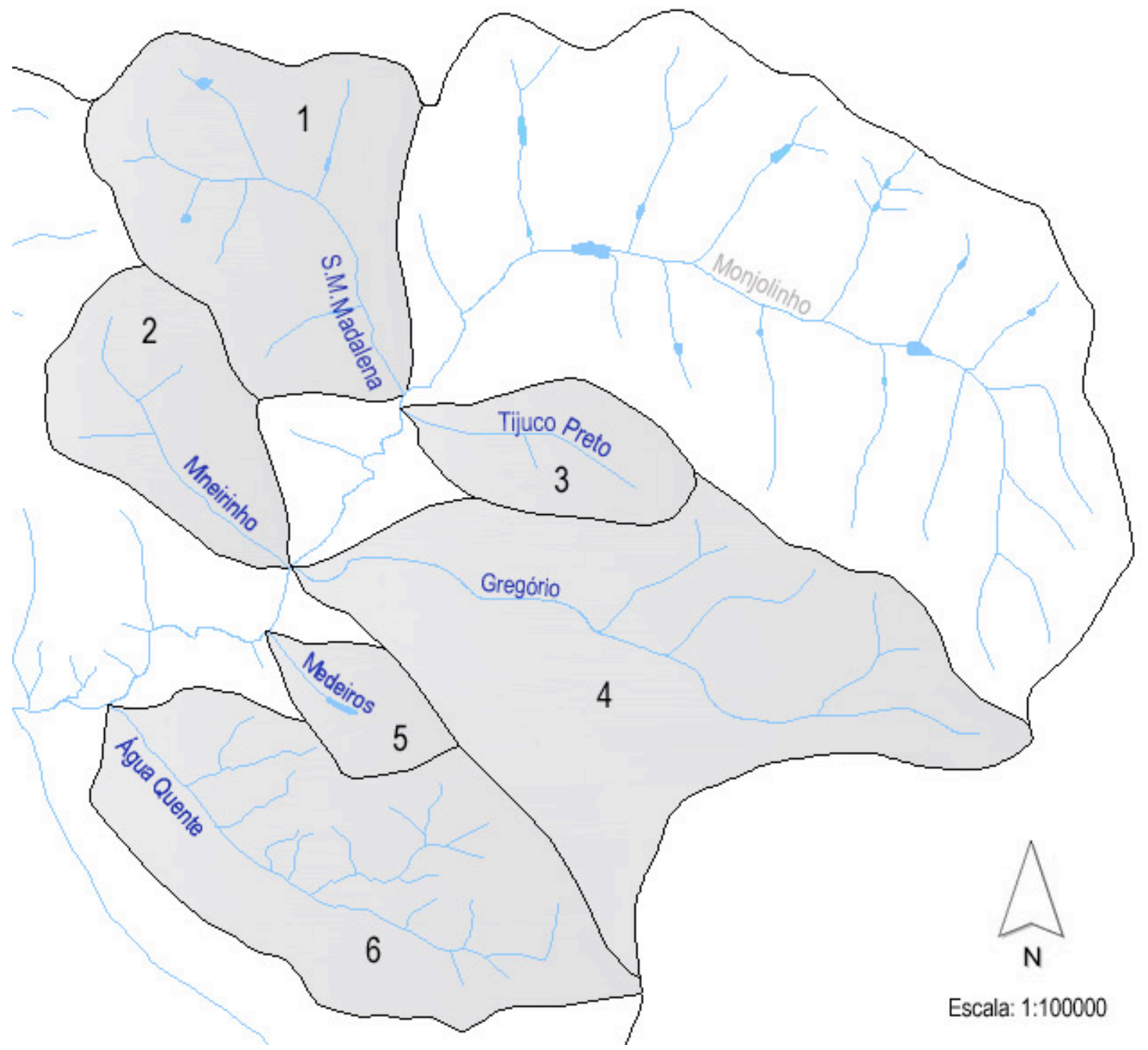

Figura 4.1 - Imagem das sub-bacias hidrográficas selecionadas na área urbana de São Carlos: 1) Santa Maria Madalena; 2) Mineirinho; 3) Tijuco Preto; 4) Gregório; 5) Medeiros; 6) Água Quente.

Tabela 4.1 - Características de 6 sub-bacias urbanas do município de São Carlos objeto de estudo. *Fonte: Esteves 2003

\begin{tabular}{lcccccc}
\hline \multicolumn{1}{c}{ Bacia } & $\begin{array}{c}\text { Área } \\
\left(\mathrm{km}^{2}\right)\end{array}$ & $\begin{array}{c}\text { Comprimento } \\
\text { Axial* } \\
(\mathrm{km})\end{array}$ & $\begin{array}{c}\mathrm{CN} \\
\mathrm{SCS} \\
(\mathrm{adm})\end{array}$ & $\begin{array}{c}\mathrm{t}_{\text {conc }} \\
\text { SCS-Lag } \\
(\mathrm{min})\end{array}$ & $\begin{array}{c}\text { Densidade } \\
\text { populacional } \\
(\text { hab/ha })\end{array}$ & $\begin{array}{c}\text { População } \\
(\mathrm{hab})\end{array}$ \\
\hline Santa M. Madalena & 10,88 & 5,38 & 76,1 & 303,3 & 7,8 & 8478 \\
\hline Mineirinho & 5,38 & 4,28 & 84,5 & 155,5 & 29,3 & 15728 \\
\hline Tijuco Preto & 3,52 & 3,54 & 89,3 & 91,4 & 54,7 & 19217 \\
\hline Gregório & 19,01 & 8,99 & 83 & 318,2 & 23,6 & 44826 \\
\hline Medeiros & 1,99 & 2,359 & 91,8 & 53,5 & 74,7 & 14835 \\
\hline Água Quente & 13,32 & 7,560 & 83,2 & 234,9 & 24,3 & 32346 \\
\hline
\end{tabular}




\subsection{Portal web-GIS}

A estrutura do portal web-GIS foi inspirada nos mash ups ${ }^{12}$ de Google Maps com dados inseridos pelos usuários. Há exemplos na internet de portais Google Maps que transmitem informações em tempo real, por exemplo de meteorologia; ou anteriormente coletadas, como áreas de risco sísmico ou regiões atingidas por desastres naturais. Dentre eles pode-se citar:

$$
\begin{aligned}
& \text { http://www.tornadohistoryproject.com/tornadomap.php } \\
& \text { http://www.weatherbonk.com/ } \\
& \text { http://geology.com/san-andreas-fault/ } \\
& \text { http://www.mananciais.org.br/expedicao/ }
\end{aligned}
$$

O portal web tem o objetivo de funcionar como ponto de encontro aberto, onde todos os usuários têm os mesmos privilégios quanto ao acesso aos dados e ao fornecimento destes. O usuário precisa sentir que a sua contribuição é importante para si e para a coletividade e que a sua participação será audível e visível aos outros. A potencialidade resulta em conseguir notícias pela web em curto prazo de maneira automatizada.

A idéia foi criar uma interface que permite a avaliação de alguns parâmetros ambientais pelo usuário, o qual pode assim contribuir em traçar o perfil da área de interesse, resultando em um zoneamento que não é quantitativo, mas percebido.

A metodologia de referência para a criação do portal com base nos objetivos, nas funcionalidades (features) e na interface usuário seguiu a proposta de Garret (2000) em "The Elements of User Experience", com ênfase na experiência de navegação do usuário. Quanto ao projeto de web mapping com ênfase na facilidade de uso do design, adotaram-se as guias propostas em “Trends in Web Mapping: It's all about usability” por Vlugt e Stanley (2005).

\footnotetext{
${ }^{12}$ Com o termo mash up entende-se um site ou uma aplicação web que combina conteúdo de mais de uma fonte numa experiência integrada.
} 


\subsubsection{Criação do portal}

Após a assinatura de um domínio web com o seguinte endereço: http://www.floodrisk.w1host.com/ foi solicitada à Google uma chave Google Maps API para usufruir do serviço de mapeamento dinâmico dentro do site. Uma vez obtida a chave foi possível inseri-la no início da página e começar a criar sobre o mapa o mecanismo de inserção de dados localizados. No mapa, objeto principal da página inicial, foi criada uma legenda com graus de avaliação baseado em cores e um menu contextual que permite ao usuário visualizar as entradas por cada uma das três categorias de risco e para o risco total.

Em seguida inseriu-se o mecanismo que permite, através de click com o mouse em um ponto do mapa, a abertura de uma janela na qual o usuário encontra as perguntas sobre o risco e a respectiva escala de avaliação com 5 graus de percepção de risco. Após a escolha do grau de risco em resposta a cada pergunta, tem-se a opção "salvar" para que a avaliação seja armazenada no banco de dados e disponibilizada no site.

Tal mecanismo foi possível por meio de instruções escritas em linguagem JavaScript (Anexo 1) que se integra à interface do mapa dinâmico Google Maps. Além da linguagem, foi necessário carregar bibliotecas AJAX no domínio para assegurar um funcionamento ágil, em coerência com o mapa dinâmico ao qual as instruções se superpõem.

Posteriormente criou-se um banco de dados online. O domínio em que encontra-se hospedado o site oferece o serviço de banco de dados MySQL, o qual foi utilizado para armazenar os dados coletados.

Foram criados três campos diferentes relativos às três perguntas a serem preenchidas na janela de avaliação. No anexo 2 é possível visualizar os campos e as características designadas. Os dados armazenados segundo o esquema, além de serem visíveis no portal, são também disponíveis para serem baixados do servidor online em vários formatos, entre eles “.csv", "access", o que torna possível elaborar os dados numa ferramenta distinta como um 
SIG desktop. Analogamente, dados coletados de forma off-line, por exemplo por meio de entrevistas efetuadas nas ruas, como no caso desta pesquisa, podem ser carregados como descrito no item 4.2.2.2, para disponibilização no mapa online.

Na visualização de default do portal, aparece o mapa dinâmico centrado na cidade de São Carlos. Para mostrar as sub-bacias da cidade de maneira mais clara optou-se para inserção destas em formato ".kml” diretamente superposta ao mapa Google Maps. Os arquivos ".kml” foram criados operando no Google Earth, dentro do qual foi utilizado, juntamente à base de mapas oferecida pelo software, um mapa das sub-bacias urbanas que foi obtido valendo-se de mapas retirados do material de suporte para elaboração do plano diretor de São Carlos (2002), confeccionados com software AutoCAD ${ }^{\circledR}$. Uma vez armazenados os polígonos georreferenciados, estes foram carregados no domínio e disponibilizados no portal. O resultado é mostrado em figura 5.2.

\subsubsection{Entrevista sobre risco de inundação aos habitantes}

Com o intuito de recolher informações de risco percebido pelos habitantes foi criado um roteiro de entrevistas com questões fechadas para o web-GIS. A entrevista (Figura 4.3) foi aplicada em ruas e praças do centro de São Carlos, já que o site encontrava-se em fase de preparação. Deste modo, as respostas ao questionário foram disponibilizadas no site após sua finalização. Na Figura 4.2 são mostradas em seqüência as fases realizadas a partir do armazenamento dos dados das entrevistas até a disponibilização destes online no web-GIS. Encontraram-se com auxilio do Google Earth as coordenadas dos entrevistados segundo o endereço fornecido por eles, inseriram-se no banco de dados off-line criado ad hoc as respostas e as outras informações obtidas (sexo, faixa etária). Sucessivamente exportou-se um arquivo do banco de dados em formato ".csv" que foi importado online pelo banco de dados MySQL relacionado ao domínio do web-GIS. 


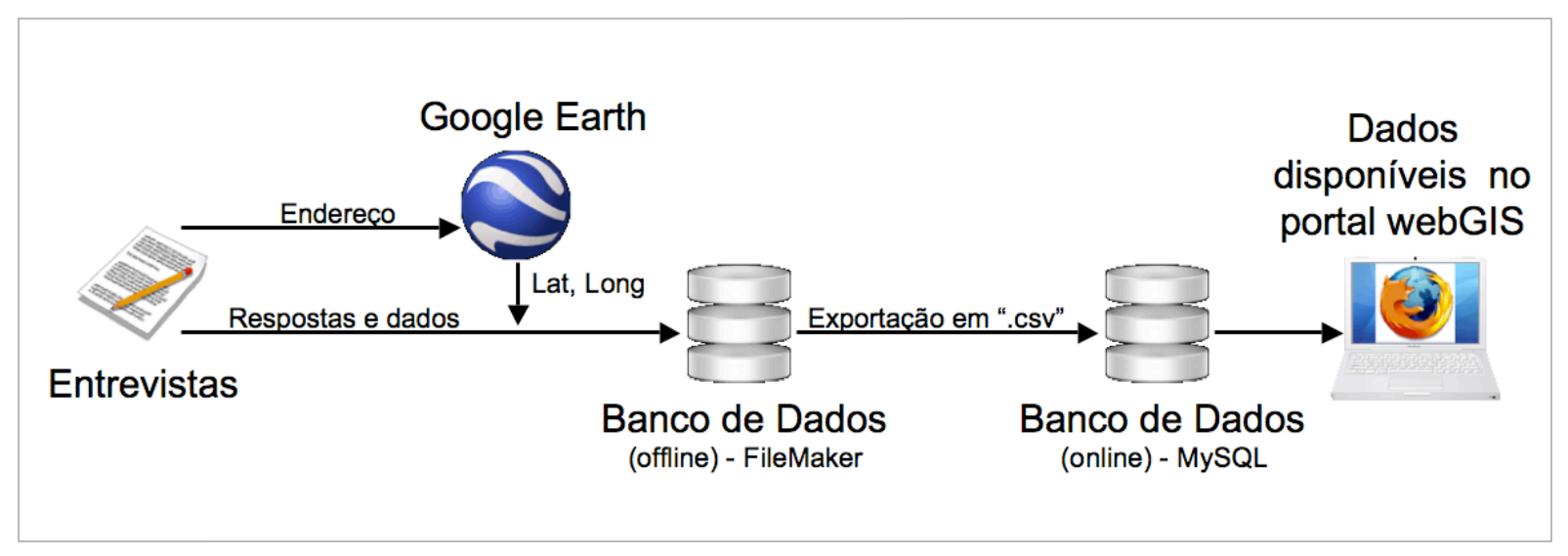

Figura 4.2 - Seqüência de passos seguidos para armazenar os dados obtidos das entrevistas para sucessivamente disponibiliza-los online.

As entrevistas foram efetuadas durante quatro saídas a campo em áreas do centro da cidade (Estação Rodoviária, Mercado Municipal e Avenida São Carlos) nos meses de dezembro 2007 e janeiro 2008.

As perguntas foram formuladas em função do triângulo do risco visando a avaliação de ameaça, exposição e vulnerabilidade, tentando manter um fácil entendimento para os entrevistados, em sua maioria, leigos. A formulação das perguntas teve como base o questionário (flood survey) aplicado pelo Governo Escocês e proposto por Werritty et al. (2007) no relatório "Exploring the social impacts of flood risk and flooding in Scotland". Trata-se de um questionário muito articulado e extenso, mas que trata de maneira aprofundada a percepção do risco por parte dos habitantes, fato tratado com pouca freqüência pelas administrações públicas e pelos tomadores de decisão. 


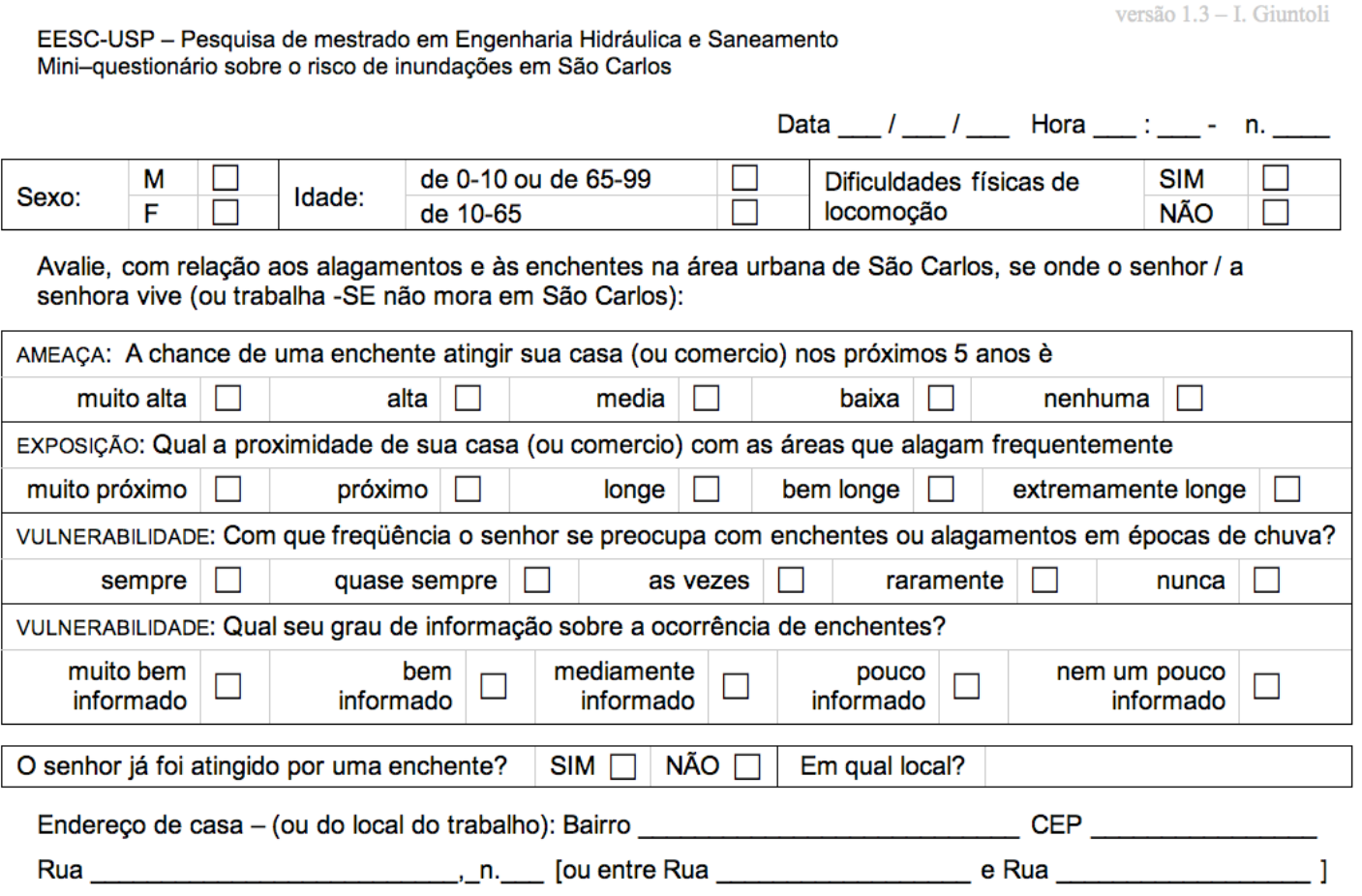

Figura 4.3 - Roteiro de questões fechadas sobre risco de inundações em São Carlos proposto aos habitantes.

A entrevista consistiu de 4 perguntas sobre os componentes do risco. Para estas usaram-se cinco categorias de resposta sendo os dois extremos: 1 - sempre ou muito e 5 nunca ou nenhum. Perguntou-se também se o entrevistado tinha sido ou não atingido por enchente e em qual local e, se podia indicar o endereço de casa ou comércio referente às suas respostas. Além disso, anotaram-se variáveis sócio-demográficas como o sexo e a faixa etária. A idade foi dividida em duas faixas: vulnerável, considerada de 0 a 10 anos e acima de 65; e não vulnerável para indivíduos com idade entre 10 e 65 anos. A escolha da divisão de vulnerabilidade foi realizada em virtude da fórmula do risco (equação 4.1) que foi sucessivamente aplicada para avaliação deste por sub-bacia. 


\subsubsection{Participantes}

As entrevistas foram feitas a cidadãos encontrados nas ruas do centro de São Carlos (SP). Não teve nenhuma seleção dos participantes, no entanto como requisito para responder às perguntas, o entrevistado deveria morar ou trabalhar na área urbana da cidade.

O método de amostragem adotado foi de amostragem conveniente (convenience sampling) pelo qual os elementos da população a ser representada não são selecionados de maneira aleatória e independente e portanto não se obtém os atributos de eqüiprobabilidade e de independência de uma amostra aleatória simples (AAS). Contudo este método, mais rápido e econômico da AAS, pressupõe que a amostragem se aproxima bem a uma amostra aleatória (Devore, 2004), por isso é usado nas fases preliminares de experimentação nas quais o pesquisador está interessado em obter uma aproximação da realidade, sem gastar esforços ou sem incorrer no custo ou no tempo requeridos para selecionar uma amostra aleatória.

Após o preenchimento das fichas em campo, as respostas foram inseridas numa base de dados criada ad hoc no software FileMaker Pro ${ }^{\circledR}$. Paralelamente os endereços dos entrevistados foram localizados no Google Earth $^{\circledR}$, para associar a cada ficha coordenadas de Latitude e Longitude.

\subsubsection{Transferência dos dados do banco de dados ao portal web-GIS}

Uma vez inseridos os dados das entrevistas na base de dados - que continha também as coordenadas geográficas (Lat-Long) dos entrevistados obtidas pelo Google Earth $^{\circledR}$ - foi necessário transferir as informações para o portal. $\mathrm{O}$ gerenciador do portal, por meio de interface de acesso ao MySQL ${ }^{\circledR}$, permite importar dados em formato “.csv". Foi, portanto exportado do arquivo Filemaker ${ }^{\circledR}$ (normalmente com extensão “.fp7”) - contendo o resultado dos questionários - para excel, e deste para “.csv". Finalmente efetuou-se a importação dos dados em “.csv” para o MySQL ${ }^{\circledR}$ disponibilizando deste modo, os dados no portal online. 


\subsection{Estimativa do risco de inundação}

Foi estimada para cada sub-bacia urbana considerada na área de estudo a seguinte fórmula do risco, adaptada da equação 3.1 descrita anteriormente.

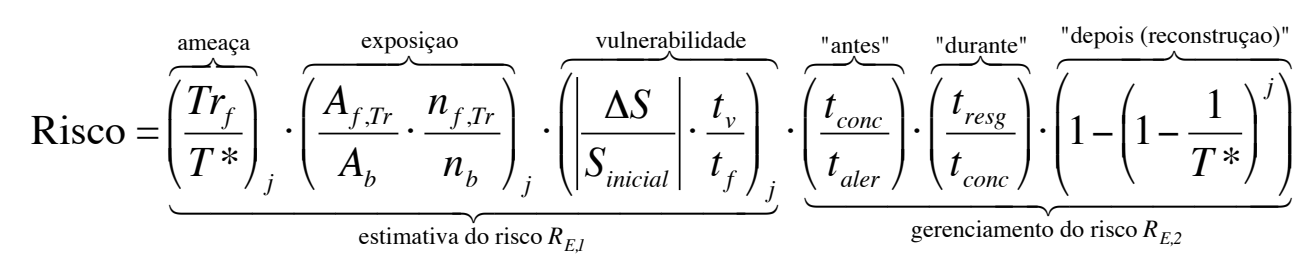

De acordo com o exemplo de Mendiondo (2008) propuseram-se estimativas de risco segundo dois cenários: reativo - segundo o qual o governo da cidade e os tomadores de decisão tomam providências contra fenômenos de risco em favor dos habitantes, uma vez que o evento ocorre - e pró-ativo - no qual são implantadas políticas de prevenção e gestão de risco antes que um evento crítico se manifeste.

\subsubsection{Componentes da expressão do Risco}

\subsubsection{Termo "Ameaça"}

A ameaça é dada por um valor de freqüência de ocorrência da inundação e é expressa pela razão de tempos de retorno de projeto e de inundação (nível de cheia).

$$
\left(\frac{\operatorname{Tr}_{f}}{T^{*}}\right)_{j}
$$

Considerou-se um tempo de retorno de projeto $\left(T^{*}\right)$ para a infra-estrutura do canal fixo com valor de 20 anos, valor recomendado pelo DAEE/CETESB (1980) apud Batista et al. (2005) e por Mays (2001) apud Tomaz (2002).

Para o tempo de retorno $\left(\operatorname{Tr}_{f}\right)$ foi estimado - para cada incremento $j$ - um valor aleatório com distribuição uniforme (entre 0 e 1) para conferir a natureza casual das 
ocorrências ao longo dos 50 anos do cenário. Os valores assumidos foram mantidos iguais para os cenários de todas as sub-bacias.

\subsubsection{Termo "Exposição"}

Este termo quantifica a exposição das pessoas e construções à ameaça de um evento. Chega-se nesta expressão pelas razões entre as áreas - sujeita a inundação e total da bacia - e o número de habitantes - que ocupam áreas sujeitas a inundação e o número total.

$$
\left(\frac{A_{f, T r}}{A_{b}} \cdot \frac{n_{f, T r}}{n_{b}}\right)_{j}
$$

Em relação à porção da área inundável das bacias, calculou-se a área total $\left(A_{b}\right)$ utilizando mapas do plano diretor de São Carlos (2002) confeccionados com software AutoCAD $^{\circledR}$. Estes valores foram conferidos com outros computados no Google Earth ${ }^{\circledR}$ por meio de arquivos polígono “.kml” (visíveis no site floodrisk). Para o cálculo da área inundável $\left(A_{f, T r}\right)$ foi adotado o produto de $1 / 3$ do comprimento do talvegue pela largura de 40 metros. Tal hipótese foi realizada considerando-se que a área inundável encontra-se geralmente na parte a jusante da bacia (no caso o último 1/3 de talvegue até o exutório). Além disso, a natureza das sub-bacias analisadas é urbana, freqüentemente caracterizada pela presença de rodovias marginais aos lados dos canais ou cursos de água, por isso optou-se por utilizar uma largura de 40 metros, valor equivalente à largura da estrada.

O número de habitantes das bacias $\left(n_{b}\right)$ foi calculado a partir de mapas de densidade demográfica parte do mesmo material de suporte para elaboração do plano diretor de São Carlos (2002) considerado no item 4.2.1. A densidade demográfica teve por base o censo demográfico IBGE (2000) e consistiu de 3 classes: 0-50, 50-100, 100-200 hab/ha.

Consideraram-se para estimativa do número de habitantes da área urbana os valores de densidade demográfica médios: $25,75,150$ hab/ha. No caso de bacias que compreendem área 
rural (Gregório, Santa Maria Madalena, Mineirinho, Água Quente) adotou-se para esta a densidade de 0,4 hab/ha.

Analogamente, o número de habitantes em áreas inundáveis $\left(n_{f, T r}\right)$ foi calculado utilizando as mesmas bases cartográficas com densidade demográfica relativas as áreas $A_{f, T r}$ descrita acima.

\subsubsection{Termo "Vulnerabilidade"}

A vulnerabilidade exprime a propensão a sofrer dano por inundação. Neste caso a expressão considera o lado físico da vulnerabilidade - com a evolução do armazenamento potencial de água no solo - e social por meio da razão entre tempo ocorrido para se deslocar, por parte de cidadãos com bons níveis de saúde e outros mais vulneráveis como idosos ou portadores de deficiência, em caso de inundação.

$$
\left(\left|\frac{\Delta S}{S_{\text {inicial }}}\right| \cdot \frac{t_{v}}{t_{f}}\right)_{j}
$$

O parâmetro $S$ exprime o armazenamento potencial de água no solo. Ele está diretamente relacionado com o potencial de escoamento, expresso em hidrologia pelo parâmetro $\mathrm{CN}$ (Curva Numero). A densidade populacional, que exprime uma medida de urbanização, pode ser usada para descrever o potencial de escoamento $(\mathrm{CN})$, o qual por sua vez é utilizado para o cálculo do armazenamento potencial. O valor de $\mathrm{CN}$ considerado para cada sub-bacia foi associado à densidade populacional (hab/ha), crescente ao longo dos anos, deste modo foi possível calcular o armazenamento potencial de água no solo por meio da fórmula SCS Lag - 1975 (Tucci et al., 1995):

$$
S=\frac{25400}{C N-254}
$$

Adotou-se para o armazenamento inicial de água no solo, considerando as condições de pré-urbanização $\left(S_{\text {inicial }}\right)$, o valor de $208 \mathrm{~mm}$, resultante de um valor de $\mathrm{CN}$ igual a 55 
associado a uma densidade populacional de $55 \mathrm{hab} / \mathrm{km}^{2}$. Para o cálculo de $S_{j}$ utilizou-se uma equação obtida pela regressão dos pontos descritos por CN (igual a 55 no passado e, na maioria dos casos, igual a 80-90 no presente) e pela densidade populacional. A diferença de armazenamento de água no solo $(\Delta S)$ atual e anteriormente à urbanização, calculada a cada incremento $j$-simo, resultou da subtração do valor fixo $S_{\text {inicial }}$.

A relação entre tempos de vulnerabilidade para pessoas vulneráveis como, por exemplo, crianças, idosos ou deficientes físicos e as não vulneráveis, foi obtida a partir dos dados das entrevistas efetuadas para o web-GIS. Adotou-se como hipótese de trabalho a mesma relação para todas as sub-bacias de estudo e o cálculo foi feito da maneira descrita a seguir.

Em relação às perguntas sobre vulnerabilidade (perguntas 4 e 5) as respostas dos entrevistados - variando numa escala de um (menos vulnerável) a cinco (mais vulnerável) foram subdivididas em duas classes: vulnerabilidade alta (com resposta entre 4 e 5 na escala) e vulnerabilidade baixa (com resposta entre 1, 2 e 3). Desta maneira, calculou-se um coeficiente $c_{v}$ para as duas classes:

$$
c_{v}=\left(\frac{\sum_{i=1}^{j} \text { respostas }_{j}}{\sum_{i=1}^{n} \text { respostas }_{n}-\sum_{i=1}^{j} \text { respostas }_{j}}\right)
$$

com $\mathrm{j}=1,2,3$ para a vulnerabilidade médio-baixa" e $\mathrm{j}=4,5$ para a vulnerabilidade alta.

Com base no cálculo desses coeficientes obtiveram-se dois valores para cada classe, cuja média foi inserida nos termos da equação $t_{v}-$ termo de vulnerabilidade alta - e $t_{f}-$ termo de vulnerabilidade médio-baixa.

Para o cenário reativo a relação $t_{v} / t_{f}$ foi incrementada com taxa de $1,5 \%$ o ano ao longo dos 50 anos, ao passo que no cenário pró-ativo a relação decresceu exponencialmente 
com expoente igual a 0,995 . Na Tabela 4.2 é possível observar a evolução da relação por tipo de cenário.

\subsubsection{Termo "Antes"}

Quanto as etapas de gerenciamento do risco, no que diz respeito à fase antecedente à ocorrência, considera-se a razão do tempo de concentração do curso de água com o tempo de alerta à população.

$$
\left(\frac{t_{\text {conc }}}{t_{\text {aler }}}\right)
$$

O tempo de concentração $t_{\text {conc }}$ foi calculado com a fórmula SCS "Lag" - 1975 (Tucci et al., 1995). Em virtude do $t_{c o n c}$ ser inversamente proporcional ao parâmetro $\mathrm{CN}$ - que varia com $\mathrm{S}$ e com a densidade habitacional que cresce ao longo dos 50 anos - um aumento deste último corresponde a uma diminuição do tempo de concentração.

O tempo de alerta $t_{\text {aler }}$, foi fixado em 10 minutos, para indicar o tempo reduzido de alerta atual que permanece constante para o cenário reativo, ao passo que, no cenário próativo, partindo do mesmo valor chegou-se, para o ano 50, a um valor igual a 50 minutos seguindo uma equação logarítmica de segunda ordem. $\mathrm{O}$ aumento do tempo de alerta no cenário pró-ativo tem como base hipóteses como o aumento da tecnologia com o tempo e a implementação de políticas ambientais que incentivem a diminuição do risco de inundação.

\subsubsection{Termo "Durante"}

A segunda etapa do gerenciamento do risco refere-se ao momento em que o evento ocorre, considerando-se neste caso, além do tempo de concentração do curso de água como no tempo "antes", o tempo de resgate à população atingida.

$$
\left(\frac{t_{\text {resg }}}{t_{\text {conc }}}\right)
$$




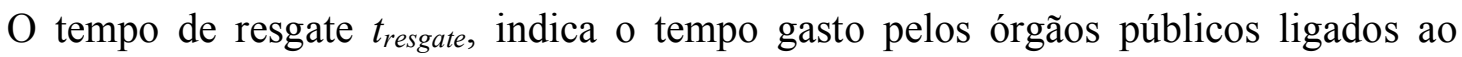
resgate da população para chegar ao local atingido. Para cada sub-bacia tal tempo foi calculado por meio do serviço online GoogleMaps ${ }^{\circledR}$, traçando o percurso entre o ponto correspondente ao exutório da sub-bacia considerada e aquele mais próximo entre a sede do Corpo de Bombeiros - São Carlos, bairro Vila Brasília, Rua Equador, 200 - e a sede da Defesa Civil - São Carlos, bairro Jardim Ricetti, Rua Totó Leite, 100. O serviço Google Maps $^{\circledR}$ fornece para o percurso urbano, além da distância percorrida por carro, o tempo gasto - com velocidade média de $25 \mathrm{~km} / \mathrm{h}$. Além do tempo gasto para se percorrer o caminho, foi somado um tempo fixo adotado igual a 12 minutos para o cenário reativo e 6 minutos para o pró-ativo, tempo este que transcorre entre atender o pedido de resgate e a saída da equipe de resgate.

\subsubsection{Termo "Depois"}

O último componente de gerenciamento exprime o risco após a ocorrência, é constituído pela equação que relaciona o risco hidrológico ao tempo de retorno, e segundo a qual os prejuízos causados por uma falha de funcionamento da estrutura diminuem com o aumento do tempo de retorno $\left(T^{*}\right)$ adotado em projeto (Baptista et al., 2005).

$$
\left(1-\left(1-\frac{1}{T^{*}}\right)^{j}\right)
$$

A modificação realizada na expressão proposta por Mendiondo (2008) compreende a substituição do expoente " $N-j$ ” pela expressão “ $j$ ” a fim de garantir o aumento do valor da expressão ao longo dos anos. Para os dois cenários (pró-ativo e reativo) os valores da expressão permanecem os mesmos. 


\subsubsection{Componentes da expressão do risco}

$\mathrm{Na}$ Tabela 4.2 são mostradas as tendências dos componentes da fórmula que influenciam diretamente o resultado completo da estimativa. Como esperado o cenário próativo apresenta aumentos pouco acentuados dos componentes ao longo do tempo, em alguns casos encontra-se um comportamento estacional ou também um decréscimo, situação que não ocorre para o cenário reativo.

Tabela 4.2 - Tendências de cada componente da fórmula do risco ao longo do prazo considerado de 50 anos para os cenários reativo e pró-ativo.

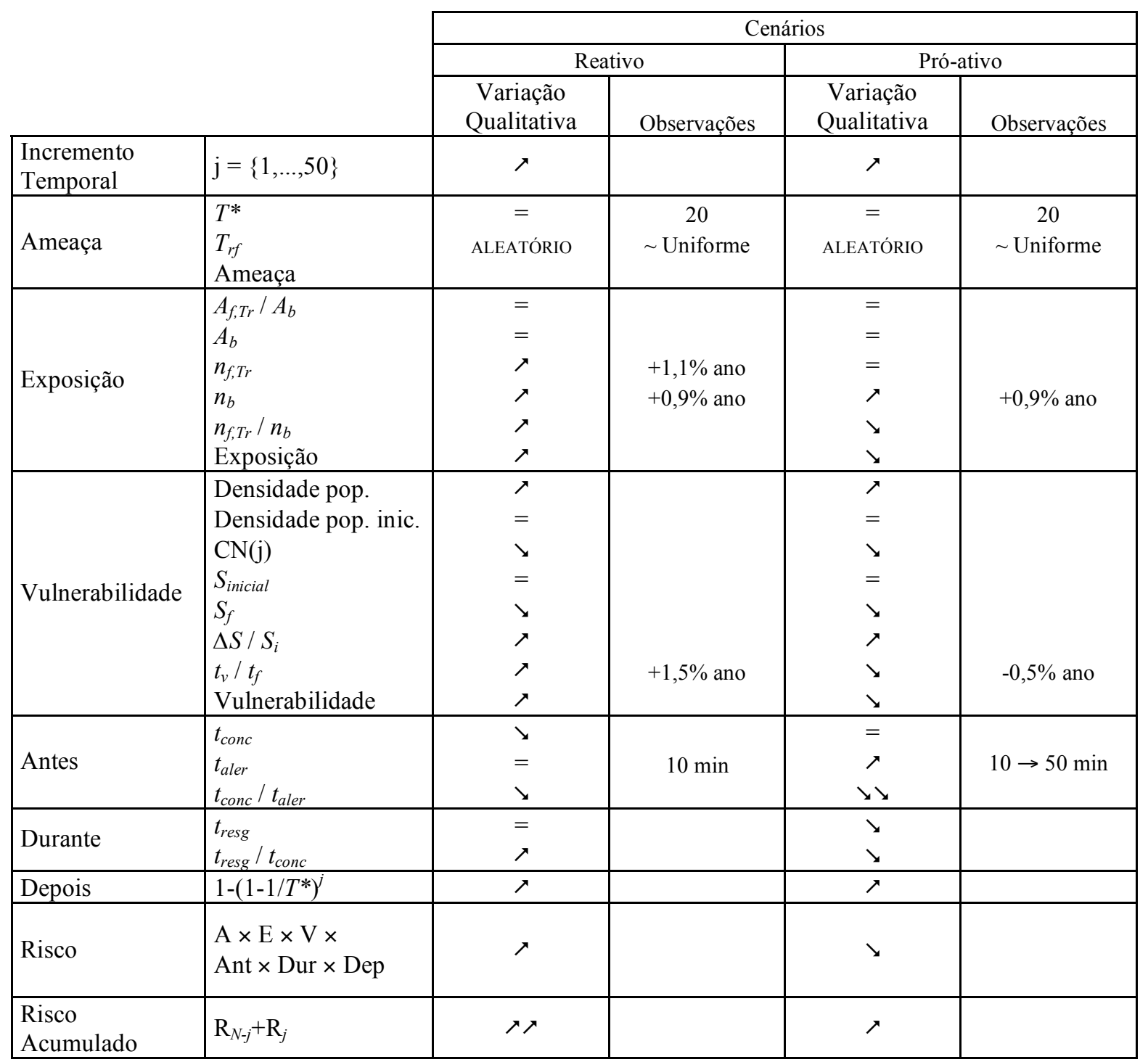


Simbologia utilizada em tabela: $\boldsymbol{\lambda}$ indica um crescimento do termo, $\boldsymbol{\nearrow} \boldsymbol{\lambda}$ indica um crescimento mais acentuado, $=$ indica que os valores permanecem iguais ou estáveis ao longo do tempo, $\searrow$ indica uma diminuição do termo, \〉 indica uma diminuição mais acentuada. 


\section{RESULTADOS}

\subsection{Portal web-GIS}

O portal web-GIS acessível ao endereço http://www.floodrisk.w1host.com é apresentado em Figura 5.1.
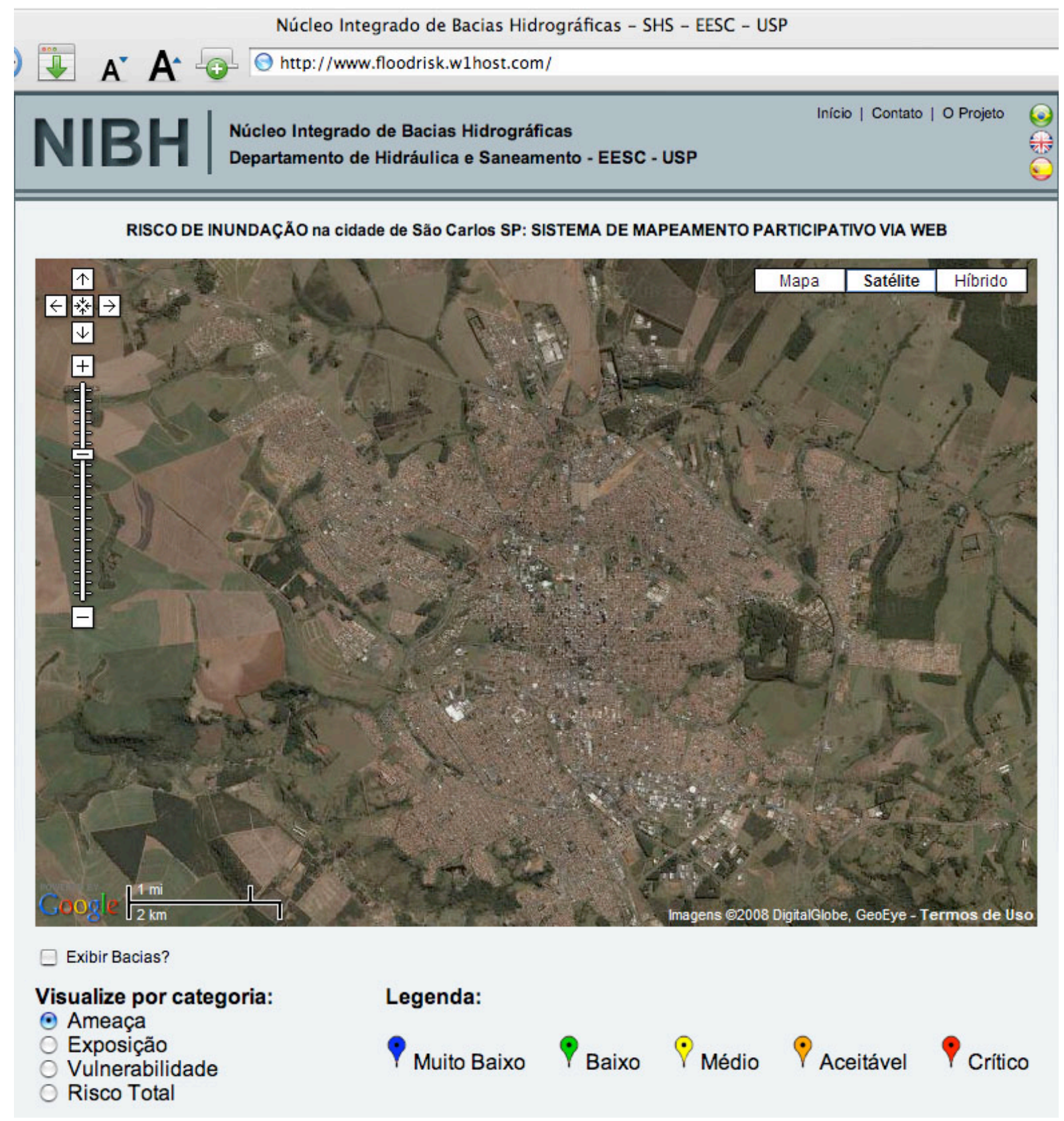

Figura 5.1 - Tela de apresentação da homepage do portal web-GIS. 
O botão "Exibir Bacias" na base do mapa permite a visualização das sub-bacias urbanas no formato “.kml” (Figura 5.2).



$\square$ Exibir Bacias?

Figura 5.2 - Visualização das sub-bacias carregadas pelo mapa dinâmico em formato “.kml”.

Ao clicar no ponto do mapa correspondente ao endereço do usuário, apresenta-se uma janela (Figura 5.3) contendo perguntas que avaliam a situação do risco à qual o usuário está sujeito. Obtida esta informação pelo usuário, a qual é disposta na homepage por um ícone em forma de balão, indica-se o nível de risco em função de três categorias: ameaça, exposição e vulnerabilidade. 


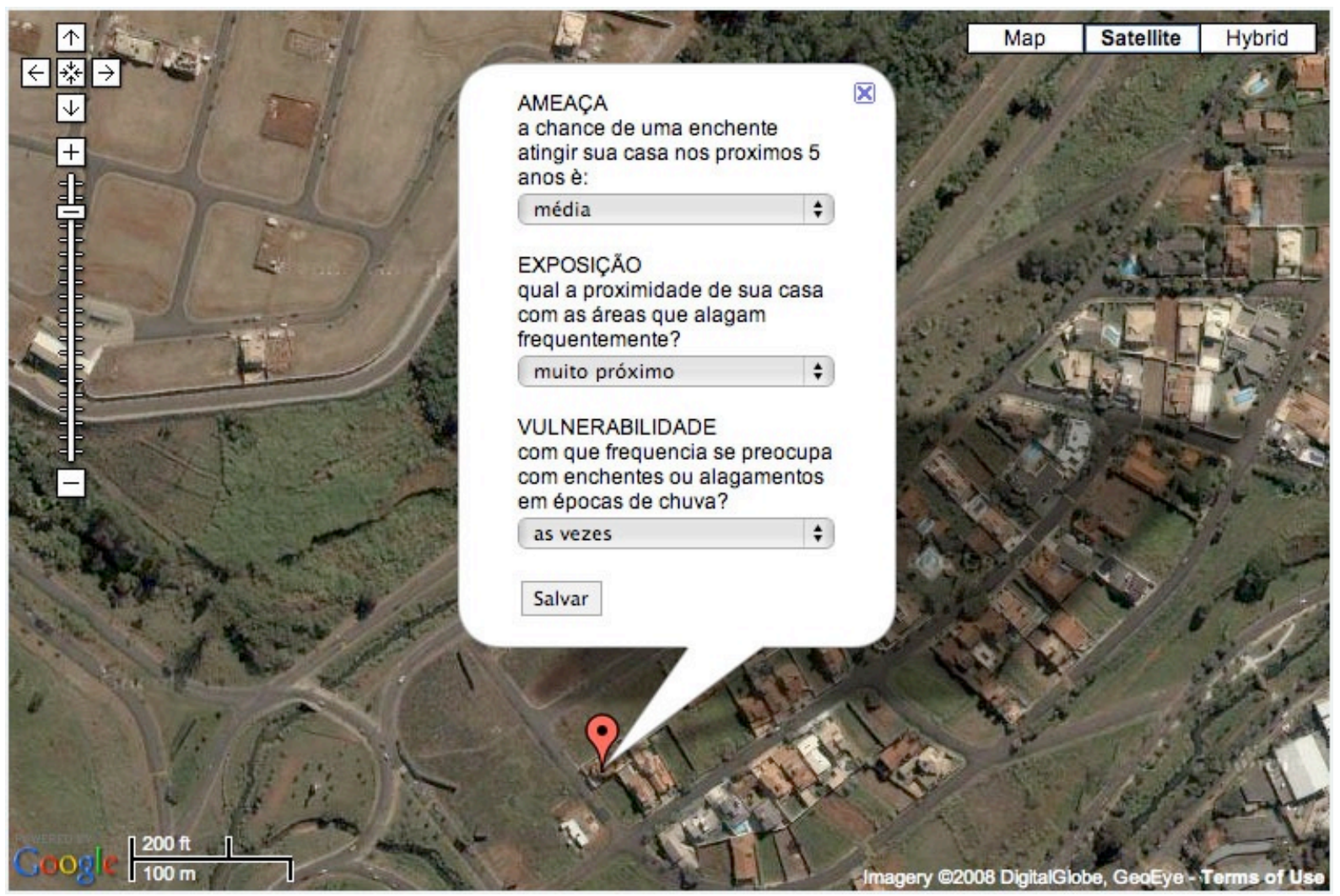

Figura 5.3 - Janela que aparece clicando em um ponto do mapa para avaliar o risco.

O procedimento descrito anteriormente está disponível para os usuários que visitam o site online. Os pontos atualmente visíveis resultam da inserção de dados obtidos de entrevistas a 163 usuários, cujo roteiro foi apresentado no item 4.2.2. 


\subsection{Entrevistas aos habitantes}

Dezembro e janeiro são os meses com maiores índices pluviométricos e há um número maior de ocorrências de enchentes e inundações na cidade de São Carlos. Deste modo, as entrevistas foram efetuadas durante os meses de dezembro 2007 e janeiro 2008 em quatro saídas a campo em áreas do centro da cidade (Tabela 5.1).

Tabela 5.1 - Número de entrevistas efetuadas por data e respectivos locais.

\begin{tabular}{ccccc}
\hline \multirow{2}{*}{ Data } & \multicolumn{3}{c}{2007} & \multicolumn{3}{c}{2008} \\
\cline { 2 - 5 } & $15 \mathrm{DEZ}$ & $22 \mathrm{DEZ}$ & $20 \mathrm{JAN}$ & 25 JAN \\
\hline $\mathrm{N}$ & 32 & 59 & 32 & 40 \\
\hline \multirow{2}{*}{ Local } & $\begin{array}{c}\text { Mercado } / \\
\text { Centro }\end{array}$ & $\begin{array}{c}\text { Praça 15/ } \\
\text { Av. São Carlos }\end{array}$ & Rodoviária & Rodoviária \\
\hline
\end{tabular}

Foram entrevistados 163 habitantes, dos quais 128 residem na área de estudo (Anexo 4), desta forma apenas as respostas destes foram utilizadas para a avaliação do risco percebido.

Os participantes responderam às seguintes perguntas (Figura 4.3):

1. A chance de uma enchente atingir a sua casa (ou comércio) nos próximos cinco anos? As alternativas: 1. muito alta; 2. alta; 3. media, 4. baixa; e 5. nenhuma.

2. Qual a proximidade de sua casa (ou comércio) com as áreas que alagam freqüentemente? As alternativas: 1. muito próximo; 2. próximo; 3. longe; 4. bem longe; e 5. extremamente longe.

3. Com que freqüência o senhor se preocupa com enchentes ou alagamentos em épocas de chuva? As alternativas: 1. sempre; 2. quase sempre; 3. as vezes; 4. raramente; e 5. nunca.

4. Qual seu grau de informação sobre a ocorrência de enchentes? As alternativas: 1 . muito bem informado; 2 . bem informado; 3 mediamente informado; 4 . pouco informado; e 5. nem um pouco informado. 
A Tabela 5.2 apresenta as estatísticas relativas à amostra. Os resultados divididos por bacia são mostrados na Tabela 5.3.

Tabela 5.2 - Estatísticas da amostra de entrevistados.

\begin{tabular}{lcc}
\hline \multicolumn{1}{c}{$\mathrm{N}$} & \multicolumn{2}{c}{ Amostra } \\
\hline Idade & \multicolumn{2}{c}{163} \\
$\quad$ Vulnerável [ $>65$ ] & 15 & $9,2 \%$ \\
$\quad$ Não vulnerável & 148 & $90,8 \%$ \\
\hline Gênero & & \\
$\quad$ Masculino & 72 & $44,2 \%$ \\
$\quad$ Feminino & 91 & $55,8 \%$ \\
\hline Atingidos por enchente & 32 & $19,6 \%$ \\
\hline
\end{tabular}

Salienta-se que o roteiro de perguntas foi elaborado apenas para aplicação neste trabalho sem aplicação de um roteiro piloto. Portanto, não houve reformulação das perguntas apesar de ter-se constatado que algumas perguntas e alternativas de respostas não estavam bem colocadas.

$\mathrm{Na}$ pergunta sobre exposição (n.2) duas das respostas estavam incoerentes, pois as opções passam de "próximo" a "longe" quando se questiona sobre a proximidade com as áreas suscetíveis aos alagamentos.

Quanto à primeira pergunta sobre vulnerabilidade (n.3), a maioria das respostas foi "sempre" e "quase sempre", demonstrando o caráter tendencioso da pergunta. Os questionados não se preocuparam apenas com o próprio domicílio ou lugar de trabalho, mas também com familiares, conhecidos e com a cidade de maneira geral. Desta forma, as avaliações de vulnerabilidade não estavam necessariamente relacionadas à localização geográfica do entrevistado.

De maneira semelhante, a pergunta n.4 pode ser questionada na avaliação da vulnerabilidade, pois notou-se que os entrevistados a interpretavam de maneira errônea, associando o grau de informação sobre enchentes apenas após o evento e não antes da 
ocorrência deste. Portanto, pode-se inferir que as respostas obtidas não estão totalmente de acordo com o objetivo da pergunta. 
Tabela 5.3 - Estatísticas das respostas às perguntas do questionário por sub-bacia.

\begin{tabular}{|c|c|c|c|c|c|c|c|c|}
\hline \multirow{3}{*}{ 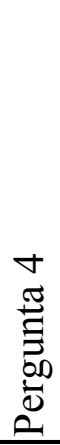 } & \multirow{3}{*}{ 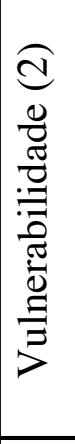 } & $\mid \stackrel{D}{=}$ & $\hat{i}$ & $\stackrel{d}{i}$ & $\tilde{n}$ & ñ & $\stackrel{b}{i}$ & $\stackrel{\nabla}{i}$ \\
\hline & & 8 & 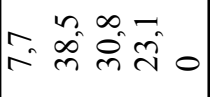 & 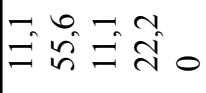 & 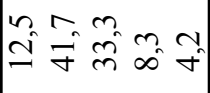 & 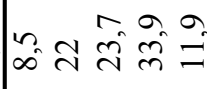 & 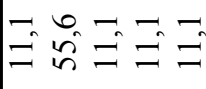 & 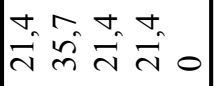 \\
\hline & & \begin{tabular}{|c|} 
\\
0 \\
0 \\
0 \\
$\#$
\end{tabular} & $-n+m o$ & $-n-N o$ & $n \bigcirc \infty N-$ & $n= \pm$ n & $-n--7$ & minmo \\
\hline \multirow{3}{*}{ 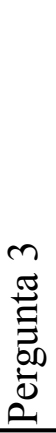 } & \multirow{3}{*}{ 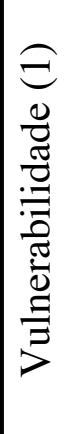 } & $\mid \vec{D}$ & in & $\vec{m}$ & $\stackrel{b}{i}$ & $\ddot{m}$ & $\stackrel{+}{n}$ & $\stackrel{m}{m}$ \\
\hline & & 8 & 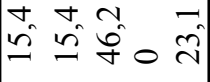 & 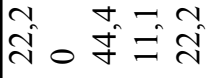 & 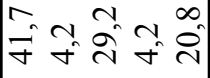 & 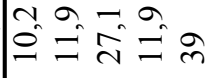 & î. & 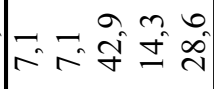 \\
\hline & & \begin{tabular}{|c|} 
\\
0 \\
0 \\
$¥$
\end{tabular} & $N N G 0 \mathrm{~m}$ & NOt $-N$ & $O-n-n$ & $0-2-2$ & Nomor & $--6 N \gamma$ \\
\hline \multirow{3}{*}{$N$} & \multirow{3}{*}{ 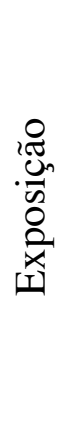 } & : & ते & $\stackrel{\infty}{i}$ & $\stackrel{0}{i}$ & $\stackrel{m}{m}$ & $\hat{i}$ & $\stackrel{+}{i}$ \\
\hline & & के: & 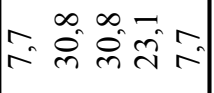 & 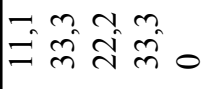 & $m_{\infty}=m_{0}^{m} \hat{\sigma} 0$ & m & 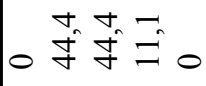 & 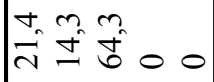 \\
\hline & & $\mid \begin{array}{l}\mid \overline{0} \\
0 \\
0 \\
\#\end{array}$ & $-\sigma+m-$ & $-m \sim m o$ & $\sim \stackrel{\infty}{\infty}+0$ & $\sim ㅇ ㅛ$. & $0+\theta-0$ & mNaO \\
\hline \multirow{3}{*}{-} & \multirow{3}{*}{$\begin{array}{l}\mathbb{E}_{n} \\
\stackrel{\mathbb{E}}{\mathscr{Z}} \\
\dot{Z}\end{array}$} & : & $\vec{i}$ & 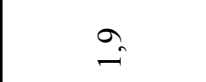 & $n$ & ñ & $\stackrel{0}{i}$ & $\stackrel{0}{i}$ \\
\hline & & 2 & 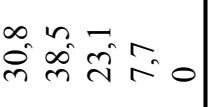 & $\begin{array}{l}\dot{n}=0 \\
\dot{n}=\tilde{d}=0\end{array}$ & 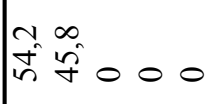 & 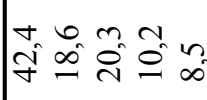 & $\hat{m} \vec{m}=\vec{f}=0$ & in $\tilde{n}=\vec{n} 0$ \\
\hline & & $\begin{array}{c}0 \\
0 \\
0 \\
\#\end{array}$ & $\tan m-0$ & $n-N-0$ & $m=000$ & $\approx= \pm$ o i & $n+-$ & $1-n--0$ \\
\hline & \multirow[t]{2}{*}{ 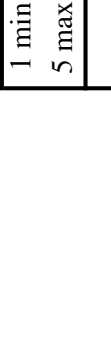 } & & $-N m+n$ & $-N m+n$ & $-N m+n$ & $-N m+n$ & $-N m+n$ & $-N m+n$ \\
\hline & & & 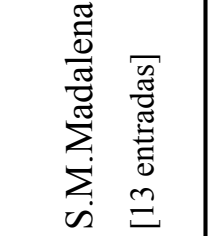 & 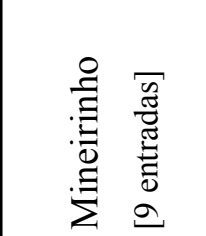 & 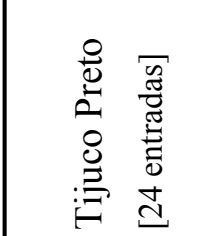 & 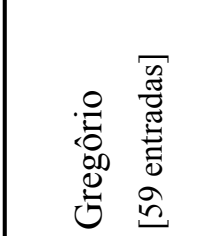 & 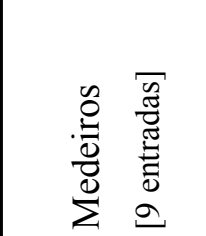 & 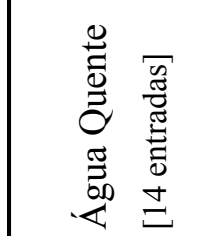 \\
\hline
\end{tabular}


A Tabela 5.5 mostra, para cada sub-bacia, os produtos das médias ponderadas das componentes do risco. Portanto o risco percebido, resultante do produto referentes às perguntas de Ameaça, Exposição e Vulnerabilidade (1), é denominado “ $R_{P, 1}$ ”, enquanto o termo " $R_{P, 2}$ " é utilizado para o risco percebido resultante do produto de Ameaça, Exposição e Vulnerabilidade (2).

Com base nos resultados $R_{P, 1}$ e $R_{P, 2}$ foi criada uma escala de risco percebido. A subdivisão em classes dessa escala foi realizada após uma análise das freqüências das respostas como ilustrado na Figura 5.4. A cada classe foi sucessivamente associada uma cor para descrição visual do nível de risco (Tabela 5.4).

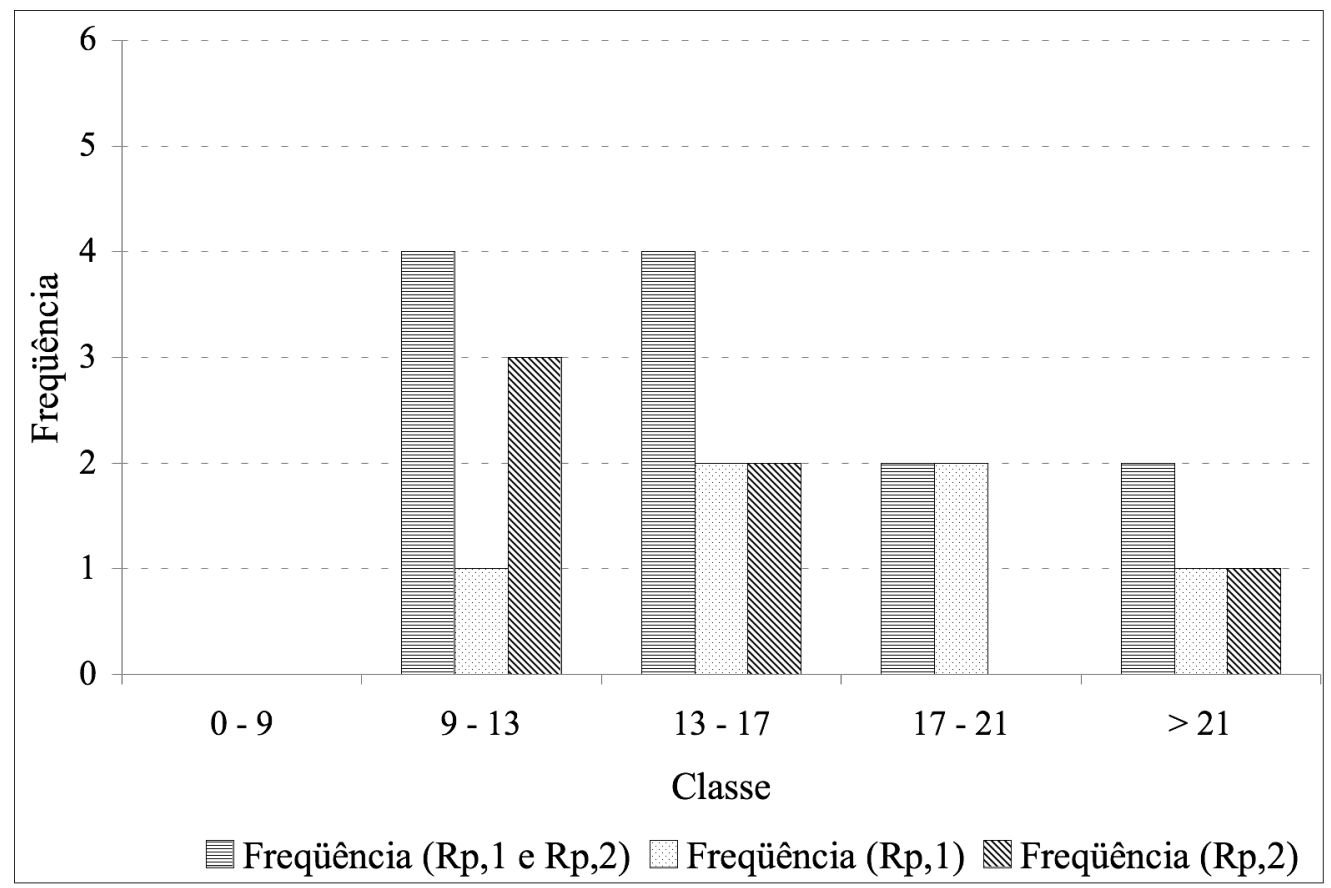

Figura 5.4 - Distribuição de freqüências de valores obtidos dos produtos $R_{P, 1}$ e $R_{P, 2}$ segundo a divisão em classes escolhida. 
Tabela 5.4 - Legenda da escala de risco percebido subdividida em cinco níveis.

\begin{tabular}{|l|c|c|c|c|c|}
\cline { 2 - 6 } \multicolumn{1}{c|}{} & \multicolumn{5}{c|}{ Legenda da escala de Risco Percebido - $\mathrm{R}_{\mathrm{P}}$} \\
\hline Cor & & & & & \\
\hline Classes $\mathrm{R}_{\mathrm{P}}$ & $0-9$ & $9-13$ & $13-17$ & $17-21$ & $>21$ \\
\hline $\begin{array}{l}\text { Níveis de } \\
\text { Risco }\end{array}$ & $\begin{array}{l}\text { Muito } \\
\text { Baixo }\end{array}$ & Baixo & Médio & Alto & $\begin{array}{l}\text { Muito } \\
\text { Alto }\end{array}$ \\
\hline
\end{tabular}

Tabela 5.5 - Riscos percebidos resultantes do produto das componentes Ameaça, Exposição e Vulnerabilidade (1) para $R_{P, I}$ e Vulnerabilidade (2) para $R_{P, 2}$.

\begin{tabular}{|l|r|r|l|l|}
\cline { 2 - 5 } \multicolumn{1}{c|}{} & Pergunta 1 & Pergunta 2 & Pergunta 3 & Pergunta 4 \\
\cline { 2 - 5 } \multicolumn{1}{c|}{} & Ameaça & Exposição & Vulnerabilidade (1) & Vulnerabilidade (2) \\
\hline $\begin{array}{l}1 \mathrm{~min} \\
5 \mathrm{max}\end{array}$ & nivel & nivel & nivel & nivel \\
\hline S.M.Madalena & 2,1 & 2,9 & 3,0 & 2,7 \\
\hline Mineirinho & 1,9 & 2,8 & 3,1 & 2,4 \\
\hline Tijuco Preto & 1,5 & 2,6 & 2,6 & 2,5 \\
\hline Gregório & 2,2 & 3,3 & 3,6 & 3,2 \\
\hline Medeiros & 2,0 & 2,7 & 3,4 & 2,6 \\
\hline Água Quente & 2,0 & 2,4 & 3,5 & 2,4 \\
\hline
\end{tabular}

\begin{tabular}{|c|}
\hline $\mathrm{R}_{\mathrm{P}, 1}$ \\
\hline $\mathrm{A} * \mathrm{E} * \mathrm{~V}(1)$ \\
\hline $\begin{array}{c}\text { produto } \\
\text { resultante }\end{array}$ \\
\hline 18,3 \\
\hline 16,3 \\
\hline 9,7 \\
\hline 26,2 \\
\hline 18,3 \\
\hline 17,0 \\
\hline
\end{tabular}

\begin{tabular}{|c|}
\hline $\mathrm{R}_{\mathrm{P}, 2}$ \\
\hline $\mathrm{A} * \mathrm{E} * \mathrm{~V}(2)$ \\
\hline $\begin{array}{c}\text { produto } \\
\text { resultante }\end{array}$ \\
\hline 16,4 \\
\hline 12,8 \\
\hline 9,4 \\
\hline 23,3 \\
\hline 13,6 \\
\hline 11,8 \\
\hline
\end{tabular}

A Figura 5.5 ilustra os intervalos de risco percebido $\left(R_{P, 1}-R_{P, 2}\right)$ e seus respectivos valores médios:

$$
\overline{R_{P}}=\left(\frac{R_{P, 1}+R_{P, 2}}{2}\right)
$$

Cabe observar que nos intervalos ilustrados o menor valor de $R_{P}$ é sempre constituído por $R_{P, 2}$ e, conseqüentemente, o maior valor por $R_{P, 1}$. Este comportamento pode-se explicar pelo fato do risco $R_{P, 2}$ ser constituído pela vulnerabilidade (2), a qual foi sub-estimada nas respostas dos entrevistados como descrito anteriormente. Entretanto o risco $R_{P, 1}$ resulta maior por ser constituído pela vulnerabilidade (1), a qual foi sobre-estimada por ter sido avaliada a nível de cidade e não de local de trabalho ou moradia dos questionados. 


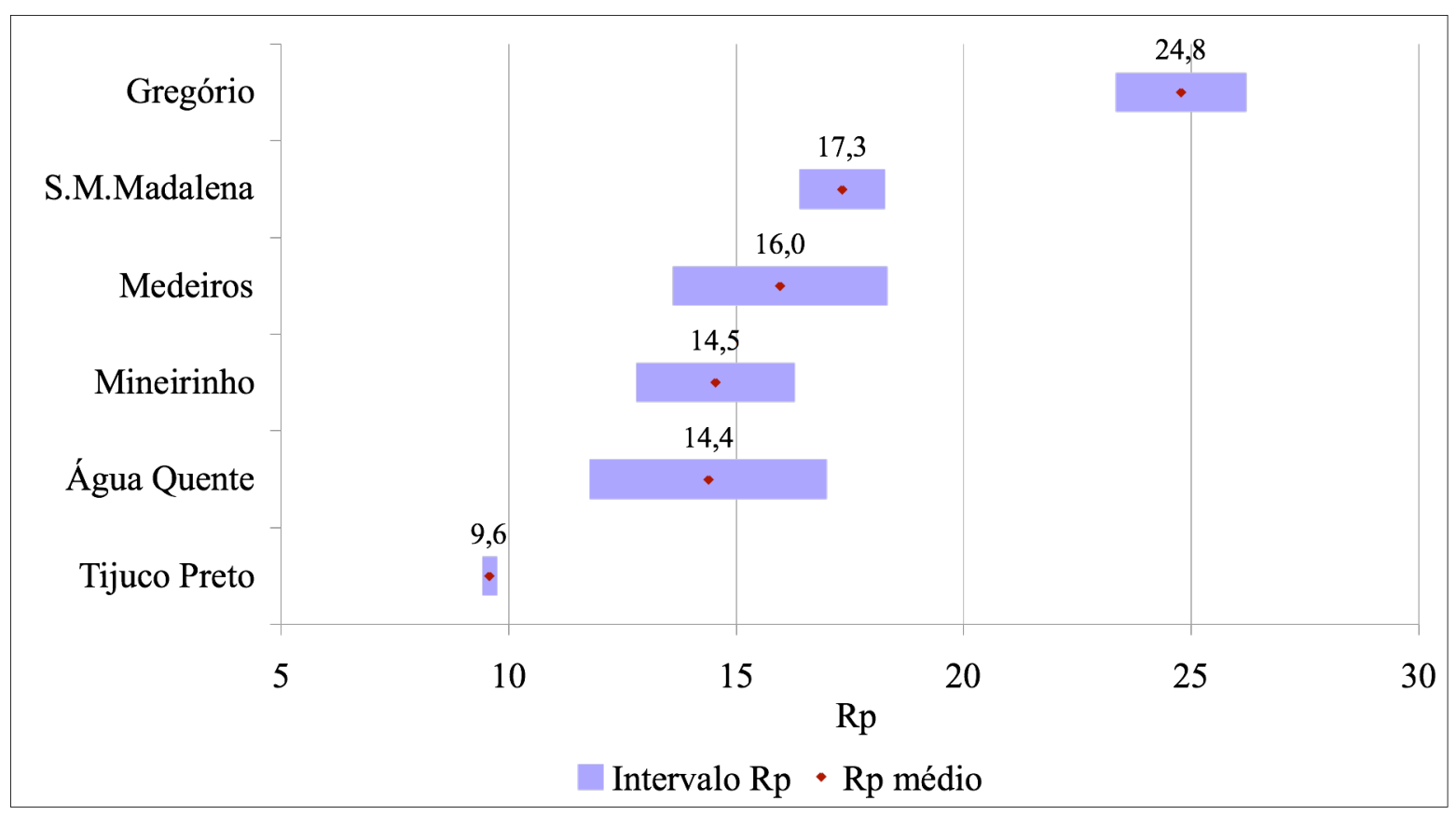

Figura 5.5 - Intervalos de Risco percebido $\left(R_{P, 1}-R_{P, 2}\right)$ por sub-bacia e respectivos valores médios.

A Figura 5.5 mostra, como já observado na Tabela 5.5, que a bacia com maior risco percebido é a do Gregório, com valores bem mais altos em relação às outras bacias. Isto pode ser explicado pelo fato que para esta bacia, uma boa parte das entrevistas foram efetuadas nas áreas do Mercado Municipal, na parte a jusante da bacia. Nesta área ocorrem anualmente fenômenos de enchente e inundação gerados pelas inadequadas dimensões do canal do córrego e em geral pelas limitadas infra-estruturas de drenagem que têm causado danos econômicos ao comércio e prejuízo ao tráfego veicular e à população em geral.

Observa-se também que os intervalos de risco podem ser bastante amplos, como no caso da bacia de Água Quente e Medeiros, ou bem restritos, como para a bacia do Tijuco Preto, para a qual se obteve uma variação quase nula. 


\subsection{Inserção dos dados das entrevistas no web-GIS}

Realizadas as entrevistas com uma amostra de 163 habitantes da cidade de São Carlos, as informações fornecidas por eles, que avaliam o nível de risco a qual estão sujeitos, foram inseridas no portal web-GIS como descrito no item 4.2.2.2. Na Figura 5.6 é mostrada a tela do portal com os pontos referentes às avaliações.
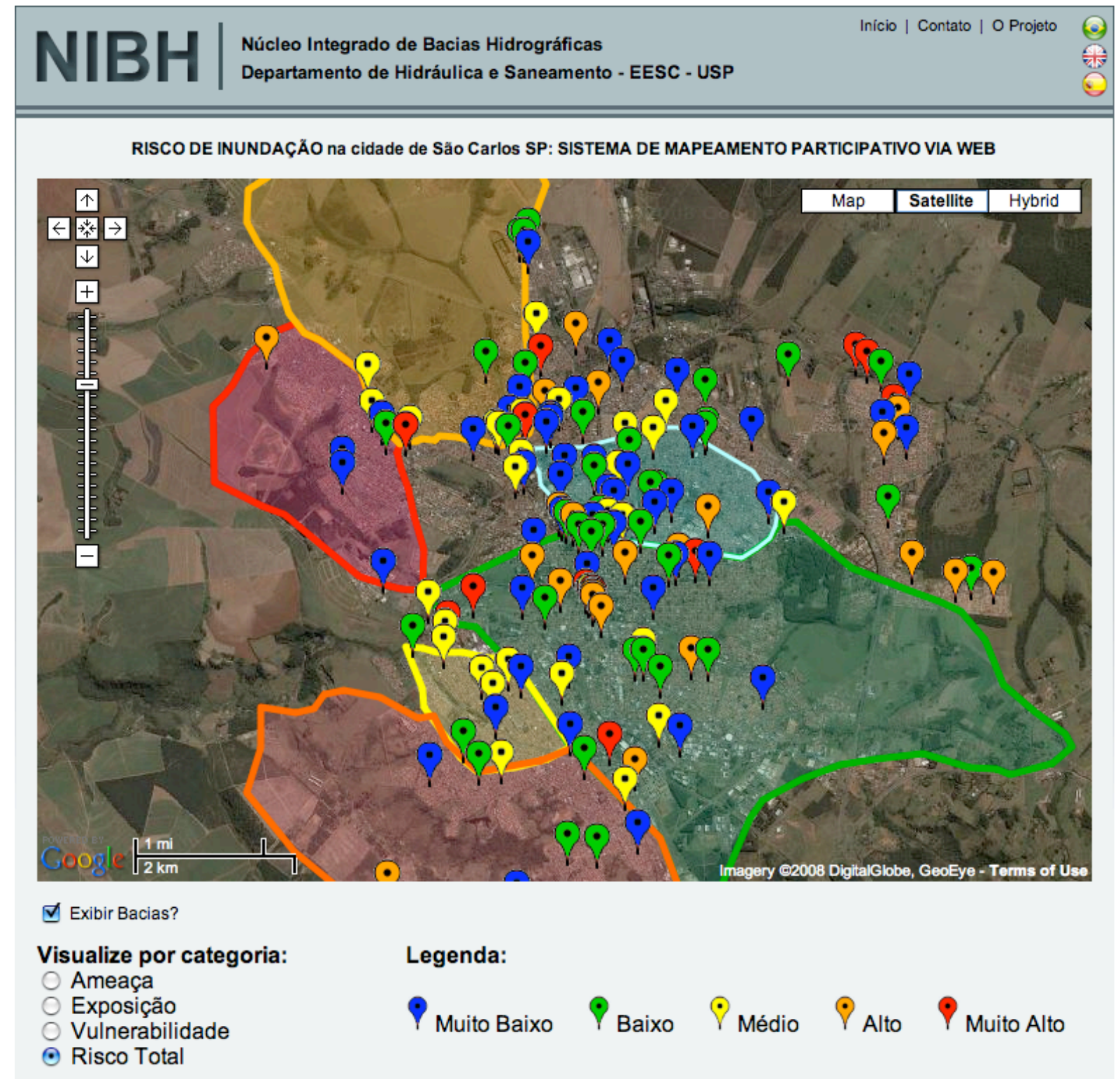

Figura 5.6 - Tela do portal web-GIS após a inserção dos dados dos entrevistados. Os níveis de cores se referem ao Risco Total. 


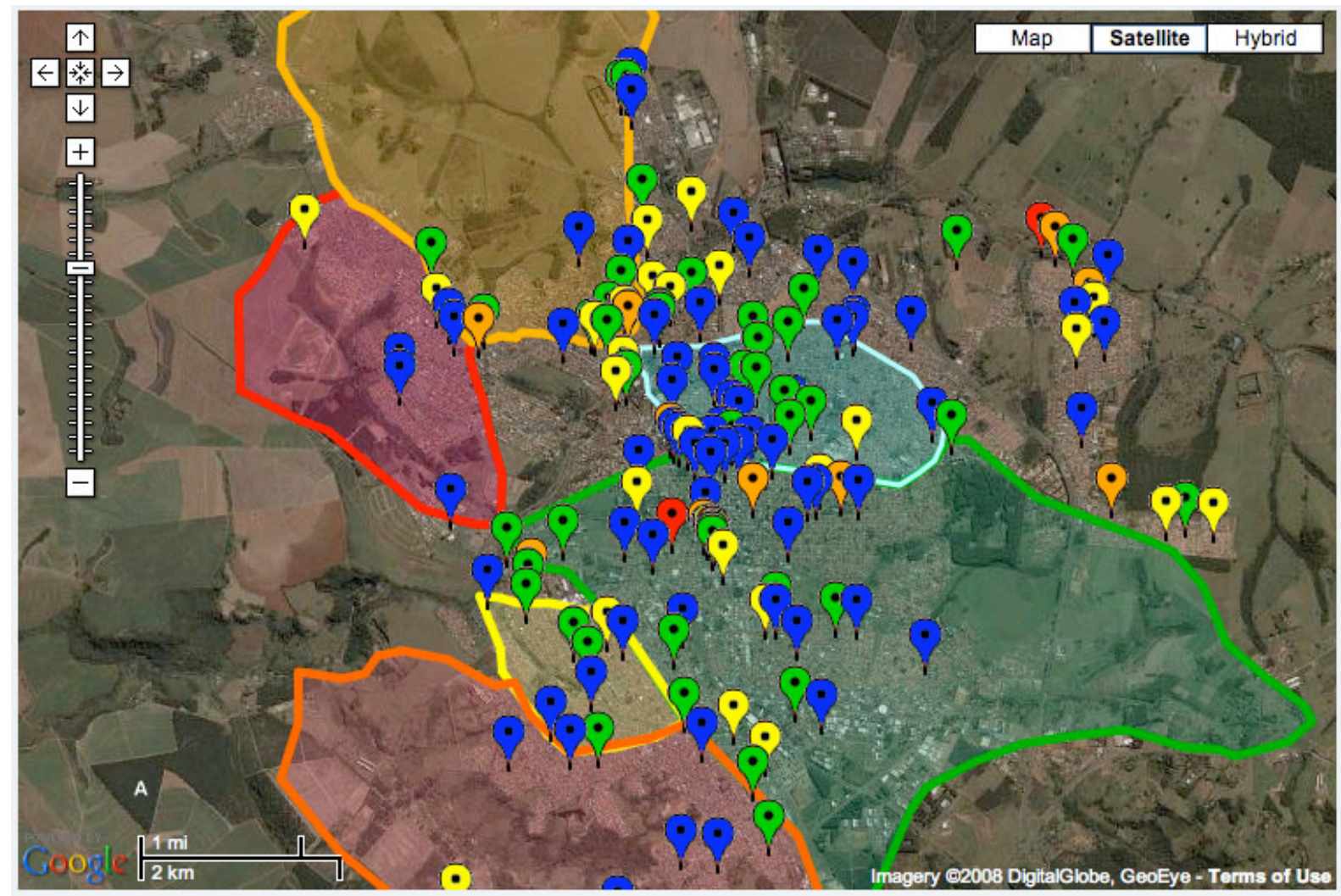

Figura 5.7 - Níveis de cores referentes à Ameaça.

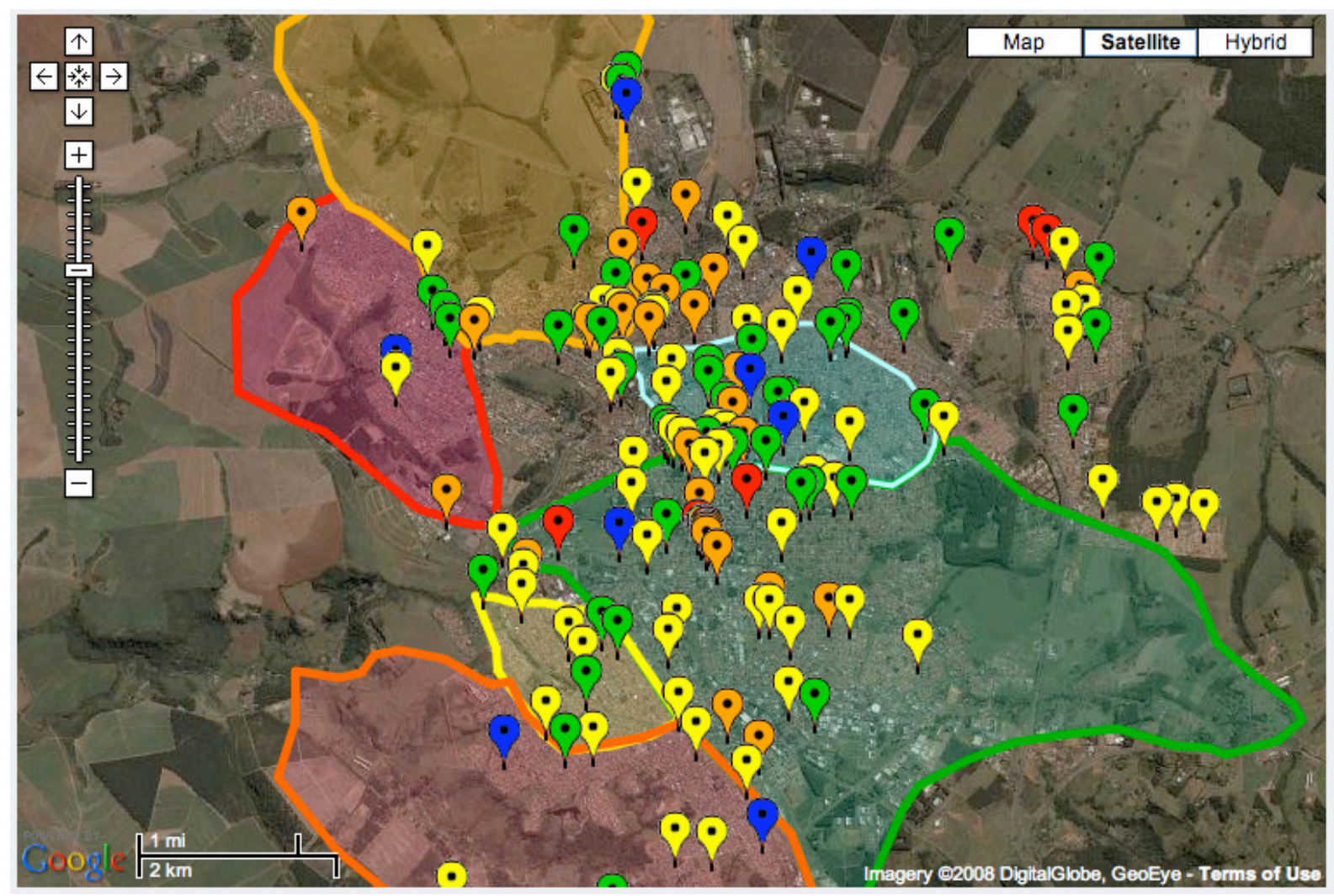

Figura 5.8 - Níveis de cores referentes à Exposição. 


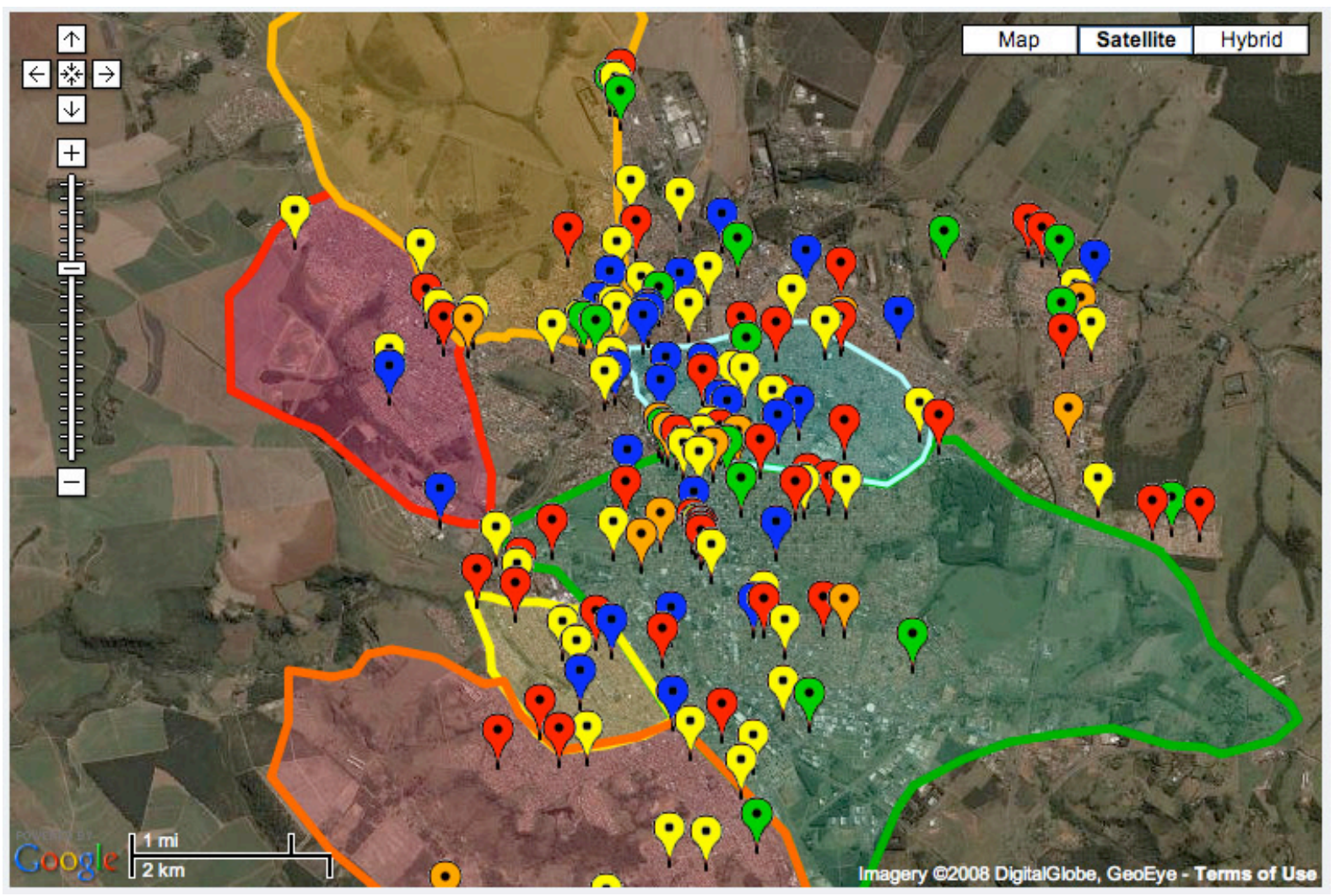

Figura 5.9 - Níveis de cores referentes à Vulnerabilidade.

Pode-se observar que para as visualizações das categorias de risco no portal, as avaliações indicam, de maneira geral, que a percepção dos usuários em relação à categoria ameaça é de que ela é baixa; já para a exposição, as avaliações tenderam para um nível intermediário; por fim, para a vulnerabilidade, se encontram altos níveis espalhados em toda a área urbana, o que demonstra a contínua preocupação dos moradores com a susceptibilidade à fenômenos de enchentes, que podem afetar a eles próprios ou a conhecidos que residem em outras áreas.

Na tela mostrada em Figura 5.6 é apresentado o "Risco Total", que indica o risco percebido total $\left(R_{P, 1}\right)$, obtido pelo produto das entradas das três categorias citadas.

A Figura 5.10 mostra a distribuição escolhida para divisão em classes de risco total percebido. Este é obtido ao de clicar na opção "Risco Total" no campo "Visualize por categorias". 
No estudo de mapeamento de risco em áreas urbanas de Gwilliam et al. (2006), adotaram-se as seguintes classes de risco: muito alto (95 percentil), alto (75-95 percentil), médio (50-75 percentil), baixo ( $<50$ percentil). Analogamente adotou-se, para escala de risco percebido do portal, uma distribuição decrescente das classes de freqüência, para que os riscos "alto" e "muito alto" resultassem num número menor em comparação com a maioria dos pontos, facilitando deste modo a visualização das entradas.

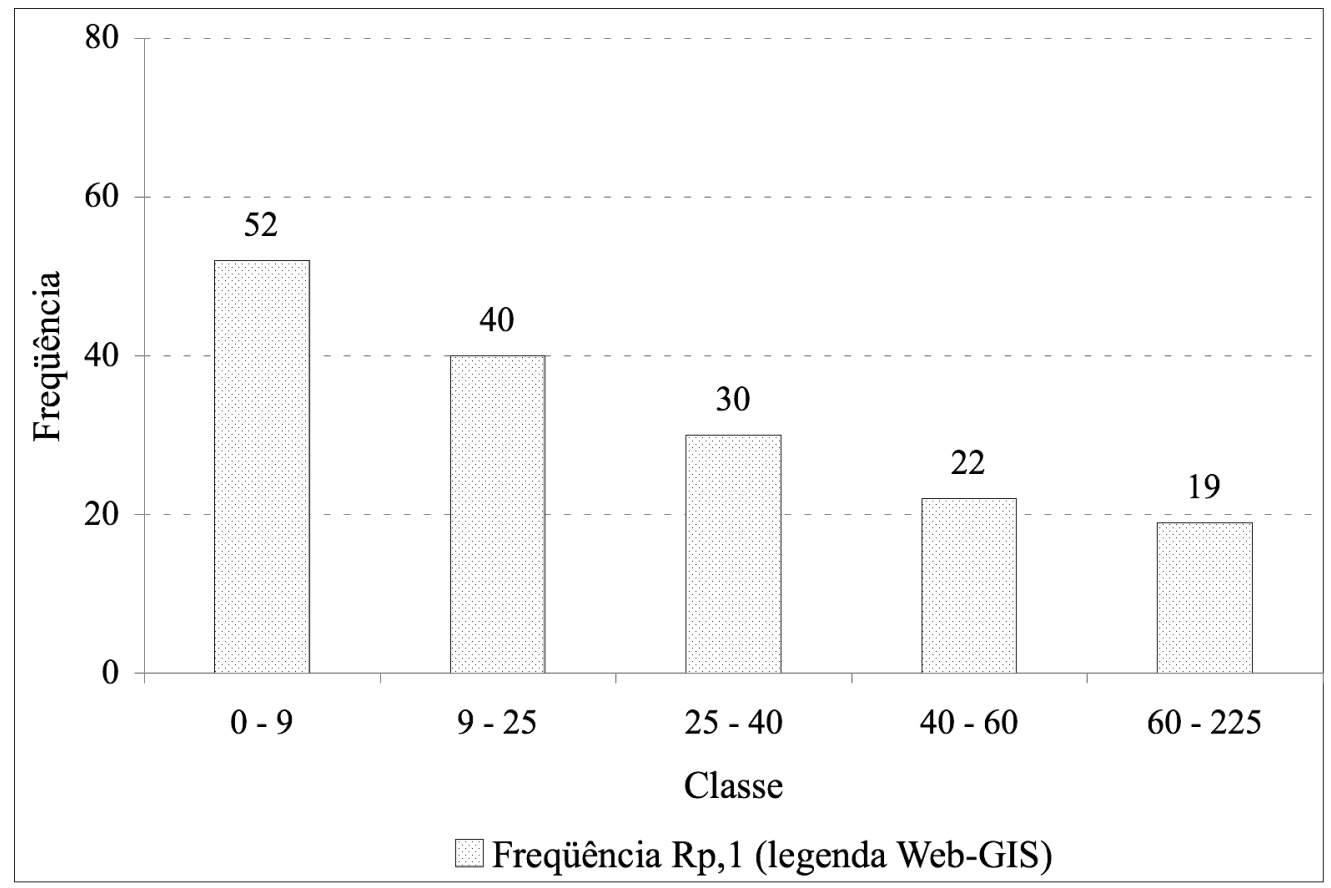

Figura 5.10 - Distribuição da freqüência dos resultados de Risco Total $\left(R_{P, 1}\right)$ em classes: muito baixo (0-9), baixo (9-25), médio (25-40), alto (40-60), muito alto (60-225). 


\subsection{Resultados da expressão do risco}

Segundo a metodologia descrita no item 4.3 calcularam-se as projeções do risco para as 6 sub-bacias urbanas examinadas por meio de planilhas de cálculo Excel $^{\circledR}$. Os resultados são descritos segundo cenários futuros considerados: reativo e pró-ativo.

O comportamento dos componentes da expressão do risco depende do cenário considerado. Mostram-se, a título de exemplo, os gráficos referentes a alguns parâmetros da bacia do Gregório (abordados na Tabela 4.2). Observa-se, no âmbito da estimativa da vulnerabilidade, que a relação entre o tempo de deslocamento para pessoas vulneráveis $t_{v}$ e o mesmo tempo para pessoas não vulneráveis $t_{f}$ segue um perfil crescente no cenário reativo e decrescente no pró-ativo (Figura 5.11).

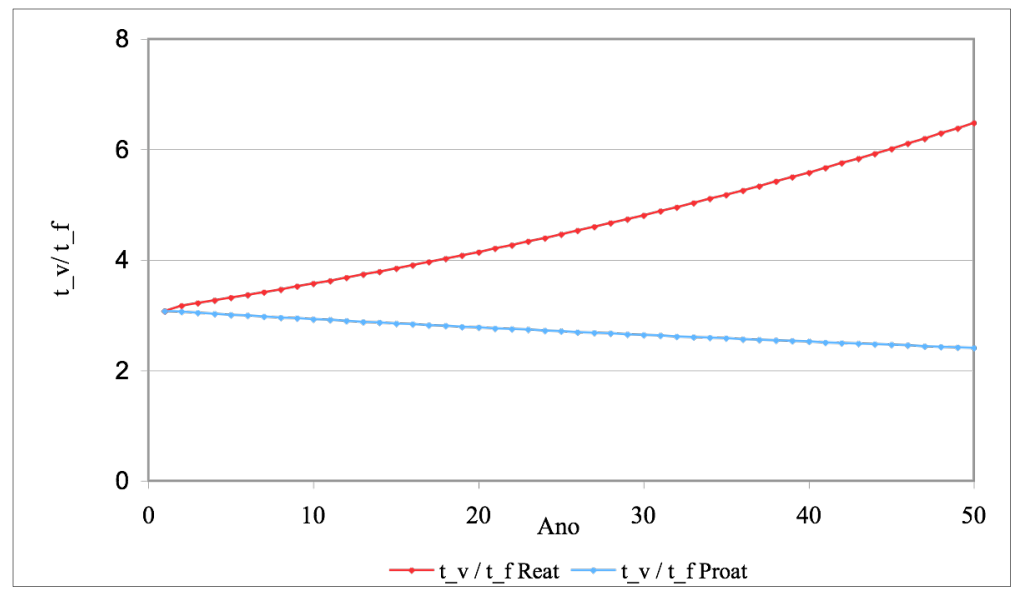

Figura 5.11 - Relação entre tempo de resgate $t_{\text {resg }}$ e tempo de concentração $t_{c}$ nos dois cenários.

No âmbito da gestão do risco na estimativa antes da ocorrência, a relação entre o tempo de concentração $t_{c o n c}$ e o tempo de alerta antecipado $t_{\text {aler }}$ tem tendência a decrescer nos dois cenários, no entanto para o cenário reativo a diminuição ocorre de maneira leve e linear, enquanto no cenário pró-ativo há uma diminuição brusca nos primeiros dez anos (Figura 5.12). Esse comportamento ocorre no primeiro caso devido à diminuição do $t_{c}$ se mantendo 
constante o $t_{\text {aler }}$, ao passo que no cenário pró-ativo o $t_{c}$ se mantém constante mas o $t_{\text {aler }}$ aumenta ao longo dos anos.

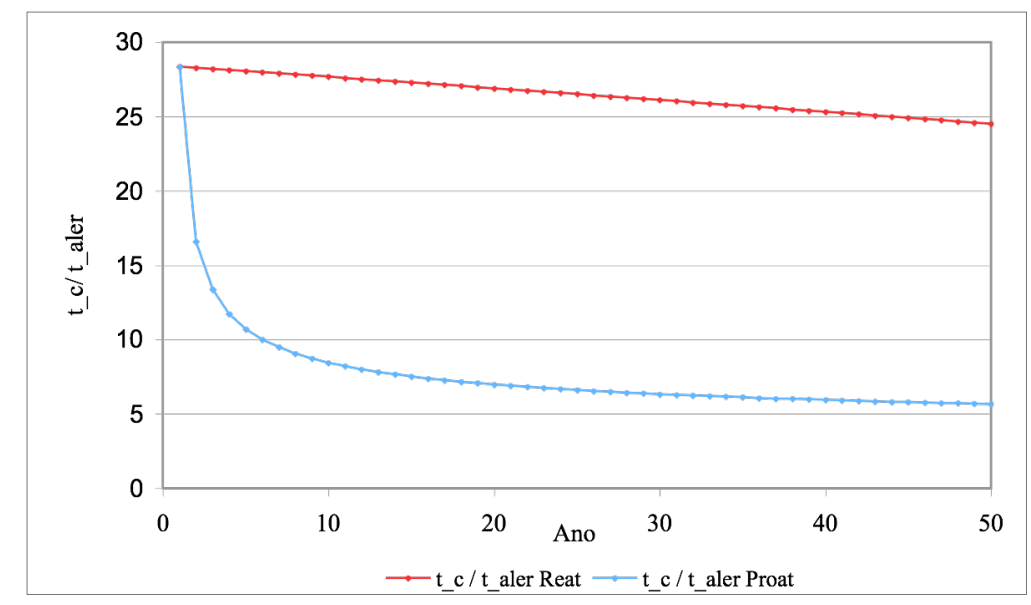

Figura 5.12 - Relação entre tempo $t_{c}$ e tempo $t_{\text {aler }}$ nos dois cenários.

Quanto à fase de gestão durante o evento, a relação entre o tempo de resgate $t_{\text {resg }}$ e o tempo de concentração $t_{c}$, observa-se um andamento similar aos precedentes (Figura 5.13). Cabe destacar que para esta fase o $t_{c}$ se encontra no denominador da expressão, assim no cenário reativo ao decrescer de $t_{c} \mathrm{o} t_{\text {resg }}$ permanece constante causando um aumento da relação no tempo; para o cenário pró-ativo, mantendo-se o $t_{c}$ constante e $t_{\text {resg }}$ diminuir, a relação decresce. 


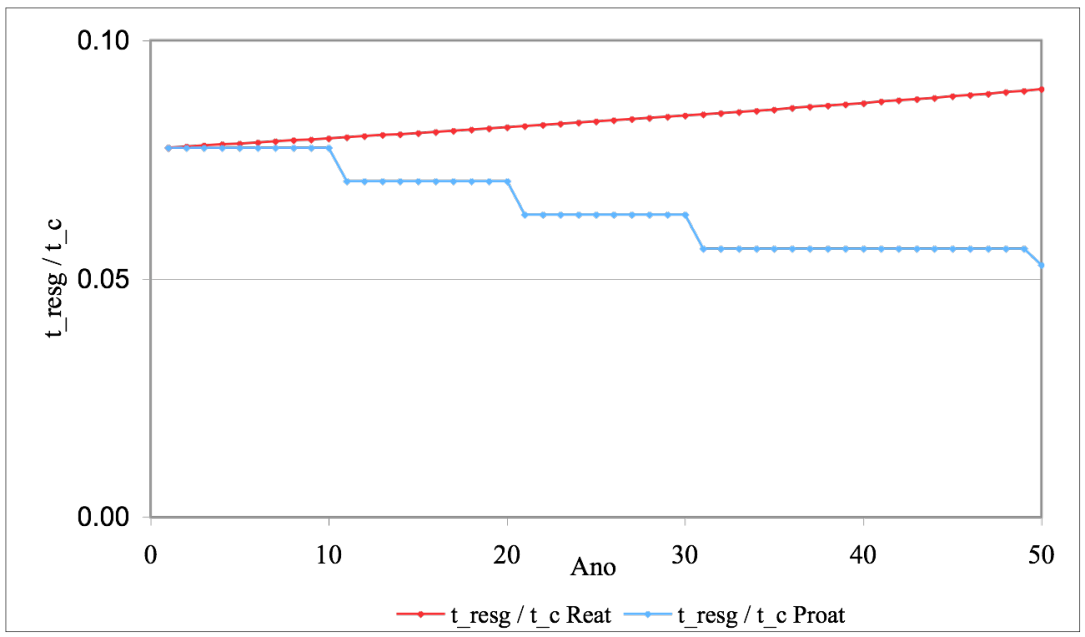

Figura 5.13 - Relação entre tempo $t_{\text {resg }}$ e tempo $t_{c}$ nos dois cenários. 
Os gráficos (Figura 5.14 e Figura 5.15) ilustram a variação dos parâmetros da expressão do risco agrupados por fase: em azul o produto dos parâmetros da estimativa do risco (ameaça $\times$ exposição $\times$ vulnerabilidade); em verde o produto dos parâmetros da gestão do risco (antes $\times$ durante $\times$ depois $)$. Com o objetivo de padronizar os valores de Risco estimado, as parcelas da estimativa do risco $\left(R_{E, 1}\right)$ e da gestão do risco $\left(R_{E, 2}\right)$ foram multiplicadas pelo fator $10^{3,5}$, logo os valores de $R_{E}$ total, produto de $R_{E, 1}$ e $R_{E, 2}$, foram expressos com um fator de $10^{7}$.

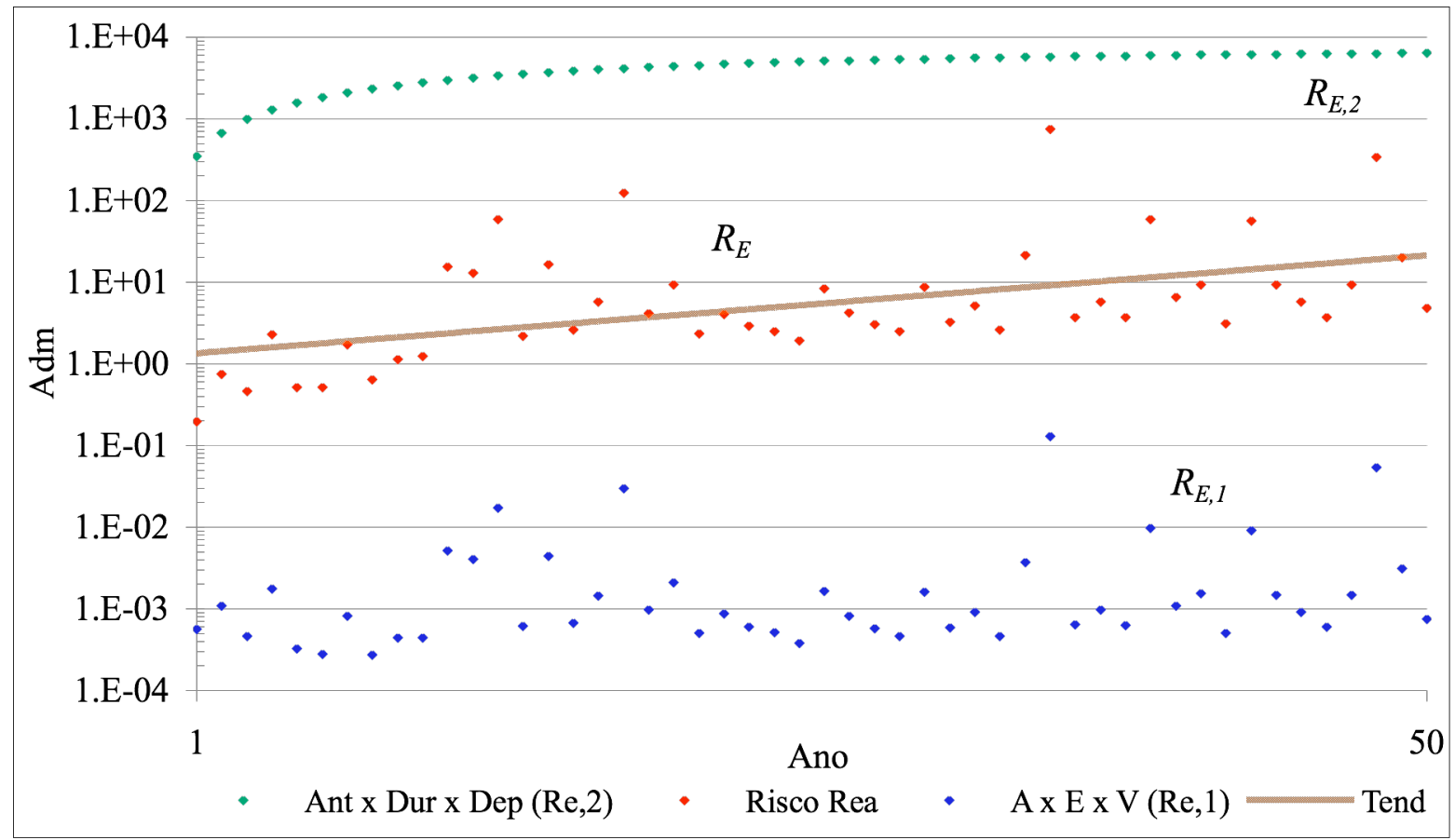

Figura 5.14 - Andamento das componentes da expressão do risco segundo o cenário Reativo. Bacia do Gregório.

Aos dados de risco estimado total $\left(R_{E}\right)$, produto de $R_{E, 1}$ e $R_{E, 2}$, foi adicionada uma curva de tendência para evidenciar que no caso do cenário reativo (Figura 5.14) o risco médio sofre um aumento ao longo do tempo, enquanto no cenário pró-ativo (Figura 5.15) o risco médio permanece constante, ou, em alguns casos, diminui. 


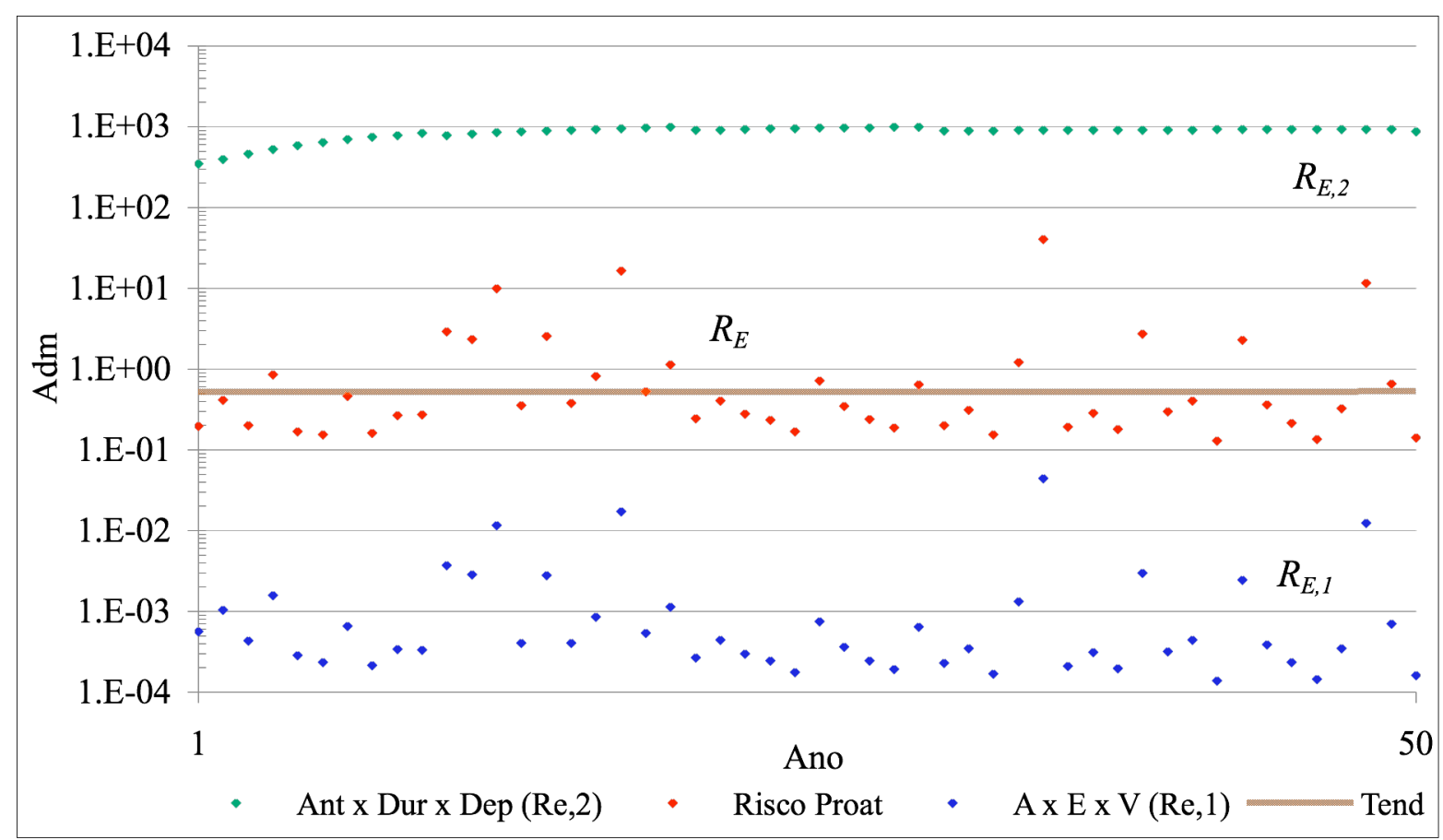

Figura 5.15 - Andamento das componentes da expressão do risco segundo o cenário Pro-ativo. Bacia do Gregório.

A diferença entre os dois cenários torna-se mais evidente no gráfico da Figura 5.16 no qual são ilustradas as curvas de tendência do risco referentes aos dois cenários para a bacia do Gregório. 


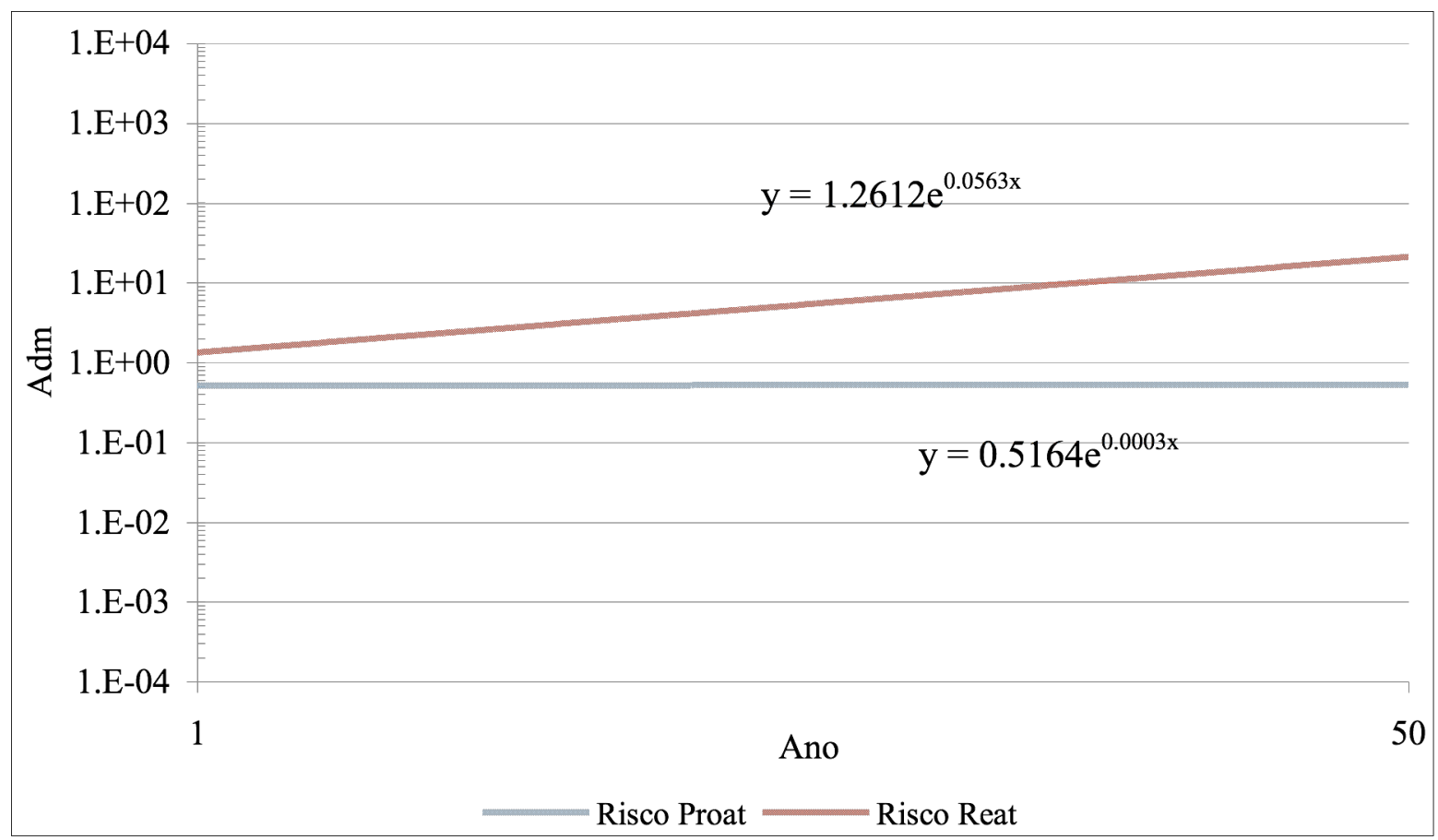

Figura 5.16 - Curvas de tendência referentes ao risco estimado no cenário Reativo e no cenário Proativo. Bacia do Gregório.

Os resultados da estimativa de risco são resumidos em Tabela 5.7. Foi calculado um valor de risco médio anual para cada sub-bacia. Com base nos valores de risco médio, assim como foi realizado para o risco percebido, atribuiu-se uma cor a cada um dos cinco intervalos considerados (Tabela 5.6).

Tabela 5.6 - Legenda da escala de risco médio subdividida em cinco níveis.

\begin{tabular}{|l|c|c|c|c|c|}
\cline { 2 - 6 } \multicolumn{1}{c|}{} & \multicolumn{5}{c|}{ Legenda da escala de Risco médio estimado $-R_{\bar{E}}$} \\
\hline Cor & & & & & \\
\hline Classes $R_{\mathrm{E}}$ & $0-1$ & $1-10$ & $10-50$ & $50-100$ & $>100$ \\
\hline $\begin{array}{l}\text { Níveis de } \\
\text { Risco }\end{array}$ & $\begin{array}{l}\text { Muito } \\
\text { Baixo }\end{array}$ & Baixo & Médio & Alto & $\begin{array}{l}\text { Muito } \\
\text { Alto }\end{array}$ \\
\hline
\end{tabular}

A divisão da escala de risco médio em classes foi realizada por meio de uma análise da freqüência dos valores referentes aos dois cenários como mostra a Figura 5.17. Segundo a 
primeira hipótese, subdividindo os valores em classes iguais, observou-se uma distribuição excessiva da freqüência nos valores da primeira classe. A hipótese escolhida é ilustrada no segundo gráfico no qual se observa uma distribuição mais homogênea das freqüências.

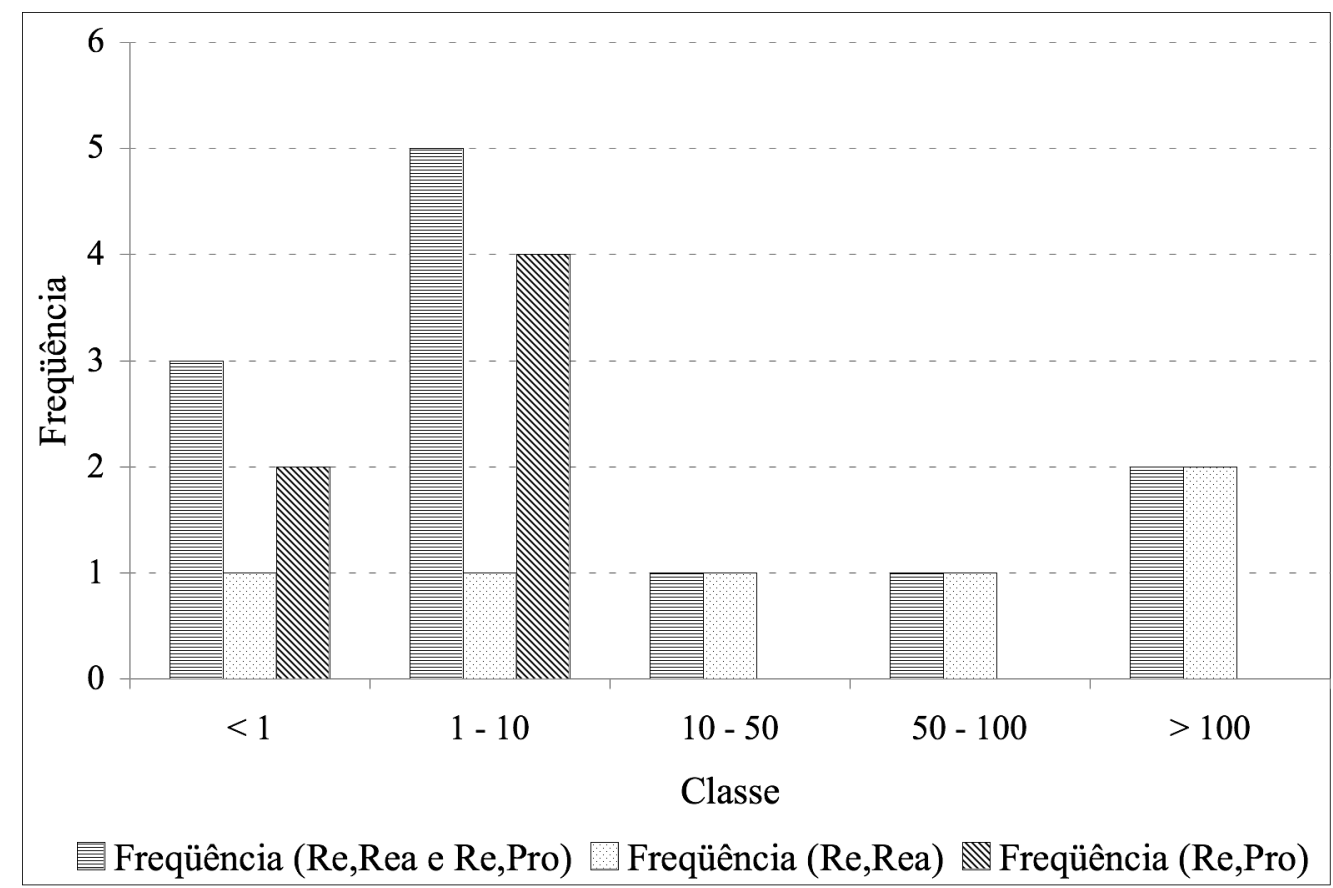

Figura 5.17 - Distribuição da freqüência em classes de freqüências da formula do risco.

A Tabela 5.7 evidencia que, segundo esta metodologia, as bacias com menor risco nos dois cenários, são Água Quente e Mineirinho, enquanto as bacias com níveis mais críticos são Tijuco Preto e Medeiros. 
Tabela 5.7 - Resultados da estimativa do risco para cada sub-bacia.

\begin{tabular}{|l|c|c|c|c|c|c|}
\cline { 2 - 7 } \multicolumn{1}{c|}{} & \multicolumn{2}{l|}{ Risco Médio } & \multicolumn{2}{l|}{ Risco Acumulado } & \multicolumn{2}{l|}{ Risco resultante [@ tabela 5.6] } \\
\cline { 2 - 7 } & Reativo & Pro-ativo & Reativo & Pro-ativo & Reativo & Pro-ativo \\
\hline S.M.Madalena & 79 & 5,0 & 3958 & 248 & & \\
\hline Mineirinho & 1,2 & 0,1 & 60 & 4 & & \\
\hline Tijuco Preto & 161 & 9,9 & 8027 & 495 & & \\
\hline Gregório & 33 & 2,1 & 1630 & 107 & & \\
\hline Medeiros & 111 & 7,4 & 5551 & 368 & & \\
\hline Água Quente & 0,9 & 0,1 & 42 & 3 & & \\
\hline
\end{tabular}

$\mathrm{O}$ risco acumulado representa uma outra forma de descrever o risco de uma bacia. $\mathrm{Na}$

Figura 5.18 são ilustrados os valores de risco acumulado em 50 anos $\left(R_{E,(\text { Acum }, 50)}\right)$.

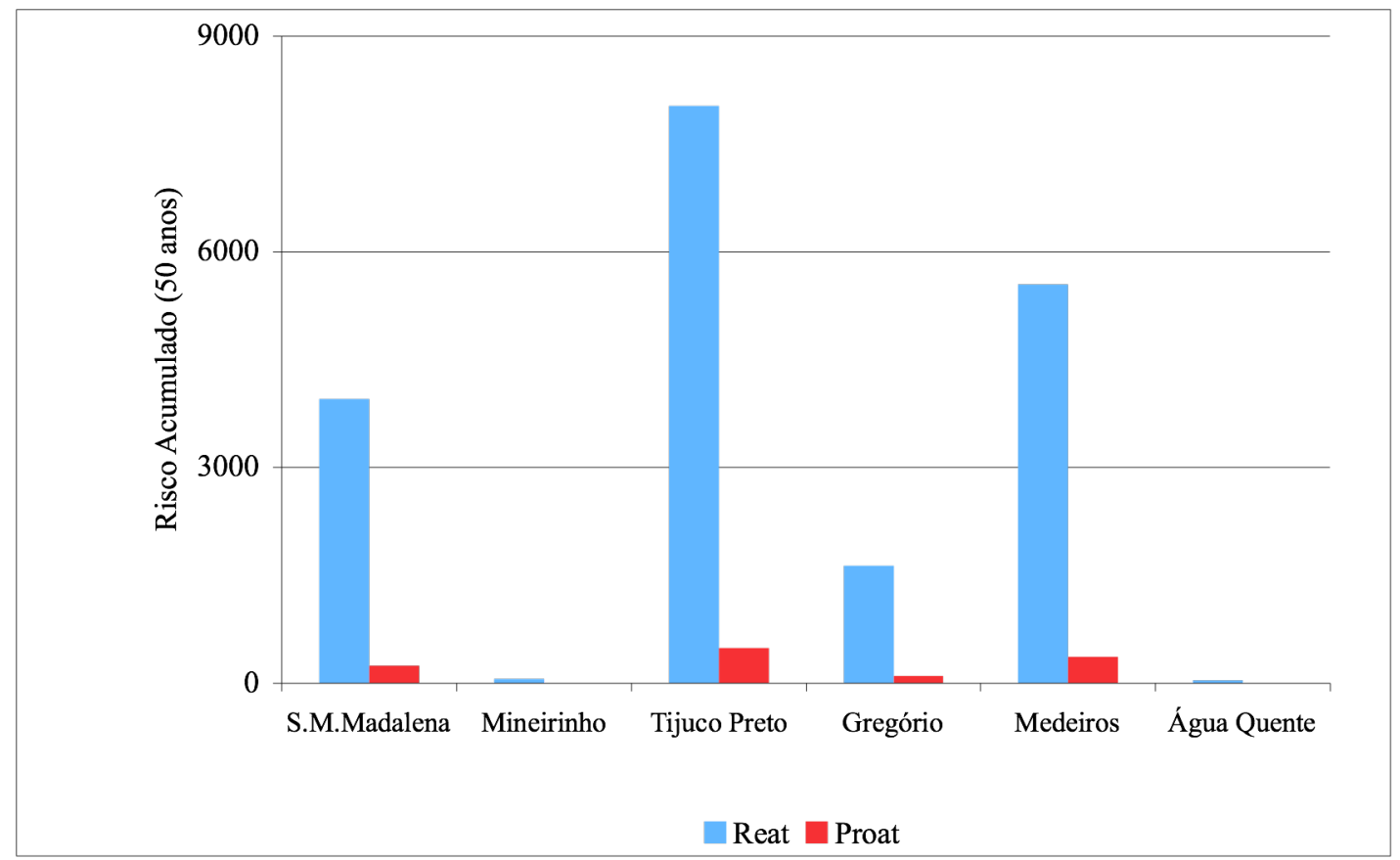

Figura 5.18 - Risco acumulado em 50 anos segundo os cenários $\left(R_{E, \text { Rea }(\text { Acum }, 50)}\right.$ e $\left.R_{E, \text { Pro }(A c u m, 50)}\right)$. 


\subsection{Comparação entre o risco percebido e o risco estimado}

Os resultados de risco percebido $\left(R_{P}\right)$ e estimado $\left(R_{E}\right)$ podem ser comparados segundo o produto das componentes Ameaça, Exposição e Vulnerabilidade. Deste modo para o $R_{E}$ é necessário considerar a primeira parte da expressão do risco $\left(R_{E, 1}\right)$ desconsiderando a segunda que avalia os passos de gerenciamento de risco, ausentes nos dados de risco percebido. Os valores de $R_{E, 1}$ estão resumidos no anexo 5 .

No gráfico a seguir (Figura 5.19) são comparados os intervalos de risco percebido $R_{P, 1}-R_{P, 2}$ (precedentemente apresentados em Figura 5.5) com os intervalos de risco médio estimado para o cenários reativo e pró-ativo: $R_{E, 1, R e a}-R_{E, 1, P r o a}$.

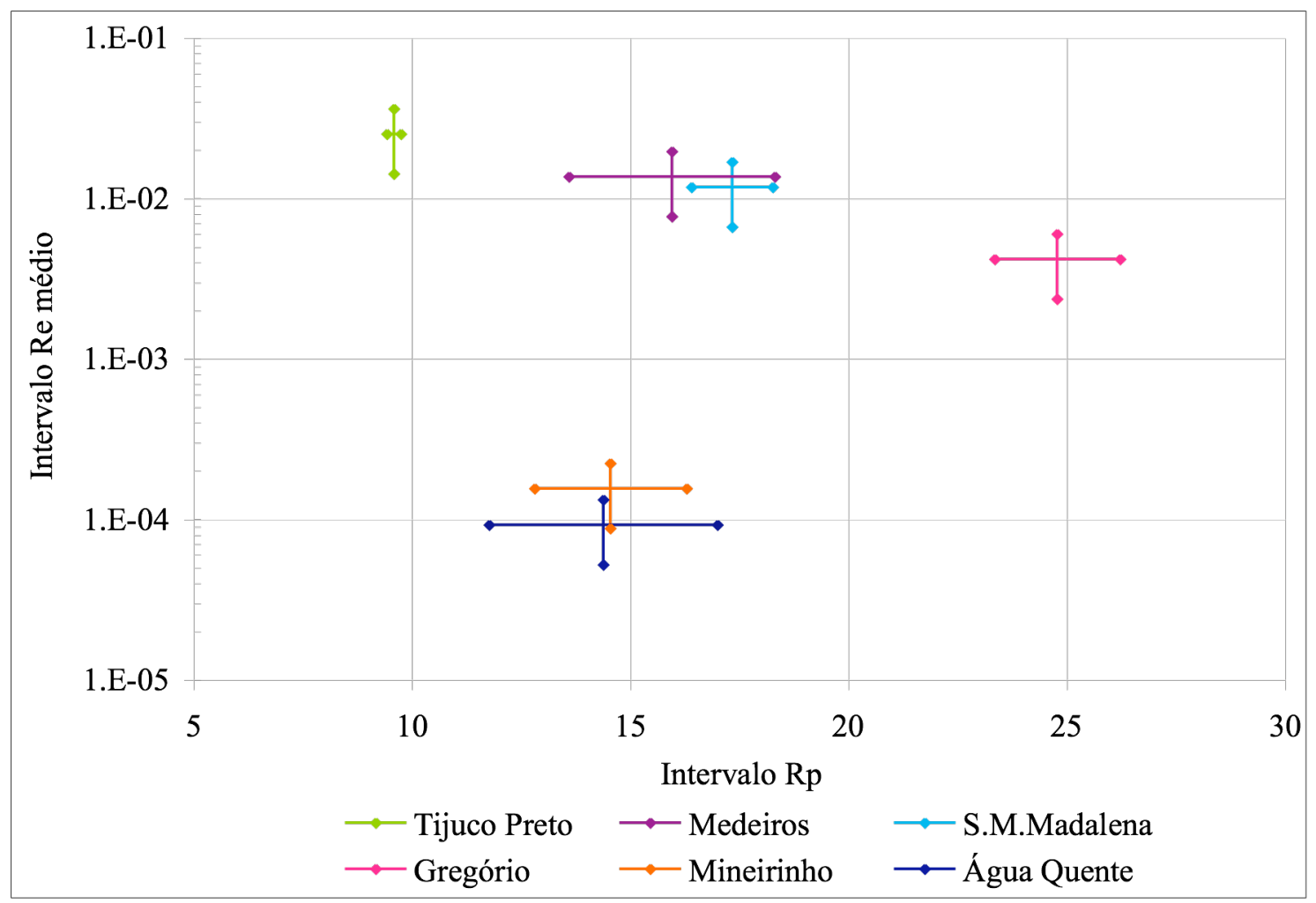

Figura 5.19 - Comparação entre intervalos de risco médio $\left(R_{E, 1, R e a}-R_{E, 1, P r o}\right)$ e intervalos de risco percebido $\left(R_{P, 1}-R_{P, 2}\right)$ das sub-bacias.

Os intervalos de risco $R_{E}$ e $R_{P}$ associados por sub-bacia não mostram uma relação constante no que diz respeito à magnitude do risco. Pode-se observar apenas em três bacias se 
encontra um andamento análogo para os dois tipos de risco: as sub-bacias “Água Quente” e "Mineirinho" denotam valores relativamente baixos tanto para $R_{E}$ que para $R_{P}$; ao mesmo tempo a sub-bacia "Gregório" se situa em altos valores de risco nas duas escalas.

No entanto para as sub-bacias "Medeiros" e "Santa Maria Madalena" a altos valores de $R_{E}$ correspondem valores medianos de $R_{P}$. A sub-bacia "Tijuco Preto" é a que mais exemplifica a falta de correspondência entre risco percebido e risco estimado. Neste caso aos mais elevados valores de $R_{E}$ correspondem os menores valores de $R_{P}$.

Nos gráficos a seguir os riscos percebidos são associados, desta vez, aos valores de $R_{E, 1}$ acumulado em 25 (Figura 5.20) e 50 anos (Figura 5.21) - $R_{E, 1, R e a(A c u m)}$ e $R_{E, 1, P r o(A c u m)}-$ com o intuito de descrever graficamente o aumento do risco estimado ao longo do tempo.

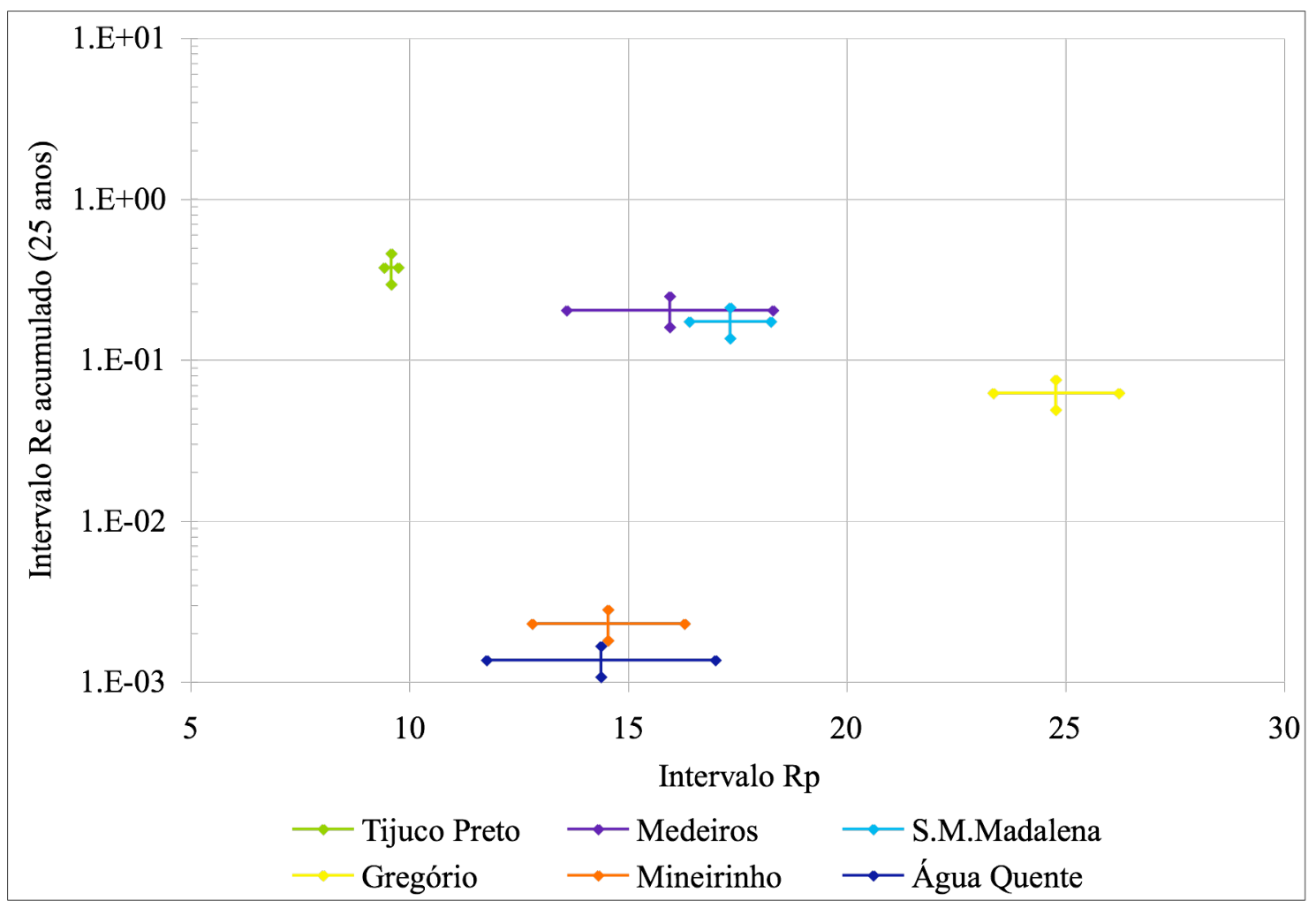

Figura 5.20 - Comparação entre intervalos de risco acumulado em 25 anos $\left(R_{E, 1, R e a(A c u m, 25)}-\right.$ $\left.R_{E, 1, P r o(A c u m, 25)}\right)$ e intervalos de risco percebido $\left(R_{P, 1}-R_{P, 2}\right)$ das sub-bacias. 
Nos dois gráficos a escala das ordenadas é maior que no caso do gráfico do $R_{E}$ médio (Figura 5.19) por se tratar de valores acumulados. O aumento de $R_{E, I}$ de 25 para 50 anos é acompanhado por uma conseqüente ampliação do intervalo de valores entre o cenário reativo (valor maior) e pró-ativo (valor menor).

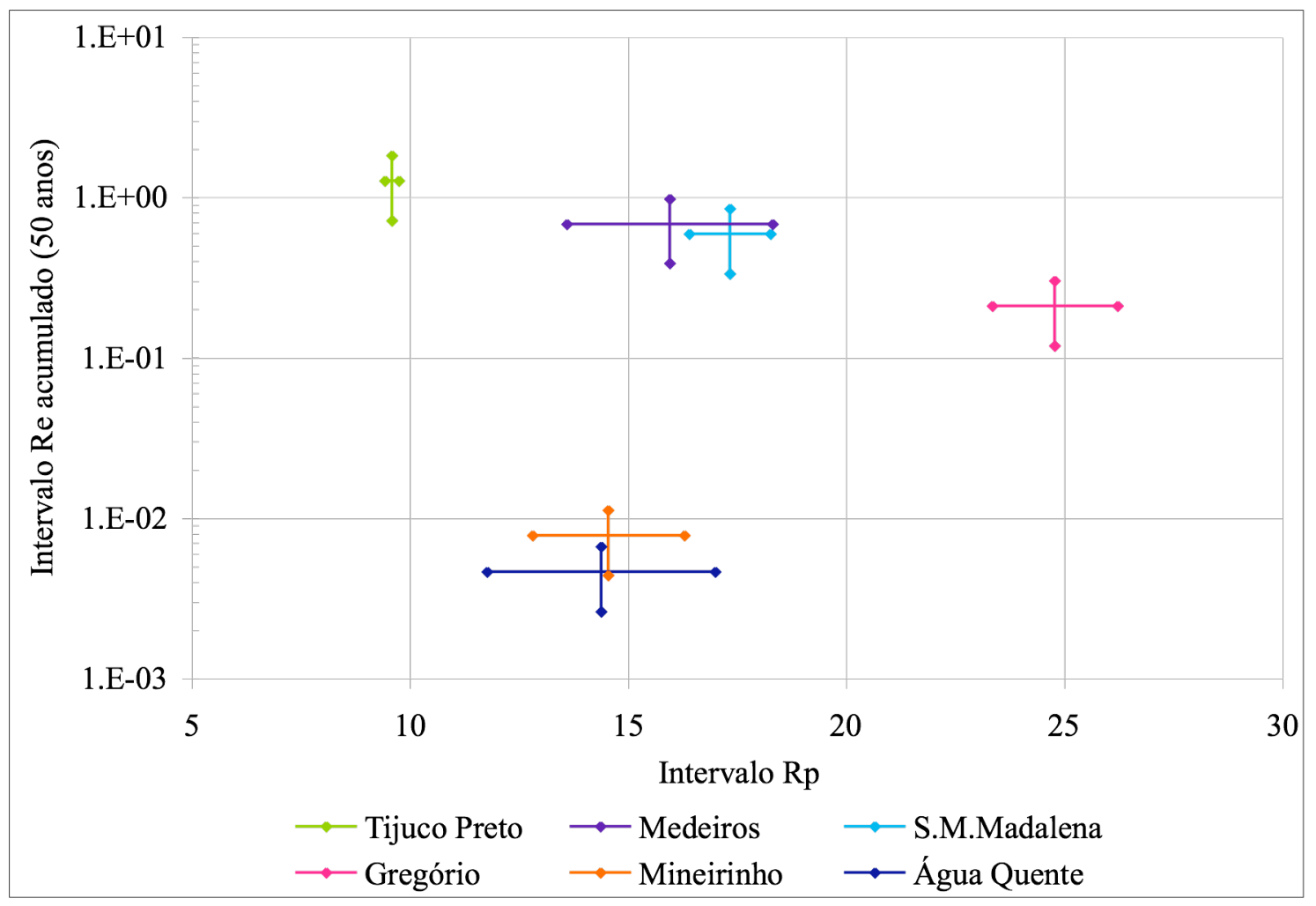

Figura 5.21 - Comparação entre intervalos de risco acumulado em 50 anos $\left(R_{E, 1, R e a(A c u m, 50)}-\right.$ $\left.R_{E, 1, P r o(A c u m, 50)}\right)$ e intervalos de risco percebido $\left(R_{P, 1}-R_{P, 2}\right)$ das sub-bacias.

Na Figura 5.22 associaram-se aos valores médios de $R_{P}$ e $R_{E, 1}$ a porcentagem de área impermeável das sub-bacias e suas densidades habitacionais (hab/ha). Como esperado, os maiores valores de risco estimado correspondem, com a exceção da bacia "Santa Maria Madalena", às sub-bacias com maiores valores de área impermeável e densidade habitacional, parâmetros que estão estreitamente relacionados. Por outro lado, o risco percebido não parece ter a mesma relação, evidenciando que para este risco as avaliações estiveram pouco ligadas 
com os fatores físicos da área considerada, o que justifica a discrepância de resultados em relação ao risco estimado.

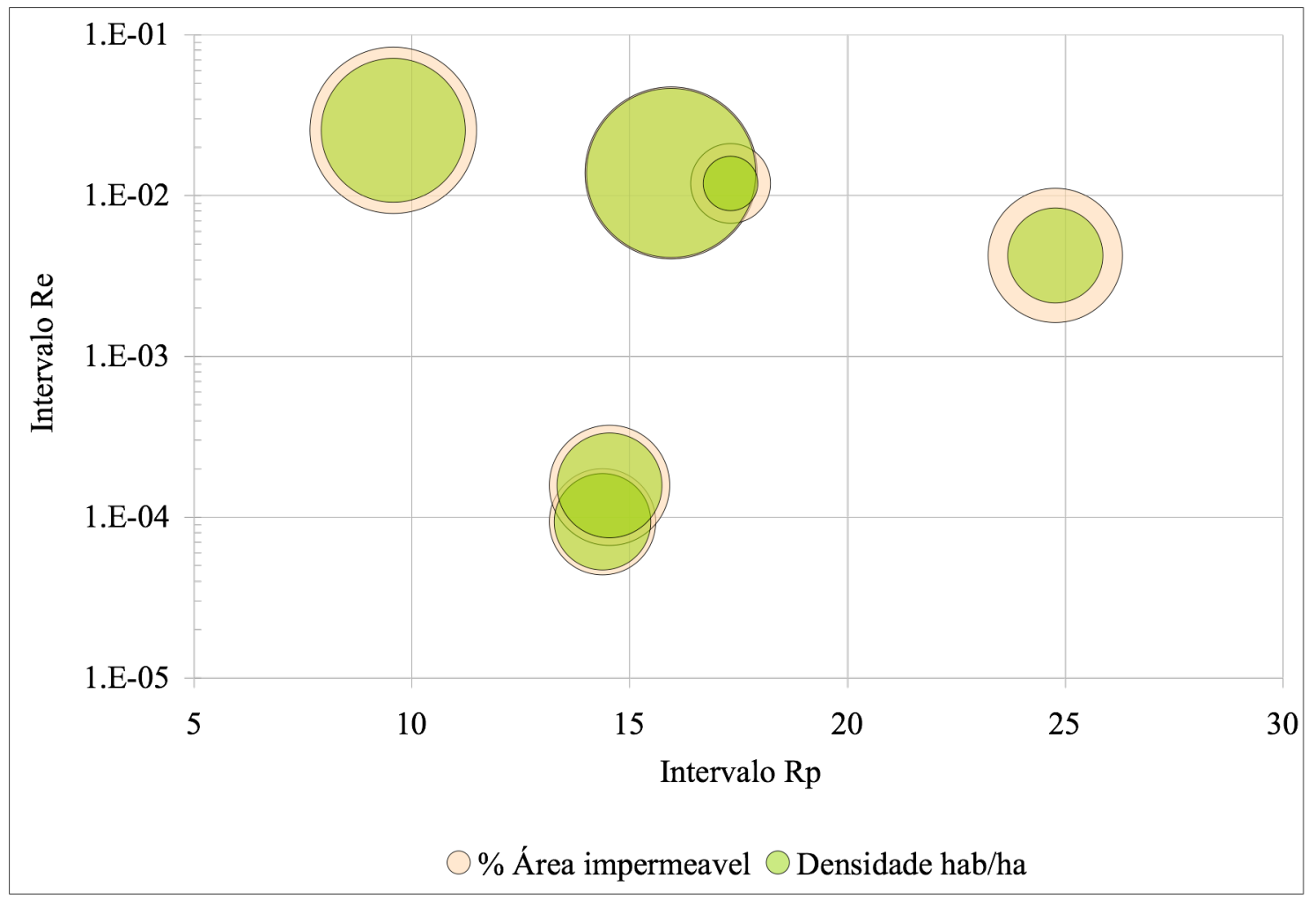

Figura 5.22 - Comparação entre as médias do risco médio $\left(R_{E, 1, R e a}-R_{E, 1, P r o}\right)$ e do risco percebido $\left(R_{P, 1}\right.$ $\left.-R_{P, 2}\right)$, associadas à porcentagem de área impermeável (\%) e à densidade habitacional (hab/ha) das sub-bacias. 


\section{CONCLUSÕES}

As Conclusões foram feitas com base nos objetivos traçados no capítulo 2.

Criar um sistema SIG integrado à internet que permita a participação dos usuários via web, visando a gestão descentralizada de risco de cheias e inundações

Entre os tipos de sistemas SIG integrados à internet encontrados na literatura e na web, optou-se pela implementação de um sistema que tivesse por base um mapa dinâmico Google Maps e ao mesmo tempo um sistema que pode-se chamar de "wiki geográfico" de coleta de dados. Desde o início o web-GIS foi concebido para um amplo público, o que requeria portanto facilidade de uso e entendimento. Deste modo, evitou-se propor no portal funcionalidades adicionais de análise espacial dos dados ou visualização de outros indicadores ambientais para não criar excesso de informação no site e deixá-lo o mais simples e amigável possível.

O portal demonstrou-se uma ferramenta consistente e eficaz podendo servir como meio de informação para a população e como subsídio para criação de mapas de inundação.

Estudar os aplicativos que compõem um sistema de informações geográficas baseado na internet (web-GIS)

A partir do momento em que o domínio esteve disponível online foi obtida uma chave Google para embutir o mapa dinâmico na home page e, em seguida, desenvolveu-se o sistema para coleta de dados por meio da linguagem Javascript e PHP suportados pelas livrarias AJAX.

A base de dados online, criada para armazenar os dados recolhidos dos usuários, mostrou-se útil para gerenciar todo dado disponibilizado no mapa dinâmico e também para efetuar exportações dos dados que podem ser aproveitados e analisados em planilhas de cálculo ou em SIG tradicionais (como ArcGIS ou Spring). 
Por meio do web-GIS foi possível mapear o risco segundo as três categorias escolhidas (ameaça, exposição e vulnerabilidade) de maneira eficaz. Porém para se fazer análises quantitativas e espaciais este recurso é limitado e necessita do suporte de um SIG tradicional. A escolha foi feita após a tentativa de se utilizar sistemas web-GIS simples e complexos na web e constatar-se que quanto mais difícil e lenta a navegação, menor o número de usuários que utilizariam este recurso.

Cabe observar que em um sistema desse tipo as contribuições dos usuários podem ser obtidas só por quem tem acesso à web, o que torna este recurso universalmente alcançável, porém limitado no que diz respeito à coleta de informações.

Mapear elementos de risco de inundações percebidos por usuários residentes em sub-bacias da cidade de São Carlos no portal web-GIS de maneira amigável

O portal web-GIS foi programado para funcionar de maneira online. Porém, deve-se salientar que os dados de percepção de risco foram obtidos por meio de entrevistas à população. Isto foi necessário para poder alimentar o site, nas fases de construção e aprimoramento.

Foi desafiador propor um roteiro com questões facilmente entendíveis sobre a percepção do risco de inundação. Freqüentemente se confundem no entender coletivo, os significados de enchentes e alagamentos - problemas de micro-drenagem urbana - com inundações que ocorrem trazendo efeitos mais graves e com freqüência de natureza mais aleatória. No roteiro de entrevistas proposto evidenciaram-se algumas dificuldades de formulação das perguntas e das categorias de respostas. Ressalta-se que para as entrevistas propostas não se realizou uma fase de teste (roteiro de entrevista piloto), a qual provavelmente minimizaria problemas acerca do entendimento das questões e dos conceitos, bem como formulação das respostas. A adaptação das perguntas aos parâmetros de ameaça, 
exposição e vulnerabilidade (componentes do triângulo do risco) foi também uma tarefa complexa.

As entrevistas foram referenciadas segundo o endereço dos entrevistados e armazenadas em uma base de dados off-line. Uma vez processadas estas foram disponibilizadas no web-GIS passando por uma importação dos dados pelo MySQL, tornando assim os dados visíveis no mapa como se cada usuário tivesse avaliado o risco de maneira online.

Deste modo obtiveram-se avaliações de risco de moradores que não usam normalmente internet e que talvez não tivessem chegado a usar o sistema se ele estivesse disponível online.

Estimar indicadores quantitativos de risco de inundação para cenários de longo prazo

A estimativa do risco de inundação por meio de indicadores ambientais oferece uma alternativa para avaliar o risco em áreas urbanas. É importante que as bacias consideradas a sejam de tamanho equiparável. Há diversos índices passíveis de serem assumidos partindo de hipóteses feitas por quem processa a avaliação.

A expressão do risco de inundação aplicada para um período de 50 anos necessitou, para alguns índices, da formulação de hipóteses diferentes segundo o cenário considerado (reativo e pró-ativo). Os resultados podem ser visualizados ao longo do tempo em gráfico ou também sob forma de valor de risco médio e acumulado considerando o prazo total do cenário. $\mathrm{O}$ valor de risco médio foi proposto devido à forte variação do termo ligado ao tempo de retorno da inundação que seguia uma função aleatória, ao passo que o valor de risco acumulado exprime uma idéia quantitativa no total do período considerado. Os dois valores demonstraram-se eficazes na individualização das sub-bacias com maior risco de inundação, porém não consideram o lugar de ocupação da bacia. No caso da bacia ser muito urbanizada 
na parte a montante os resultados são influenciados de maneira tendenciosa, pois são as áreas a jusante que são mais freqüentemente atingidas por fenômenos de inundação.

Um dos aspectos positivos na utilização desta ferramenta é o de poder auxiliar no planejamento e na formulação de projeções futuras em ambiente urbano por meio de cenários.

O limite da expressão se encontra na avaliação do risco que se obtém univocamente para uma sub-bacia sem que nesta possa se observar uma variação espacial. Além disso, por ser uma expressão nova, não passou ainda por ajustes necessários para adquirir uma certa confiança de resultados.

\section{$\underline{\text { Relacionar o risco percebido por usuários com o obtido por meio da expressão quantitativa }}$}

A coleta de dados de usuários a partir de um web-GIS representa uma ferramenta eficaz para mapear parâmetros ambientais e, quanto mais alto o número de participantes, melhor a representação espacial. O mapeamento permite a individualização de pontos críticos em uma área urbana.

A comparação dos dados de percepção do usuários com os resultados obtidos pela expressão de indicadores mostrou que os dois riscos seguem um comportamento similar apenas na metade das sub-bacias em estudo.

Após uma analise dos resultados pode-se afirmar que a relação que se esperava ter entre risco estimado e percebido não se concretizou, não podendo utilizar um dos riscos como forma de validação do outro.

É necessário realizar estudos com maior disponibilidade de dados que aprimorem a avaliação do risco percebido e se concentrem na relação deste com estimativas quantitativas de risco. 


\section{RECOMENDAÇÕES}

Sistemas web-GIS representam ferramentas adequadas para órgãos públicos que visem à colaboração de cidadãos para o monitoramento do meio ambiente e que encorajem a criação de redes de solidariedade social. Acredita-se que um web-GIS requer, para quem o fornece, a utilização em paralelo de um SIG, onde se podem processar os dados.

Sugere-se cautela na divulgação dos dados fornecidos nos web-GIS online, pois podem entrar em jogo questões ligadas à privacidade do usuário que fez a avaliação ou aos interesses econômicos de uma região que podem ser comprometidos pelo mapeamento resultante das avaliações. A título de exemplo pode-se citar o mapeamento online de locais atingidos por enchentes, o qual teria o potencial de depreciar o valor de imóveis localizados nas áreas onde as avaliações são mais densas, além de explicitar ao público a localização das vítimas.

Para trabalhos futuros de web-GIS participativos aplicados à recursos hídricos e gestão de risco de inundação recomenda-se criar um layer que indique os bairros da cidade e/ou uma ferramenta de localização de endereço visando criar um portal amigável para o usuário. Estas ferramentas poderiam ser utilizadas paralelamente à exibição do layer de sub-bacias (criado neste trabalho) que constituem unidades de difícil determinação da localização pelo usuário.

Recomenda-se maior atenção na formulação de roteiros de entrevistas à população, o que minimizará a obtenção de dados tendenciosos. Além disso, sugere-se na fase anterior à realização das entrevistas um aprofundamento em pesquisas metodológicas com aplicação de um roteiro piloto de entrevistas.

Ressalta-se a dificuldade na avaliação da vulnerabilidade, pois trata-se de um conceito amplo e de complexa quantificação por ser ligado não somente ao território, mas também às condições físicas dos habitantes e à preparação destes para enfrentar uma emergência. 
No cálculo da expressão do risco foram feitas algumas considerações que não puderam contar com o apoio de outros estudos realizados, portanto acredita-se que a estimativa de alguns parâmetros deve ser revista para seu aprimoramento. Em relação à expressão do risco outras variáveis poderiam ser contabilizadas, tais quais: a condição das margens dos rios (se ele esta canalizado ou é natural e se há presença de mata ciliar) e o nível de assoreamento.

A expressão do risco representa um ótimo recurso para avaliar quais sub-bacias apresentam prioridades de intervenção para redução do risco. Assim, associando a estimativa do risco com custos por unidade de risco ao longo do tempo (cenários futuros), cria-se uma ferramenta que os órgãos públicos/gestores podem utilizar na definição das áreas prioritárias de investimento para redução do risco.

As duas ferramentas propostas podem integrar um sistema de gerenciamento de risco de inundação e podem complementar outros componentes, entre os quais, modelos quantitativos de previsão para alerta antecipado - como o mostrado por Andrade (2007) - ou sistemas de redes de sensores (Sensor Webs) localizados em pontos adequadamente escolhidos nas sub-bacia, que aprimorariam o tempo de alerta à população, parâmetro fundamental para minimizar os danos sociais e econômicos em caso de ocorrência de inundações.

A informação e o preparo da população para enfrentar os desastres naturais precisam ser acompanhados por políticas públicas de longo prazo e por investimentos econômicos que as implementem. Além disto, é importante que os atores envolvidos na gestão do risco de inundação (Defesa Civil, Corpo de Bombeiros, Prefeitura, Universidades, Centros de pesquisa, Comitês de bacia, sociedade civil entre outros) mantenham um diálogo contínuo para garantir e mediar os interesses de todos na gestão do risco. 


\section{REFERÊNCIAS BIBLIOGRÁFICAS}

Ahmad, S.; Simonovic, S. P. (2001) Modeling Human Behavior for Evacuation Planning: A System Dynamics Approach. In: World Water and Environmental Resources Congress 2001, Orlando, USA. Anais. Bridging the Gap: Meeting the World's Water and Environmental Resources Challenges.

Almeida, C.N. (2006) Modelagem integrada de recursos hídricos com apoio de um sistema de informações geográficas. Dissertação de Doutorado - EESC / USP, São Carlos - SP.

Al-Sabhan, W.; Mulligan, M.; Blackburn, G. A. (2003) A real-time hydrological model for flood prediction using GIS and the www. Computers, Environment and Urban Systems v. 27, pp. 9-32.

Andrade, J. P. (2006) Previsão hidrometeorológica visando a sistema de alerta antecipado de cheias em bacias urbanas. Dissertação de Mestrado - EESC / USP, São Carlos - SP.

Baptista, M.; Nascimento, N.; Barraud, S. (2005) Técnicas compensatórias em drenagem urbana. Associação Brasileira de Recursos Hídricos Porto Alegre, 266 p.

Barroca, B.; Bernardara, P.; Mouchel, J. M.; Hubert, G. (2006) Indicators for identification of urban flooding vulnerability. Natural Hazards Earth System Sciences 6, 553-561.

Becchi, I. (2001) Essere informati: La migliore arma contro le alluvioni. Interviste RAICittadino, Teche RAI, Roma, Itália.

Becchi, L. e Cappugi, A. (2007) Ka-Map Una moderna interfaccia per il Web Mapping. VIII Meeting degli utenti italiani di Grass \& GFOSS, Università di Palermo, Itália.

Benkler, Y. (2006) The wealth of networks: how social production transforms markets and freedom - chapter 3 Peer Production and Sharing. Yale University Press, New Haven and London.

Bleeker, J. (2005) A Design Approach for the Geospatial Web. O'Reilly Network, O'Reilly Media, Inc.

Comissão Européia [Commission of the European Communities] (2006) Commission staff working document, annex to the Proposal for a Directive of the European Parliament and of the Council on the assessment and management of floods. SEC(2006) 66, Bruxelles, $29 \mathrm{p}$.

Crichton, D.; Mounsey, C. (1997) How the Insurance Industry will use its flood research. Proceedings of the Third MAFF Conference of Coastal and River Engineers. 131-134.

Devore, J.L. (2004) Probability and Statistics for Engineering and Sciences. Brooks/Cole.

Esteves, R. (2003) Relatório PIBIC/CNPq - EESC/USP, São Carlos, SP. Disponível no site: http://www.shs.eesc.usp.br/laboratorios/hidraulica/

Garrett, J.J. (2000) The elements of user experience - User-centered design for the web. AIGA, News Riders.

Garrett, J.J. (2005) Ajax: A New Appoach to Web Applications. Adaptive Path Publications, Adaptive Path, LLC. 
Gouveia, C.; Fonseca, A.; Câmara, A.; Ferreira F. (2004) Promoting the use of environmental data collected by concerned citizens through information and communication technologies. Journal of Environmental Management 71, 135-154.

Gwilliam, J.; Fedeski, M.; Lindley, S.; Theuray, N.; Handley, J. (2006) Methods for assessing risk from climate hazards in urban areas. Municipal Engineer 159, 245-255.

Hansen, H. S. e Prosperi, D.C. (2005) Citizen participation and Internet GIS - Some recent advances. Computers, Environment and Urban Systems 29, 617-629.

Hockenberry, M.; Gens, R.; Selker, T. (2005) User Centered Mapping: Theoretical and Practical Framework for Spatially Aware Applications. MIT.

Kobyama, M. 2006. Prevenção de desastres naturais - Conceitos básicos. Editora Organic Trading.

Marcelino, E. V. (2007) Desastres Naturais e Geotecnologias: Conceitos Básicos. INPE, Santa Maria -SC.

Mays, L. (2001) Water resources Engineering - chapter 14 Flood Control. Wiley and Sons, New York.

Mendiondo, E.M. (2005). Flood risk management of urban waters in humid tropics: early warning, protection and rehabilitation. Workshop on Integrated Urban Water Management in Humid Tropics, UNESCO IHP-VI, 04-2005, Foz do Iguaçu, Brasil.

Mendiondo, E.M.; Döll, P. (2006). Integrated dialogue under long-term perspectives as the basis for adaptive water management: A protocol of extended sustainability. IAP Water Programme Regional Workshop for the Americas, Brazil

Mendiondo, E.M. (2008) Reducing vulnerability to disasters in urban areas of humid tropics, In: J Goldenfum et al (eds) "Urban water management in humid tropics", UNESCO, Paris (accepted, under revision).

Menegon, S.; Neteler, M.; Furnalello, C.; Fontanari, S. (2004) Open Source GIS/WebGIS nella Amministrazione Pubblica. ITC-irst, Università di Trento, Italy.

Miller, C.C. (2006) A Beast in the Field: The Google Maps Mashup as GIS/2. Cartographica: The International Journal for Geographic Information and Geovisualization v. 41, n. 3, 187199

Morville, P. (2005) Ambient findability - What we find changes who we become. O'Reilly Media, Inc.

Müller, M.; Vorogushyn, S.; Maier, P.; Thieken, A.H.; Petrow, T.; Kron, A.; Buchele, B.; Wachter, J. (2006) CEDIM Risk Explorer - A map server solution in the project "Risk Map Germany". Natural Hazards and Earth System Sciences 6, 711-720.

Negretti, M. (2007) Tutorial MapServer: Introduzione a MapServer. VIII Meeting degli utenti italiani di Grass \& GFOSS, Università di Palermo, Italy.

Penning-Rowsell, E.; Floyd, P.; Ramsbottom, D.; Surendran, S. (2005) Estimating Injury and Loss of Life in Floods: A Deterministic Framework. Natural Hazards 36, 43-64. 
O'Reilly, T. (2005) What is Web 2.0, Design Patterns and Business Models for the next Generation of Software. O'Reilly Network, O'Reilly Media, Inc.

Purvis, M.; Sambells, J.; Turner, C.; (2006) Beginning Google Maps Applications with PHP and Ajax: From Novice to Professional. Apress

Priest, S.J. (2003) Responding to flood risk in the United Kingdom: a strategic reappraisal. Ph.D Thesis. Department of Geography, University of Southampton.

Reid, W.V.; Mooney, H.A. et al. (2005) Millennium Ecosystem Assessment. Ecosystems and Human Well-Being: Synthesis. Island Press, Washington, DC, USA. (p. 14-15).

Rossignol, L. (2008) Les Internautes allemands invites à enrichir la mémoire collective. Le Monde n. 19592, ano 64 (18-01-08). Paris, France.

Shaw, W.J.; Rishel, J.P.; Wang, W.; Xie, Y.; Rutz, F.C.; Seiple, T.E.; Chapman, E.G.; Allwine, K.J. (2007) Meteorological Integration for the Biological Warning and Incident Characterization (BWIC) System: General Guidance for BWIC Cities - February 2007 report. PNNL-16422. US Department of Homeland Security / Pacific Northwest National Laboratory. Seattle, USA.

Siegrist, M. e Gutscher, H. (2006) Flooding Risks: A Comparison of Lay People's Perceptions and Expert's Assessments in Switzerland. Progress in Planning 64, 7-62.

The Economist (2007) The world on your desktop. In: Science Technology Quarterly. The Economist 06/09/2007.

Tomaz, P. (2002) Cálculos hidrológicos e hidráulicos para obras municipais. Navegar Editora São Paulo. 475 p.

Treby, E.J.; Clark, M.J.; Priest, S.J. (2006) Confronting flood risk: Implications for insurance and risk transfer. Journal of Environmental Management 81, 351-359.

Tucci, C.E.M.; Porto, R.L.L.; Barros, M.T. (1995) Drenagem urbana. Editora UFRGS Porto Alegre. $428 \mathrm{p}$.

Tucci, C.E.M. (1998) Modelos hidrológicos. Editora da UFRGS, Porto Alegre.

Turner, B.L.; Kasperson, R.E.; Matson, P.A; McCarthy, J.J.; Correll, R.W.; Chriestensen, L.; Eckley, N.; Kasperson, J.X.; Luers, A; Martello, M.L.; Polsky, C.; Pulsipher, A.; Schiller, A. (2003) A Framework for vulnerability analysis in sustainability science. Proceedings of the National Acad Sciences USA. 100, 8074-8079.

United Nations World Water Assessment Programme (2006) Water, a shared responsibility Chapter 10: Managing Risks: Securing the Gains of Development. The United Nations World Water Development Report 2, UNESCO Publishing / Berghahn Books, New York, USA.

Werritty, A.; Houston, D.; Ball, T.; Tavendale, A.; Black, A. (2007) Exploring the social impacts of flood risk and flooding in Scotland. In: Scotting Executive Social Research. Blackwell Edimburgh, Scotland 157 p. 


\section{ANEXOS}

\section{ANEXO 1. Rotina do portal web-GIS para inserção de dados online}

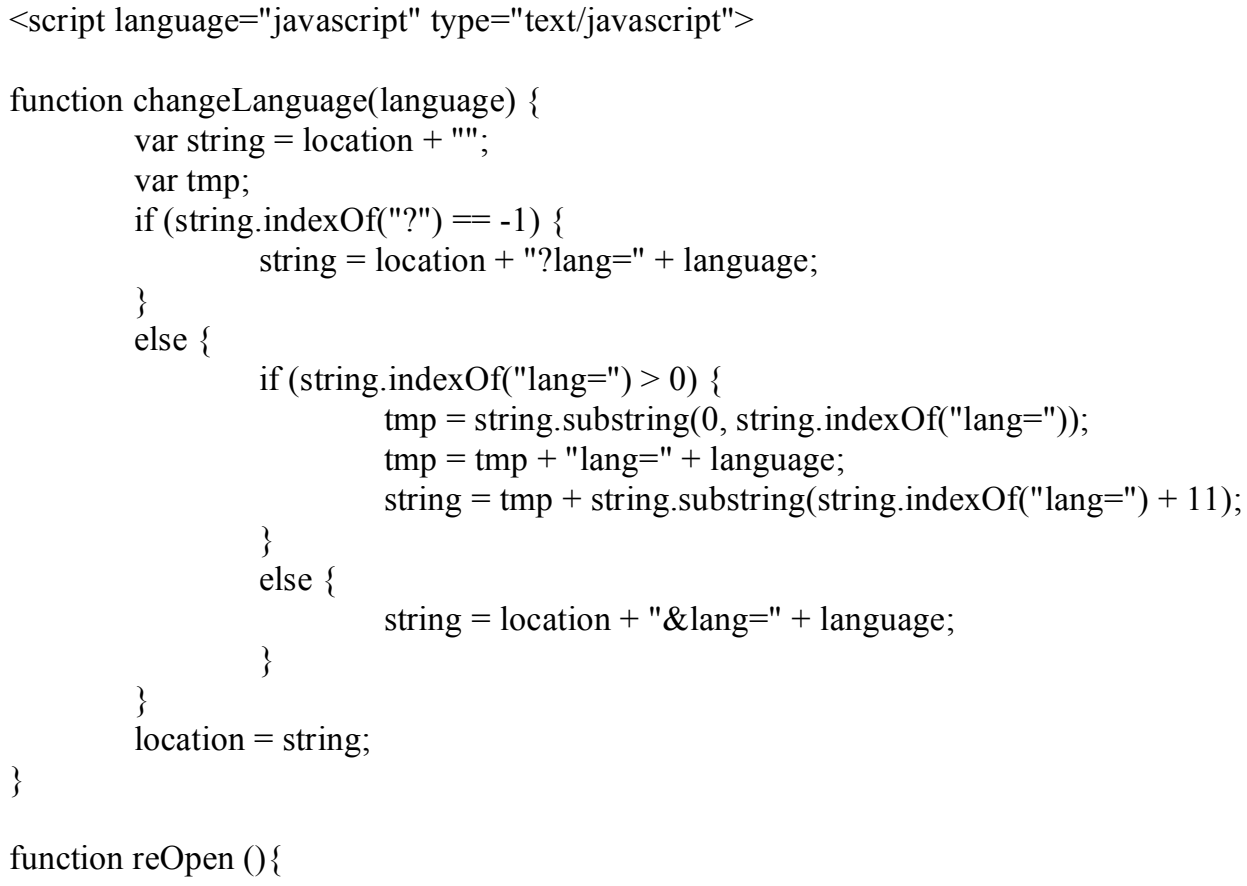




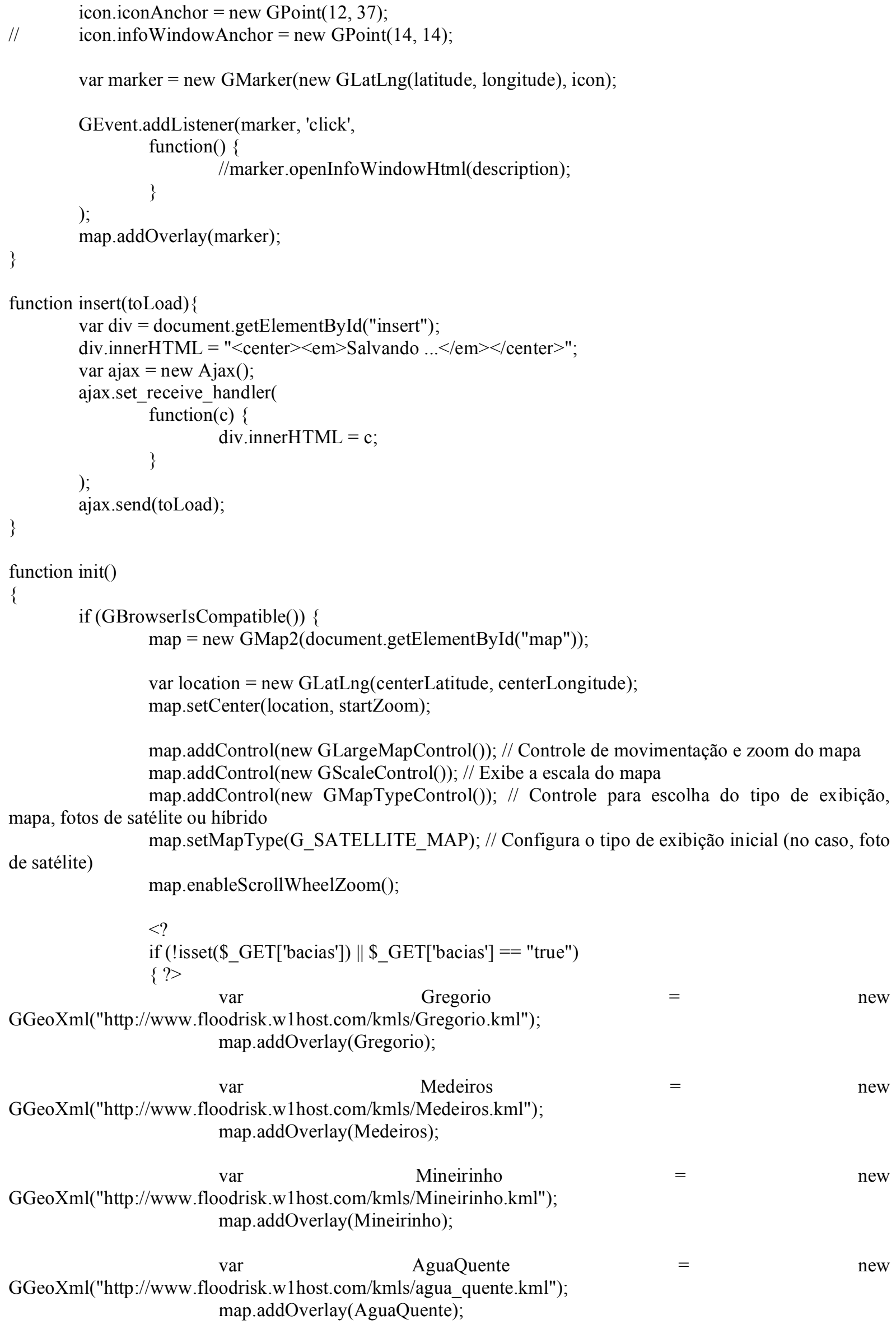

GGeoXml("http://www.floodrisk.w1host.com/kmls/Mineirinho.kml"); map.addOverlay(Mineirinho); 
GGeoXml("http://www.floodrisk.w1host.com/kmls/Tijuco_Preto.kml");

map.addOverlay(TijucoPreto);

var

SMMadalena

new

GGeoXml("http://www.floodrisk.w1host.com/kmls/Santa_Maria_Madalena.kml");

$<?$

map.addOverlay(SMMadalena);

\}

\$conId = mysq1_connect("localhost", "floodrsk_nibh", "123mudar");

mysql_select_db("floodrsk_floodrisk", \$conId);

if (isset(\$_GET['indicador']))

\$indicador $=$ \$_GET['indicador'];

else

\$indicador = "ameaca";

\$result $=$ mysql query("SELECT longitude, latitude, ".\$indicador." AS indicador FROM

risks", \$conId);

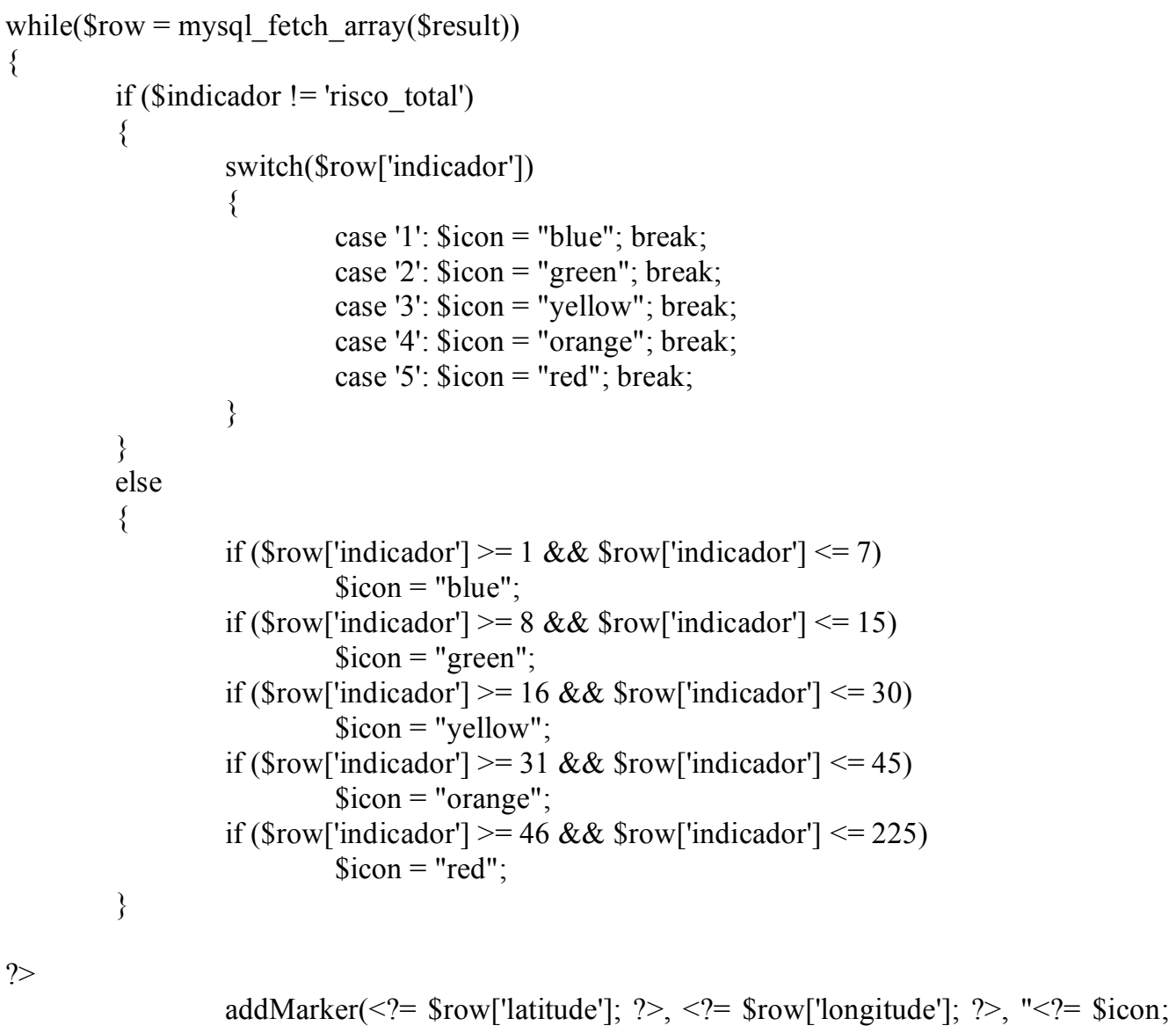

GEvent.addListener(map, "click", function(overlay, latlng) \{

var marker = new GMarker(latlng)

map.addOverlay(marker); 


$$
\begin{aligned}
& \text { var lng = latlng.lng(); } \\
& \text { var lat = latlng.lat(); } \\
& \text { alert("Longitude: " + } \operatorname{lng}+\text { " - Latitude: " + lat); }
\end{aligned}
$$

//create an HTML DOM form element var inputForm = document.createElement("form"); inputForm.setAttribute("action","');

$\{$ insert('action.php?lng='+document.getElementById('longitude').value+'\&lat='+document.getElementById('latit ude').value+'\&ameaca='+document.getElementById('ameaca').value+'\&exposicao='+document.getElementById( 'exposicao').value+'\&vulnerabilidade='+document.getElementById('vulnerabilidade').value); return true; \};

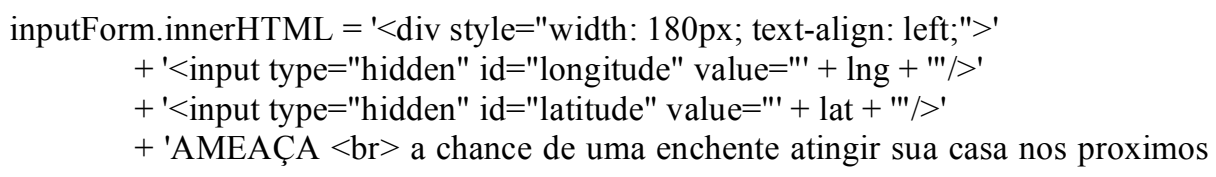

5 anos è:'

alagam frequentemente?'

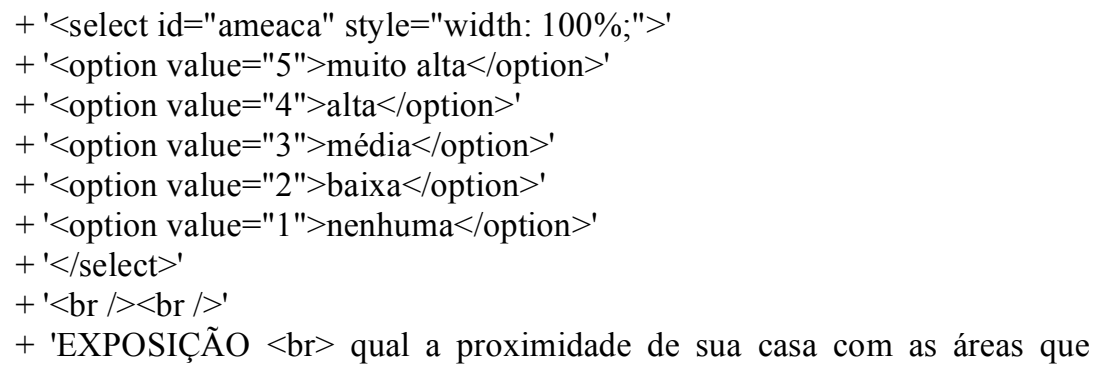

+ '<select id="exposicao" style="width: 100\%;">'

$+{ }^{\prime}<$ option value $=" 5$ " $>$ muito próximo $<$ option $>$ '

$+{ }^{\prime}<$ option value $=$ " 4 " $>$ proximo $</$ option $>$ '

$+{ }^{\prime}<$ option value $=" 3 ">$ longe $</$ option $>$ '

+ '<option value $=" 2 ">$ bem longe $</$ option $>$ '

+ '<option value $=" 1$ " $>$ extremamente longe $</$ option $>$ '

$+{ }^{\prime}<$ select $>$ '

$+'<$ br $/><$ br $/>$ '

+ 'VULNERABILIDADE <br $>$ com que frequencia se preocupa com enchentes ou alagamentos em épocas de chuva?'

$$
\begin{aligned}
& + \text { '<select id="vulnerabilidade" style="width: } 100 \% \text {;">' } \\
& + \text { '<option value }=" 5 ">\text { sempre }</ \text { option }>\text { ' } \\
& + \text { ' }<\text { option value }=\text { "4" }>\text { quase sempre }</ \text { option }>\text { ' } \\
& + \text { '<option value }=\text { " } 3 \text { " }>\text { as vezes }</ \text { option }>\text { ' } \\
& + \text { ' }<\text { option value }=\text { "2" }>\text { raramente }</ \text { option }>\text { ' } \\
& + \text { '<option value }=" 1 ">\text { nunca }</ \text { option }>\text { ' } \\
& +{ }^{\prime}<\text { /select }>\text { ' } \\
& +{ }^{\prime}<\mathrm{br} /><\mathrm{br} />\text { ' } \\
& + \text { '<input type="submit" value="Salvar" }>\text { ' } \\
& + \text { '</div }>\text { '; }
\end{aligned}
$$

\});

map.openInfoWindow (latlng,inputForm);

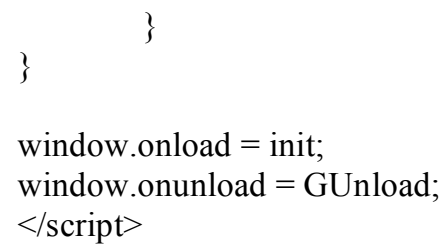




\section{ANEXO 2. Estrutura do Banco de Dados MySQL}

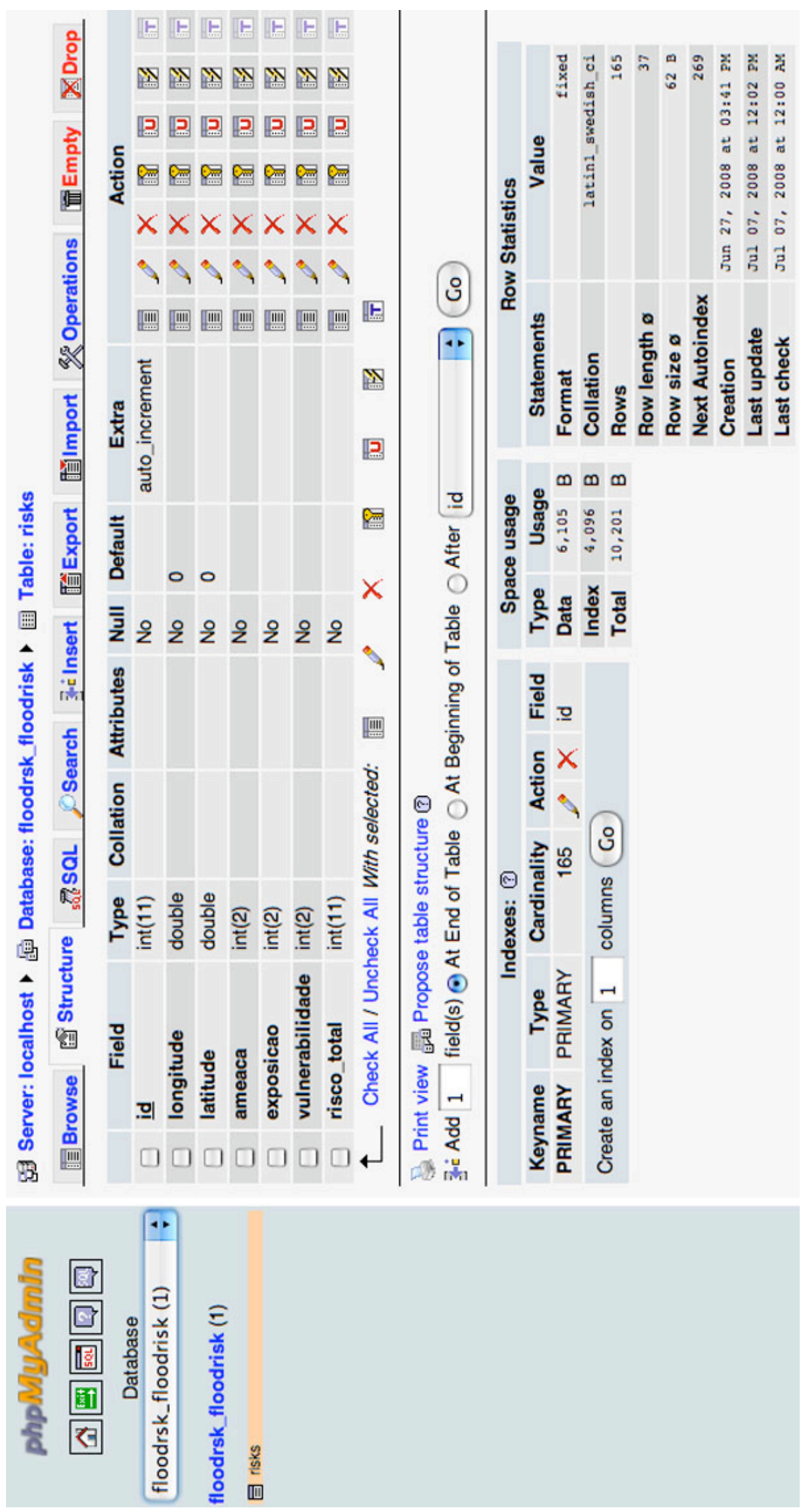


ANEXO 3. Visualização das entradas dos usuários no Banco de Dados

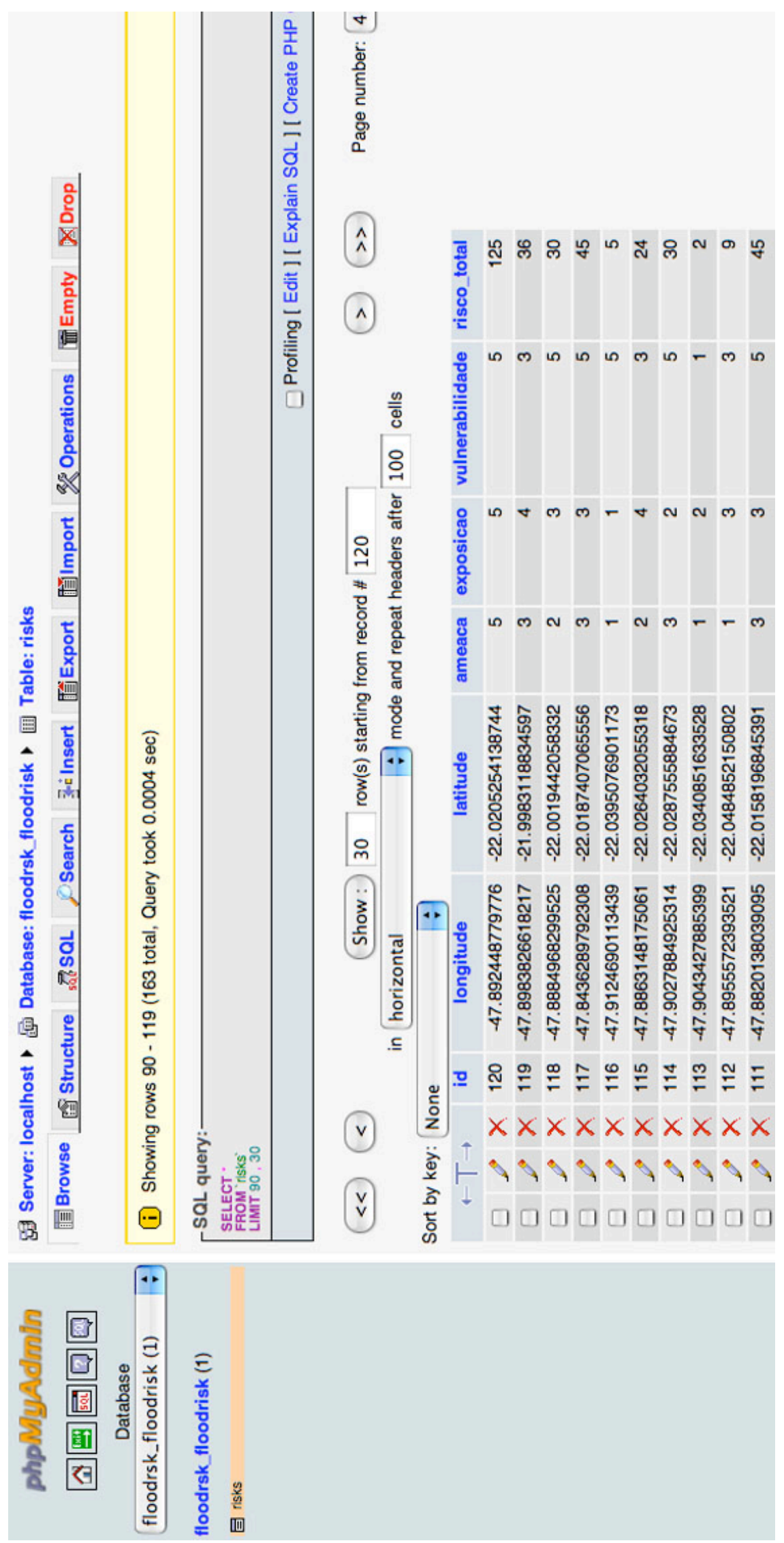




\section{ANEXO 4. Entrevistas para coleta de dados de risco percebido}

\begin{tabular}{|c|c|c|c|c|c|c|c|c|c|}
\hline codigo & data & n. $\quad$ sexo & idade & ameaça & exposição & vulnerab (1) & vulnerab (2) & flooded & subBacia \\
\hline $101-1512$ & $15 / 12 / 07$ & $1 \mathrm{M}$ & 65_99 & 3 & 3 & 3 & 4 & No & Gregorio \\
\hline $102-1512$ & $15 / 12 / 07$ & $2 M$ & $10 \_65$ & 2 & 5 & 5 & 5 & No & Gregorio \\
\hline I03-1512 & $15 / 12 / 07$ & $3 \mathrm{~F}$ & $10 \_65$ & 2 & 1 & 4 & 4 & No & Agua Quente \\
\hline 104-1512 & $15 / 12 / 07$ & $4 \mathrm{M}$ & $10-65$ & 4 & 5 & 5 & 2 & $\mathrm{SI}$ & Gregorio \\
\hline $105-1512$ & $15 / 12 / 07$ & $5 \mathrm{M}$ & $10 \_65$ & 5 & 2 & 4 & 4 & No & Gregorio \\
\hline $106-1512$ & $15 / 12 / 07$ & $6 \mathrm{~F}$ & $10 \_65$ & 4 & 4 & 3 & 2 & SI & S M Madalena \\
\hline $107-1512$ & $15 / 12 / 07$ & $7 \mathrm{M}$ & 6599 & 1 & 3 & 4 & 3 & No & Gregorio \\
\hline $108-1512$ & $15 / 12 / 07$ & $8 \mathrm{M}$ & $10-65$ & 1 & 3 & 1 & 3 & No & Mineirinho \\
\hline 109-1512 & $15 / 12 / 07$ & $9 \mathrm{~F}$ & $10 \_65$ & 1 & 1 & 3 & 2 & SI & Gregorio \\
\hline $\mid 10-1512$ & $15 / 12 / 07$ & $10 \mathrm{~F}$ & $10 \_65$ & 2 & 4 & 3 & 3 & No & Tijuco Preto \\
\hline $\mid 11-1512$ & $15 / 12 / 07$ & $11 \mathrm{~F}$ & $10-65$ & 3 & 3 & 5 & 4 & No & Gregorio \\
\hline |12-1512 & $15 / 12 / 07$ & $12 \mathrm{M}$ & $10 \_65$ & 1 & 3 & 3 & 4 & No & Agua Quente \\
\hline $113-1512$ & $15 / 12 / 07$ & $13 \mathrm{M}$ & 6599 & 1 & 2 & 1 & 4 & No & Medeiros \\
\hline |14-1512 & $15 / 12 / 07$ & $14 \mathrm{~F}$ & 65_99 & 3 & 2 & 5 & 5 & No & Medeiros \\
\hline I15-1512 & $15 / 12 / 07$ & $15 \mathrm{M}$ & $10 \_65$ & 2 & 4 & 3 & 2 & No & Gregorio \\
\hline |16-1512 & $15 / 12 / 07$ & $16 \mathrm{M}$ & $10 \_65$ & 1 & 1 & 5 & 4 & No & Agua Quente \\
\hline I17-1512 & $15 / 12 / 07$ & $17 \mathrm{~F}$ & $10-65$ & 3 & 3 & 5 & 4 & No & - \\
\hline |18-1512 & $15 / 12 / 07$ & $18 \mathrm{~F}$ & $10 \_65$ & 2 & 3 & 5 & 2 & No & Tijuco Preto \\
\hline 101-1912 & $19 / 12 / 07$ & $19 \mathrm{~F}$ & $10 \_65$ & 3 & 4 & 3 & 4 & No & S M Madalena \\
\hline D01-1512 & $15 / 12 / 07$ & $20 \mathrm{~F}$ & $10^{-} 65$ & 5 & 5 & 5 & 2 & $\mathrm{SI}$ & Gregorio \\
\hline D02-1512 & $15 / 12 / 07$ & $21 \mathrm{M}$ & $10-65$ & 5 & 5 & 2 & 1 & $\mathrm{SI}$ & Gregorio \\
\hline D03-1512 & $15 / 12 / 07$ & $22 \mathrm{~F}$ & $10 \_65$ & 5 & 5 & 5 & 2 & SI & Gregorio \\
\hline D04-1512 & $15 / 12 / 07$ & $23 \mathrm{~F}$ & 65_99 & 4 & 4 & 3 & 3 & No & Gregorio \\
\hline D05-1512 & $15 / 12 / 07$ & $24 \mathrm{~F}$ & $10-65$ & 3 & 5 & 1 & 1 & No & Gregorio \\
\hline D06-1512 & $15 / 12 / 07$ & $25 \mathrm{~F}$ & $10 \_65$ & 3 & 4 & 5 & 2 & No & Gregorio \\
\hline D07-1512 & $15 / 12 / 07$ & $26 \mathrm{M}$ & 10_65 & 2 & 4 & 5 & 1 & No & Gregorio \\
\hline D08-1512 & $15 / 12 / 07$ & $27 \mathrm{M}$ & $10-65$ & 2 & 4 & 5 & 2 & No & Gregorio \\
\hline D09-1512 & $15 / 12 / 07$ & $28 \mathrm{~F}$ & $10 \_65$ & 5 & 5 & 5 & 1 & SI & Gregorio \\
\hline D10-1512 & $15 / 12 / 07$ & $29 \mathrm{~F}$ & $10 \_65$ & 2 & 3 & 3 & 3 & No & Medeiros \\
\hline 101-2012 & $20 / 12 / 07$ & $30 \mathrm{~F}$ & $10 \_65$ & 1 & 2 & 5 & 4 & No & Tijuco Preto \\
\hline I02-2012 & $20 / 12 / 07$ & $31 \mathrm{~F}$ & $10 \_65$ & 1 & 3 & 1 & 2 & No & Tijuco Preto \\
\hline 103-2012 & $20 / 12 / 07$ & $32 \mathrm{~F}$ & $10 \_65$ & 3 & 2 & 5 & 4 & No & Mineirinho \\
\hline $101-2212$ & $22 / 12 / 07$ & $33 \mathrm{M}$ & $10-65$ & 2 & 3 & 3 & 4 & No & Gregorio \\
\hline $102-2212$ & $22 / 12 / 07$ & $34 \mathrm{M}$ & $10 \_65$ & 1 & 3 & 1 & 1 & No & - \\
\hline $103-2212$ & $22 / 12 / 07$ & $35 \mathrm{M}$ & $10 \_65$ & 1 & 2 & 2 & 3 & No & Gregorio \\
\hline 104-2212 & $22 / 12 / 07$ & $36 \mathrm{M}$ & $10 \_65$ & 1 & 2 & 5 & 3 & SI & Tijuco Preto \\
\hline $105-2212$ & $22 / 12 / 07$ & $37 \mathrm{M}$ & $10-65$ & 1 & 1 & 3 & 3 & No & Gregorio \\
\hline $106-2212$ & $22 / 12 / 07$ & $38 \mathrm{M}$ & 65_99 & 1 & 2 & 5 & 3 & No & Agua Quente \\
\hline $107-2212$ & $22 / 12 / 07$ & $39 \mathrm{~F}$ & 10_65 & 3 & 3 & 5 & 4 & No & Gregorio \\
\hline $108-2212$ & $22 / 12 / 07$ & $40 \mathrm{~F}$ & $10-65$ & 3 & 3 & 5 & 5 & No & Gregorio \\
\hline $109-2212$ & $22 / 12 / 07$ & $41 \mathrm{~F}$ & $10 \_65$ & 3 & 3 & 5 & 4 & No & Gregorio \\
\hline |110-2212 & $22 / 12 / 07$ & $42 \mathrm{~F}$ & $10 \_65$ & 3 & 3 & 1 & 5 & No & Gregorio \\
\hline $\mid 11-2212$ & $22 / 12 / 07$ & $43 \mathrm{M}$ & $10-65$ & 2 & 3 & 3 & 3 & No & - \\
\hline |12-2212 & $22 / 12 / 07$ & $44 \mathrm{~F}$ & $10 \_65$ & 3 & 4 & 3 & 3 & SI & - \\
\hline |13-2212 & $22 / 12 / 07$ & $45 \mathrm{~F}$ & $10 \_65$ & 4 & 3 & 5 & 4 & No & Gregorio \\
\hline I14-2212 & $22 / 12 / 07$ & $46 \mathrm{M}$ & 10_65 & 4 & 3 & 3 & 3 & No & Gregorio \\
\hline |15-2212 & $22 / 12 / 07$ & $47 \mathrm{M}$ & $10-65$ & 5 & 5 & 5 & 4 & $\mathrm{SI}$ & - \\
\hline |16-2212 & $22 / 12 / 07$ & $48 \mathrm{~F}$ & 65_99 & 2 & 1 & 3 & 2 & No & Tijuco Preto \\
\hline |17-2212 & $22 / 12 / 07$ & $49 \mathrm{~F}$ & $10 \_65$ & 1 & 3 & 4 & 5 & No & Gregorio \\
\hline |18-2212 & $22 / 12 / 07$ & $50 \mathrm{M}$ & $10-65$ & 2 & 1 & 1 & 2 & No & Tijuco Preto \\
\hline |19-2212 & $22 / 12 / 07$ & $51 \mathrm{M}$ & 65_99 & 1 & 2 & 2 & 3 & No & Gregorio \\
\hline I20-2212 & $22 / 12 / 07$ & $52 \mathrm{M}$ & 10_65 & 3 & 4 & 2 & 3 & SI & - \\
\hline I21-2212 & $22 / 12 / 07$ & $53 \mathrm{~F}$ & $10 \_65$ & 2 & 3 & 3 & 2 & No & Agua Quente \\
\hline 122-2212 & $22 / 12 / 07$ & $54 \mathrm{~F}$ & $10 \_65$ & 4 & 4 & 3 & 3 & SI & - \\
\hline 123-2212 & $22 / 12 / 07$ & $55 \mathrm{M}$ & 10_65 & 1 & 2 & 3 & 4 & No & Gregorio \\
\hline |24-2212 & $22 / 12 / 07$ & $56 \mathrm{M}$ & $10-65$ & 1 & 2 & 3 & 2 & No & - \\
\hline $125-2212$ & $22 / 12 / 07$ & $57 \mathrm{M}$ & $10 \_65$ & 2 & 5 & 5 & 1 & No & Gregorio \\
\hline |26-2212 & $22 / 12 / 07$ & $58 \mathrm{M}$ & 10_65 & 1 & 2 & 5 & 5 & SI & Gregorio \\
\hline $127-2212$ & $22 / 12 / 07$ & $59 \mathrm{~F}$ & 10_65 & 3 & 3 & 5 & 5 & SI & - \\
\hline I28-2212 & $22 / 12 / 07$ & $60 \mathrm{~F}$ & $10 \_65$ & 1 & 2 & 5 & 2 & No & S M Madalena \\
\hline $129-2212$ & $22 / 12 / 07$ & $61 \mathrm{M}$ & $10 \_65$ & 1 & 1 & 3 & 2 & No & Mineirinho \\
\hline $130-2212$ & $22 / 12 / 07$ & $62 \mathrm{M}$ & 10_65 & 3 & 4 & 3 & 2 & No & Gregorio \\
\hline $131-2212$ & $22 / 12 / 07$ & $63 \mathrm{~F}$ & $10-65$ & 3 & 3 & 3 & 2 & No & - \\
\hline |32-2212 & $22 / 12 / 07$ & $64 \mathrm{~F}$ & $10 \_65$ & 4 & 3 & 5 & 2 & No & Agua Quente \\
\hline |33-2212 & $22 / 12 / 07$ & $65 \mathrm{M}$ & 10_65 & 1 & 2 & 5 & 1 & No & Mineirinho \\
\hline D01-2212 & $22 / 12 / 07$ & $66 \mathrm{~F}$ & $10-65$ & 2 & 3 & 3 & 4 & No & Mineirinho \\
\hline D02-2212 & $22 / 12 / 07$ & $67 \mathrm{~F}$ & 65_99 & 2 & 3 & 5 & 2 & No & Gregorio \\
\hline D03-2212 & $22 / 12 / 07$ & $68 \mathrm{M}$ & 10_65 & 1 & 3 & 3 & 2 & SI & Agua Quente \\
\hline D04-2212 & $22 / 12 / 07$ & $69 \mathrm{~F}$ & $10 \_65$ & 1 & 2 & 5 & 1 & No & S M Madalena \\
\hline D05-2212 & $22 / 12 / 07$ & $70 \mathrm{~F}$ & $10-65$ & 3 & 4 & 3 & 4 & $\mathrm{SI}$ & Gregorio \\
\hline D06-2212 & $22 / 12 / 07$ & $71 \mathrm{~F}$ & $10 \_65$ & 2 & 3 & 3 & 1 & No & Medeiros \\
\hline D07-2212 & $22 / 12 / 07$ & $72 \mathrm{M}$ & 10_65 & 2 & 3 & 3 & 2 & No & - \\
\hline D08-2212 & $22 / 12 / 07$ & $73 \mathrm{~F}$ & $10 \_65$ & 1 & 3 & 1 & 3 & No & Gregorio \\
\hline D09-2212 & $22 / 12 / 07$ & $74 \mathrm{~F}$ & $10 \_65$ & 3 & 3 & 4 & 4 & SI & - \\
\hline D10-2212 & $22 / 12 / 07$ & $75 \mathrm{M}$ & 10_65 & 1 & 1 & 1 & 4 & SI & - \\
\hline D11-2212 & $22 / 12 / 07$ & $76 \mathrm{~F}$ & 65_99 & 1 & 1 & 1 & 3 & No & - \\
\hline D12-2212 & $22 / 12 / 07$ & $77 \mathrm{M}$ & $10 \_65$ & 1 & 2 & 5 & 3 & No & Tijuco Preto \\
\hline D13-2212 & $22 / 12 / 07$ & $78 \mathrm{~F}$ & 65_99 & 4 & 2 & 4 & 4 & SI & Gregorio \\
\hline D14-2212 & $22 / 12 / 07$ & $79 \mathrm{~F}$ & $10 \_65$ & 3 & 4 & 3 & 4 & No & - \\
\hline D15-2212 & $22 / 12 / 07$ & $80 \mathrm{M}$ & $10-65$ & 1 & 2 & 3 & 2 & No & Mineirinho \\
\hline
\end{tabular}




\begin{tabular}{|c|c|c|c|c|c|c|c|c|c|}
\hline codigo & data & n. $\quad$ sexo & idade & ameaça & exposição & vulnerab (1) & vulnerab (2) & flooded & subBacia \\
\hline D16-2212 & $22 / 12 / 07$ & $81 \mathrm{M}$ & 1065 & 2 & 3 & 5 & 3 & SI & Gregorio \\
\hline D17-2212 & $22 / 12 / 07$ & $82 \mathrm{~F}$ & $10-65$ & 2 & 3 & 1 & 2 & No & Agua Quente \\
\hline D18-2212 & $22 / 12 / 07$ & $83 \mathrm{~F}$ & $10 \_65$ & 4 & 4 & 5 & 2 & No & Medeiros \\
\hline D19-2212 & $22 / 12 / 07$ & $84 \mathrm{M}$ & $10^{-65}$ & 2 & 3 & 2 & 2 & No & S M Madalena \\
\hline D20-2212 & $22 / 12 / 07$ & $85 \mathrm{M}$ & $10 \_65$ & 1 & 1 & 3 & 1 & No & - \\
\hline D21-2212 & $22 / 12 / 07$ & $86 \mathrm{~F}$ & $10 \_65$ & 2 & 3 & 3 & 2 & No & Tijuco Preto \\
\hline D22-2212 & $22 / 12 / 07$ & $87 \mathrm{~F}$ & $10^{6} 65$ & 1 & 2 & 3 & 4 & $\mathrm{SI}$ & - \\
\hline D23-2212 & $22 / 12 / 07$ & $88 \mathrm{~F}$ & $10-65$ & 1 & 3 & 5 & 1 & SI & Agua Quente \\
\hline D24-2212 & $22 / 12 / 07$ & $89 \mathrm{~F}$ & $10 \_65$ & 3 & 3 & 3 & 3 & No & S M Madalena \\
\hline D25-2212 & $22 / 12 / 07$ & $90 \mathrm{~F}$ & $10 \_65$ & 2 & 3 & 2 & 2 & No & - \\
\hline D26-2212 & $22 / 12 / 07$ & $91 \mathrm{M}$ & 6599 & 1 & 3 & 2 & 2 & No & Gregorio \\
\hline D01-2001 & $20 / 01 / 08$ & $92 \mathrm{M}$ & $10-65$ & 1 & 2 & 1 & 2 & No & Medeiros \\
\hline D02-2001 & $20 / 01 / 08$ & $93 \mathrm{~F}$ & $10 \_65$ & 1 & 3 & 3 & 1 & No & Agua Quente \\
\hline D03-2001 & $20 / 01 / 08$ & $94 \mathrm{M}$ & $10-65$ & 1 & 2 & 2 & 2 & No & Gregorio \\
\hline D04-2001 & $20 / 01 / 08$ & $95 \mathrm{M}$ & $10-65$ & 1 & 2 & 1 & 2 & No & - \\
\hline D05-2001 & $20 / 01 / 08$ & $96 \mathrm{M}$ & $10 \_65$ & 1 & 4 & 1 & 4 & No & Gregorio \\
\hline D06-2001 & $20 / 01 / 08$ & $97 \mathrm{~F}$ & $10^{-65}$ & 2 & 3 & 2 & 4 & No & Gregorio \\
\hline D07-2001 & $20 / 01 / 08$ & $98 \mathrm{~F}$ & $10-65$ & 1 & 4 & 4 & 2 & $\mathrm{SI}$ & Gregorio \\
\hline D08-2001 & $20 / 01 / 08$ & $99 \mathrm{M}$ & $10 \_65$ & 2 & 3 & 1 & 2 & No & Tijuco Preto \\
\hline D09-2001 & $20 / 01 / 08$ & $100 \mathrm{~F}$ & $10^{6} 65$ & 1 & 3 & 3 & 3 & No & Gregorio \\
\hline D10-2001 & $20 / 01 / 08$ & $101 \mathrm{~F}$ & $10-65$ & 1 & 2 & 2 & 3 & No & - \\
\hline D11-2001 & $20 / 01 / 08$ & $102 \mathrm{~F}$ & $10 \_65$ & 1 & 4 & 3 & 3 & No & Tijuco Preto \\
\hline D12-2001 & $20 / 01 / 08$ & $103 \mathrm{~F}$ & $10 \_65$ & 1 & 2 & 1 & 1 & No & Tijuco Preto \\
\hline D13-2001 & $20 / 01 / 08$ & $104 \mathrm{M}$ & $10-65$ & 2 & 3 & 3 & 4 & No & - \\
\hline I01-2001 & $20 / 01 / 08$ & $105 \mathrm{~F}$ & 65_99 & 2 & 3 & 3 & 2 & No & Medeiros \\
\hline 102-2001 & $20 / 01 / 08$ & $106 \mathrm{M}$ & $10 \_65$ & 1 & 2 & 5 & 4 & No & Gregorio \\
\hline $103-2001$ & $20 / 01 / 08$ & $107 \mathrm{M}$ & $10-65$ & 1 & 3 & 2 & 2 & No & - \\
\hline 104-2001 & $20 / 01 / 08$ & $108 \mathrm{M}$ & $10-65$ & 1 & 3 & 5 & 4 & No & Gregorio \\
\hline I05-2001 & $20 / 01 / 08$ & $109 \mathrm{~F}$ & $10-65$ & 2 & 3 & 3 & 3 & No & S M Madalena \\
\hline $106-2001$ & $20 / 01 / 08$ & $110 \mathrm{~F}$ & 1065 & 3 & 5 & 5 & 4 & No & S M Madalena \\
\hline |07-2001 & $20 / 01 / 08$ & $111 \mathrm{~F}$ & $10-65$ & 1 & 3 & 4 & 4 & No & Gregorio \\
\hline 108-2001 & $20 / 01 / 08$ & $112 \mathrm{M}$ & 65_99 & 1 & 1 & 2 & 4 & No & S M Madalena \\
\hline 109-2001 & $20 / 01 / 08$ & $113 \mathrm{M}$ & 6599 & 2 & 3 & 3 & 3 & No & Agua Quente \\
\hline |10-2001 & $20 / 01 / 08$ & $114 \mathrm{M}$ & $10 \_65$ & 2 & 2 & 5 & 2 & No & - \\
\hline I11-2001 & $20 / 01 / 08$ & $115 \mathrm{~F}$ & $10 \_65$ & 1 & 3 & 4 & 5 & SI & Gregorio \\
\hline |12-2001 & $20 / 01 / 08$ & $116 \mathrm{M}$ & 65_99 & 1 & 3 & 1 & 5 & No & Gregorio \\
\hline |13-2001 & $20 / 01 / 08$ & $117 \mathrm{M}$ & 1065 & 1 & 2 & 1 & 3 & No & - \\
\hline I14-2001 & $20 / 01 / 08$ & $118 \mathrm{M}$ & 10_65 & 2 & 1 & 2 & 2 & No & Agua Quente \\
\hline $115-2001$ & $20 / 01 / 08$ & $119 \mathrm{~F}$ & 10_65 & 1 & 2 & 3 & 4 & $\mathrm{SI}$ & Tijuco Preto \\
\hline |16-2001 & $20 / 01 / 08$ & $120 \mathrm{~F}$ & $10-65$ & 2 & 3 & 1 & 2 & No & Tijuco Preto \\
\hline |17-2001 & $20 / 01 / 08$ & $121 \mathrm{M}$ & $10-65$ & 2 & 3 & 1 & 2 & No & S M Madalena \\
\hline |18-2001 & $20 / 01 / 08$ & $122 \mathrm{~F}$ & $10 \_65$ & 1 & 4 & 3 & 2 & No & Gregorio \\
\hline $101-2101$ & $21 / 01 / 08$ & $123 \mathrm{~F}$ & $10^{-} 65$ & 1 & 4 & 3 & 3 & No & S M Madalena \\
\hline 101-2501 & $25 / 01 / 08$ & $124 \mathrm{M}$ & $10-65$ & 1 & 2 & 3 & 4 & $\mathrm{SI}$ & Gregorio \\
\hline 102-2501 & $25 / 01 / 08$ & $125 \mathrm{~F}$ & $10-65$ & 1 & 2 & 4 & 5 & No & Tijuco Preto \\
\hline $103-2501$ & $25 / 01 / 08$ & $126 \mathrm{~F}$ & $10 \_65$ & 3 & 4 & 5 & 4 & $\mathrm{SI}$ & Gregorio \\
\hline 104-2501 & $25 / 01 / 08$ & $127 \mathrm{M}$ & $10-65$ & 3 & 3 & 3 & 2 & No & - \\
\hline 105-2501 & $25 / 01 / 08$ & $128 \mathrm{~F}$ & $10 \_65$ & 2 & 2 & 2 & 1 & No & Tijuco Preto \\
\hline $106-2501$ & $25 / 01 / 08$ & $129 \mathrm{~F}$ & $10^{-65}$ & 4 & 4 & 4 & 2 & No & Mineirinho \\
\hline 107-2501 & $25 / 01 / 08$ & $130 \mathrm{~F}$ & $10-65$ & 1 & 3 & 3 & 3 & No & Gregorio \\
\hline $108-2501$ & $25 / 01 / 08$ & $131 \mathrm{M}$ & $10 \_65$ & 2 & 3 & 5 & 2 & No & Medeiros \\
\hline 109-2501 & $25 / 01 / 08$ & $132 \mathrm{M}$ & $10 \_65$ & 4 & 5 & 2 & 4 & No & Gregorio \\
\hline I10-2501 & $25 / 01 / 08$ & $133 \mathrm{~F}$ & 10_65 & 2 & 2 & 2 & 3 & No & - \\
\hline |11-2501 & $25 / 01 / 08$ & $134 \mathrm{M}$ & $10-65$ & 2 & 3 & 5 & 4 & No & Gregorio \\
\hline |12-2501 & $25 / 01 / 08$ & $135 \mathrm{~F}$ & $10 \_65$ & 1 & 2 & 5 & 2 & SI & Medeiros \\
\hline I13-2501 & $25 / 01 / 08$ & $136 \mathrm{~F}$ & $10^{-} 65$ & 3 & 3 & 5 & 3 & No & Gregorio \\
\hline I14-2501 & $25 / 01 / 08$ & $137 \mathrm{M}$ & $10-65$ & 2 & 3 & 2 & 3 & No & - \\
\hline |15-2501 & $25 / 01 / 08$ & $138 \mathrm{~F}$ & $10 \_65$ & 2 & 2 & 3 & 2 & No & S M Madalena \\
\hline $116-2501$ & $25 / 01 / 08$ & $139 \mathrm{M}$ & 10_65 & 1 & 2 & 4 & 3 & No & - \\
\hline |17-2501 & $25 / 01 / 08$ & $140 \mathrm{~F}$ & $10-65$ & 3 & 4 & 3 & 2 & SI & Mineirinho \\
\hline |18-2501 & $25 / 01 / 08$ & $141 \mathrm{~F}$ & $10 \_65$ & 3 & 3 & 4 & 3 & $\mathrm{SI}$ & Agua Quente \\
\hline $119-2501$ & $25 / 01 / 08$ & $142 \mathrm{M}$ & 10_65 & 1 & 2 & 3 & 1 & No & Agua Quente \\
\hline |20-2501 & $25 / 01 / 08$ & $143 \mathrm{M}$ & $10^{-} 65$ & 1 & 2 & 5 & 2 & No & - \\
\hline |21-2501 & $25 / 01 / 08$ & $144 \mathrm{~F}$ & $10-65$ & 1 & 2 & 1 & 3 & No & Tijuco Preto \\
\hline |22-2501 & $25 / 01 / 08$ & $145 \mathrm{M}$ & $10 \_65$ & 2 & 4 & 5 & 4 & SI & Gregorio \\
\hline D01-2501 & $25 / 01 / 08$ & $146 \mathrm{M}$ & 10_65 & 2 & 2 & 1 & 3 & No & - \\
\hline D02-2501 & $25 / 01 / 08$ & $147 \mathrm{~F}$ & $10-65$ & 1 & 4 & 1 & 2 & No & Mineirinho \\
\hline D03-2501 & $25 / 01 / 08$ & $148 \mathrm{~F}$ & $10 \_65$ & 1 & 3 & 1 & 3 & No & Gregorio \\
\hline D04-2501 & $25 / 01 / 08$ & $149 \mathrm{~F}$ & $10^{6} 65$ & 2 & 2 & 1 & 3 & No & S M Madalena \\
\hline D05-2501 & $25 / 01 / 08$ & $150 \mathrm{~F}$ & $10-65$ & 1 & 3 & 1 & 2 & No & Tijuco Preto \\
\hline D06-2501 & $25 / 01 / 08$ & $151 \mathrm{~F}$ & $10 \_65$ & 1 & 4 & 1 & 2 & No & Tijuco Preto \\
\hline D07-2501 & $25 / 01 / 08$ & $152 \mathrm{M}$ & 10_65 & 2 & 2 & 3 & 3 & SI & Tijuco Preto \\
\hline D08-2501 & $25 / 01 / 08$ & $153 \mathrm{M}$ & $10-65$ & 1 & 4 & 1 & 3 & No & Tijuco Preto \\
\hline D09-2501 & $25 / 01 / 08$ & $154 \mathrm{~F}$ & 10_65 & 1 & 2 & 3 & 3 & No & Gregorio \\
\hline D10-2501 & $25 / 01 / 08$ & $155 \mathrm{~F}$ & $10 \_65$ & 2 & 3 & 5 & 3 & No & Tijuco Preto \\
\hline D11-2501 & $25 / 01 / 08$ & $156 \mathrm{M}$ & $10-65$ & 1 & 3 & 3 & 3 & No & Gregorio \\
\hline D12-2501 & $25 / 01 / 08$ & $157 \mathrm{~F}$ & $10-65$ & 2 & 2 & 1 & 4 & No & - \\
\hline D13-2501 & $25 / 01 / 08$ & $158 \mathrm{~F}$ & $10 \_65$ & 1 & 2 & 3 & 1 & No & Tijuco Preto \\
\hline D14-2501 & $25 / 01 / 08$ & $159 \mathrm{~F}$ & 10_65 & 2 & 2 & 2 & 2 & No & - \\
\hline D15-2501 & $25 / 01 / 08$ & $160 \mathrm{~F}$ & $10-65$ & 4 & 5 & 5 & 3 & No & - \\
\hline D16-2501 & $25 / 01 / 08$ & $161 \mathrm{~F}$ & $10 \_65$ & 1 & 3 & 2 & 3 & No & - \\
\hline D17-2501 & $25 / 01 / 08$ & $162 \mathrm{~F}$ & $10^{6} 65$ & 2 & 3 & 1 & 2 & No & Tijuco Preto \\
\hline D18-2501 & $25 / 01 / 08$ & $163 \mathrm{M}$ & $10-65$ & 3 & 4 & 2 & 3 & No & - \\
\hline
\end{tabular}




\section{ANEXO 5. Riscos estimados ( $\left({ }^{\mathrm{a}}\right.$ parte da expressão)}

\begin{tabular}{|c|c|c|c|c|c|c|}
\hline & \multicolumn{2}{|c|}{$\begin{array}{l}\text { Risco Médio } \\
\left(1^{\mathrm{a}} \text { parte da expressão) }\right.\end{array}$} & \multicolumn{4}{|c|}{$\begin{array}{l}\text { Risco Acumulado } \\
\text { (1 }{ }^{\mathrm{a}} \text { parte da expressão) }\end{array}$} \\
\hline & $\mathrm{R}_{\mathrm{E}, 1, \text { Rea }}$ & $\mathrm{R}_{\mathrm{E}, 1, \operatorname{Pro}}$ & $\mathrm{R}_{\mathrm{E}, 1, \operatorname{Rea}(\mathrm{Acum}, 25)}$ & $\mathrm{R}_{\mathrm{E}, 1, \mathrm{Pro}(\mathrm{Acum}, 25)}$ & $\mathrm{R}_{\mathrm{E}, 1, \mathrm{Rea}(\mathrm{Acum}, 50)}$ & $\mathrm{R}_{\mathrm{E}, 1, \operatorname{Pro}(\text { Acum }, 50)}$ \\
\hline S.M.Madalena & 0,0170 & 0,0067 & 0,2118 & 0,1363 & 0,8504 & 0,3339 \\
\hline Mineirinho & 0,0002 & 0,0001 & 0,0028 & 0,0018 & 0,0112 & 0,0044 \\
\hline Tijuco Preto & 0,0365 & 0,0143 & 0,4579 & 0,2947 & 1,8225 & 0,7169 \\
\hline Gregório & 0,0061 & 0,0024 & 0,0758 & 0,0488 & 0,3027 & 0,1190 \\
\hline Medeiros & 0,0197 & 0,0078 & 0,2481 & 0,1597 & 0,9864 & 0,3883 \\
\hline Água Quente & 0,0001 & 0,0001 & 0,0017 & 0,0011 & 0,0067 & 0,0026 \\
\hline
\end{tabular}




\section{ANEXO 6. Sites Internet de interesse}

Surface Water Data Viewer - Floodplain Theme [Wisconsin Dept of Natural Resources] http://dnrmaps.wisconsin.gov/imf/imf.jsp?site=SurfaceWaterViewer.floodplain

Early Warning Floods [HVZ-LUBW]

http://www.hvz.baden-wuerttemberg.de/

Water watch - Current Water Resources Conditions [USGS]

http://water.usgs.gov/waterwatch/ 